Florida International University FIU Digital Commons

\title{
Representative Bureaucracy in German Public Schools: An Assessment of the Mechanisms of Passive Representation
}

Gretha Burchard

Florida International University, gburc003@fiu.edu

DOI: $10.25148 /$ etd.FIDC001944

Follow this and additional works at: https:// digitalcommons.fiu.edu/etd

Part of the Educational Assessment, Evaluation, and Research Commons, and the Public Administration Commons

\section{Recommended Citation}

Burchard, Gretha, "Representative Bureaucracy in German Public Schools: An Assessment of the Mechanisms of Passive Representation" (2017). FIU Electronic Theses and Dissertations. 3394.

https://digitalcommons.fiu.edu/etd/3394 


\section{FLORIDA INTERNATIONAL UNIVERSITY}

Miami, Florida

REPRESENTATIVE BUREAUCRACY IN GERMAN PUBLIC SCHOOLS: AN ASSESSMENT OF THE MECHANISMS OF PASSIVE REPRESENTATION

A dissertation submitted in partial fulfillment of the requirements for the degree of DOCTOR OF PHILOSOPHY

in

PUBLIC AFFAIRS

by

Gretha K. Burchard 
To: Dean John F. Stack, Jr.

Steven J. Green School of International and Public Affairs

This dissertation, written by Gretha K. Burchard, and entitled Representative Bureaucracy in German Public Schools: An Assessment of the Mechanisms of Passive Representation, having been approved in respect to style and intellectual content, is referred to you for judgment.

We have read this dissertation and recommend that it be approved.

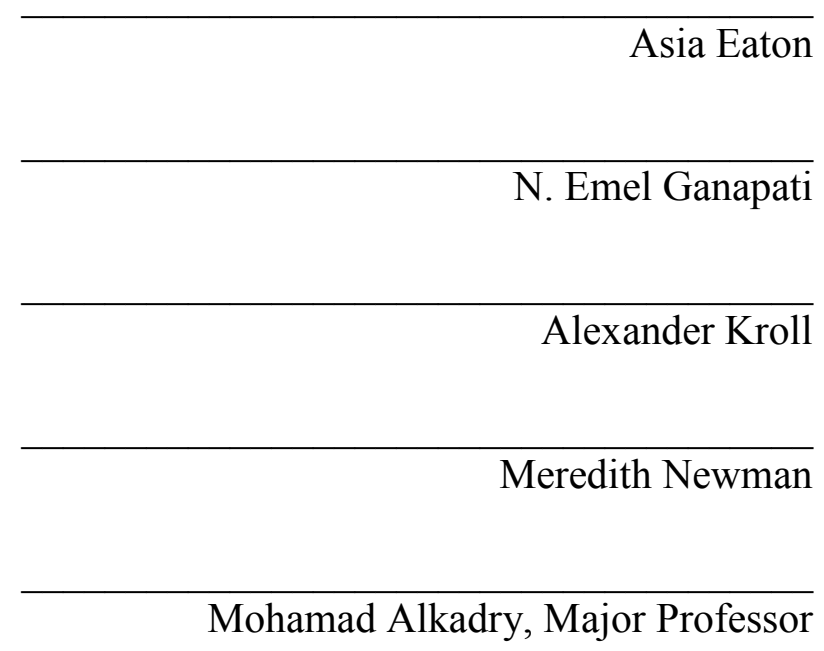

Date of Defense: June 28, 2017

The dissertation of Gretha K. Burchard is approved.

Dean John F. Stack, Jr. Steven J. Green School of International and Public Affairs

Andrés G. Gil Vice President for Research and Economic Development and Dean of the University Graduate School

Florida International University, 2017 
(C) Copyright 2017 by Gretha K. Burchard All rights reserved. 


\section{DEDICATION}

To Aziz - my husband, soulmate, and best friend. Thank you for your endless patience, understanding, and support. And to our son, Jonathan. Your smile makes me enjoy every single day. 


\section{ACKNOWLEDGMENTS}

This dissertation would not have been completed without the help of many people. I would like to express my sincere gratitude to my advisor and dissertation chair, Dr. Mohamad Alkadry, for his continuous support of my Ph.D. study and related research, for his patience, motivation, and knowledge. His guidance helped me in all the time working on this dissertation. I also wish to thank the other members of my committee for their unwavering support. Dr. N. Emel Ganapati has introduced me to the excitement of qualitative data collection in my first Ph.D. term and was particularly helpful in guiding me through the qualitative part of this dissertation. Dr. Alexander Kroll and Dr. Asia Eaton provided me with extensive feedback on the quantitative analysis. Finally, Dr. Meredith Newman has encouraged me to always keep in mind the relevance of my study for practice.

Special thanks goes to Dr. Allan Rosenbaum for making me join the Ph.D. in Public Affairs Program at FIU. In the four years as his research assistant, I learned many things from him, both related to public administration and beyond. He and the other members of the Institute for Public Management and Community Service, Dr. Cristina Rodriguez, Jeisson Rodriguez, Viviana Quintero, and Carlota Valdez, had their doors always open for me.

I would also like to thank the Ph.D. program directors, Dr. Sukumar Ganapati and Dr. Milena Neshkova, as well as the staff of the Public Administration department, for their continuous support.

My heartfelt gratitude goes to my fellow students at FIU who have turned from colleagues to my family away from home. The countless hours of inspiring conversations in the Ph.D. room, the journeys to public administration conferences, and the fun we had 
together have made my time at FIU unforgettable. Special thanks to Jeisson, Auzeen, and Sebawit who helped me extensively with administrative details when I was abroad.

The University Graduate School at FIU has supported me financially toward completing this dissertation by providing me with the dissertation evidence acquisition fellowship (DEA) and the dissertation year fellowship (DYF). Also, the Coalition of Women in German has provided me with the Zantop Travel Award for data collection. I am grateful for the financial support.

My deepest gratitude also goes to the 26 school teachers and 194 students from schools in Lower Saxony and Bremen in Germany who have agreed to take part in this study. Their participation did not only enable me to complete this dissertation, but also inspired me to further pursue the topic.

A heartfelt thank you also goes to my friends Dr. Ildiko Barsony and Dr. Ilyana Albarran. Besides rehearsing with me and sharing their honest opinions on my dissertation and presentation, they and their families have shared their homes with me and my family and have always been there for us. I am forever grateful.

Finally, I would like to thank my family. Special thanks go to my mother-in-law and my own mother for taking care of my son with all their love and passion at the final stage of the writing process. Without them, this dissertation would be far from being completed. Last but not least, my father, with his belief in the importance of good education, has always encouraged me to reach for more. 
ABSTRACT 2$) \square 7+(\square, 66(57 \$ 7,21$

REPRESENTATIVE BUREAUCRACY IN GERMAN PUBLIC SCHOOLS: AN

ASSESSMENT OF THE MECHANISMS OF PASSIVE REPRESENTATION

by

Gretha K. Burchard

Florida International University, 2017

Miami, Florida

Professor Mohamad Alkadry, Major Professor

According to representative bureaucracy theory, a bureaucracy that mirrors the population it serves - in terms of demographic composition - is more responsive to the interests of all groups in the population. Most research in this area has examined the link between passive representation (i.e., occurrences in which minority bureaucrats mirror the population) and active representation (i.e., occurrences in which minority bureaucrats actively pursue the interests of those they represent). Less attention has been directed toward the notion that different mechanisms can make representative bureaucracy have an effect.

Focusing on the German public school sector, the aim of this study is to understand through which mechanisms teachers with migration backgrounds can have an impact on their students and how they become representatives. The German government has recently begun to support intensified recruitment of people with migration background into the teacher workforce. Assessing the mechanisms of representation is, thus, not only crucial for a better theoretical understanding of representative bureaucracy, but it can also provide policy guidance for future government efforts. 
The mechanisms include demand inducement, coproduction inducement, advocacy, shared values and empathic understanding, and peer influence. Substantive effects are operationalized as students' grades, career expectations, and perceived classroom climate. Applying a sequential mixed-methods approach, OLS regressions based on data from 194 surveys collected at six German high schools measure the mediating effect of the mechanisms on the relationship between the representation of students and the three substantive effects. Furthermore, a comprehensive qualitative analysis of 26 in-depth interviews provides insight into teachers' perceptions on their role as representatives.

Overall, the findings indicate that for the occurrence of most mechanisms, a teacher's personality is at least as crucial as a common migration background. A mediating effect of demand and coproduction inducement on the relationship between passive representation and substantive effects was found in the quantitative analysis. The qualitative analysis reveals the importance of empathic understanding and advocacy as mechanisms of representation and points to the potential of peer influence as influential mechanism of representation. Furthermore, the findings highlight the importance of matching backgrounds and a critical mass of teachers with migration background in the workforce to overcome racism. 


\section{TABLE F CONTENTS}

CHAPTER

PAGE

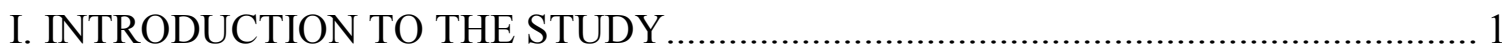

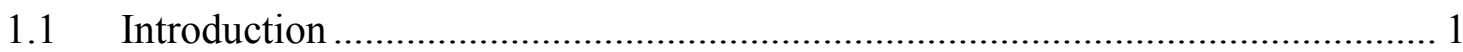

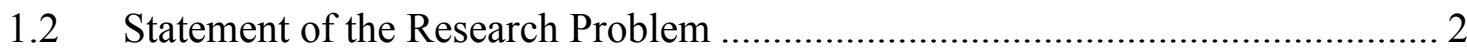

1.3 Significance of the Study .......................................................................... 3

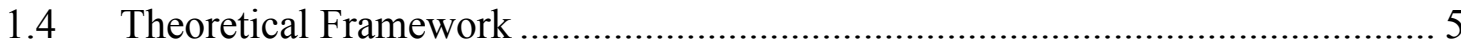

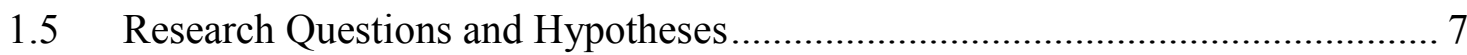

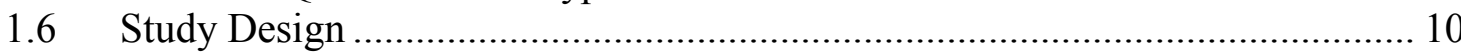

1.7 Organization of Chapters ………………….............................................. 12

II. REPRESENTATIVE BUREAUCRACY - A LITERATURE REVIEW ................... 14

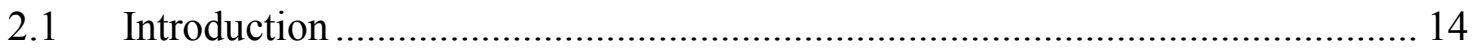

2.2 Traditional Bureaucracy and its Criticism ........................................................ 16

2.3 The Nature and Development of Representative Bureaucracy Theory.............. 21

2.4 Passive and Active Representative Bureaucracy …………….......................... 22

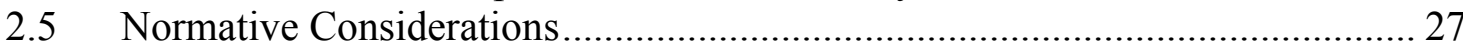

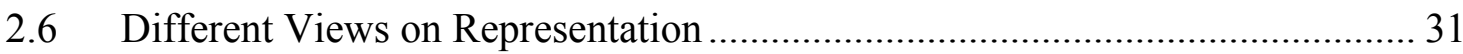

2.7 New Research Directions: Lim's (2006) Substantive Effects and Atkins, Fertig, and Wilkins' (2014) Causal Mechanisms..................................................... 35

2.8 Representative Bureaucracy in Public Schools .................................................. 41

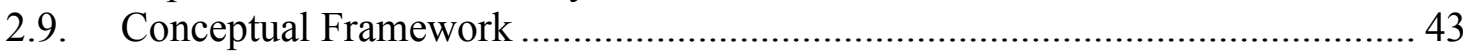

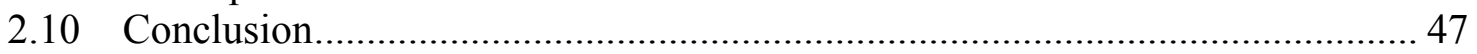

III. CONTEXT AND RESEARCH METHODS …………............................................ 51

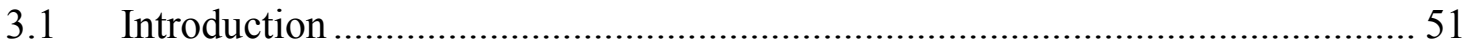

3.2 Ontological and Epistemological Considerations ………................................. 51

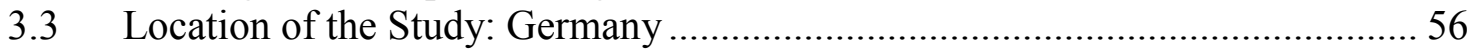

3.3.1 German Public School System................................................................. 56

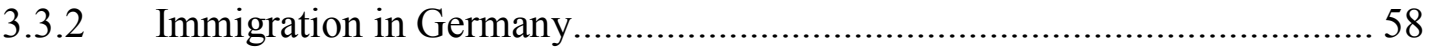

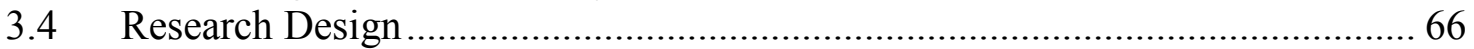

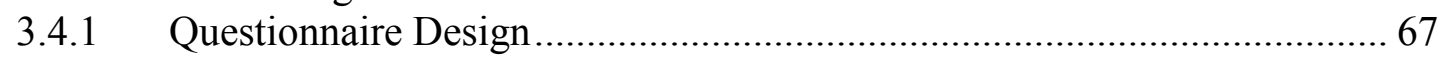

3.4.2 In-depth Interview Schedule Design......................................................... 75

3.4.3 Data collection: First Set of Interviews .................................................. 78

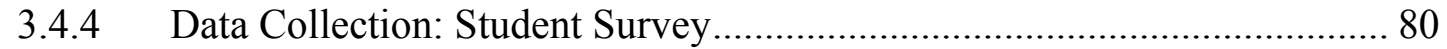

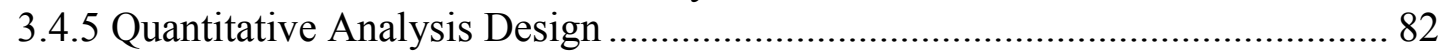

3.4.6 Data Collection: Second Set of In-depth Interviews................................... 87

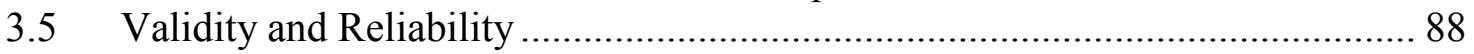

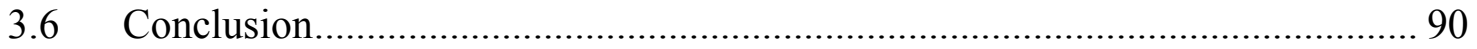

IV. THE MECHANISMS OF REPRESENTATION - FINDINGS ……….................. 92

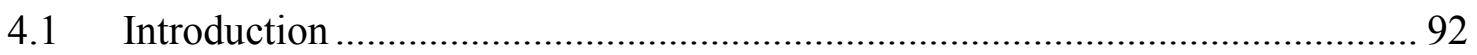

4.2 Quantitative Analysis .................................................................................. 92 


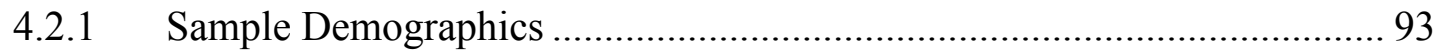

4.2.2 One-way MANOVA Results ............................................................... 94

4.2.3 Mediation Analysis Results ............................................................... 100

4.2.4 Summary and Discussion of Quantitative Findings................................. 116

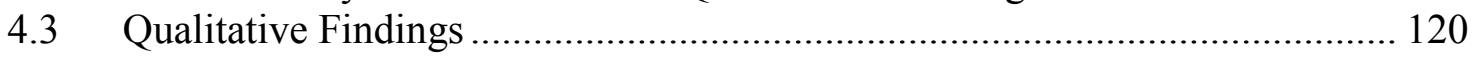

4.3.1 Results for Research Question 2 ……………….................................. 121

4.3.2 Summary and Discussion of Qualitative Findings................................... 152

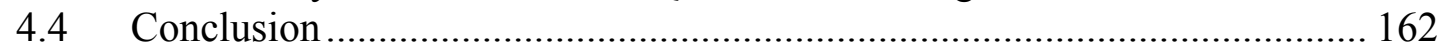

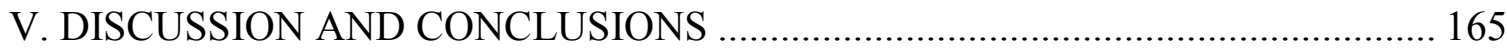

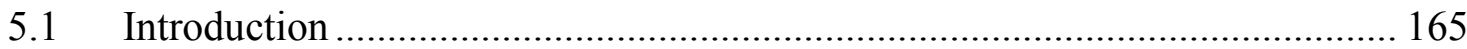

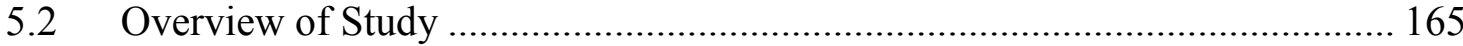

5.3 Discussion of Synthesized Research Findings ................................................ 166

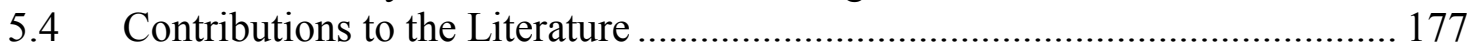

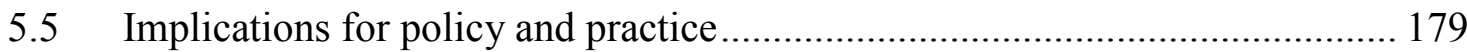

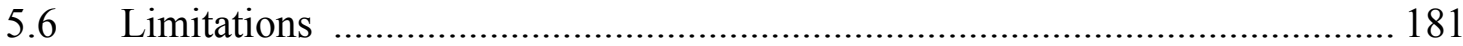

5.7 Recommendations for Future Research ……….......................................... 183

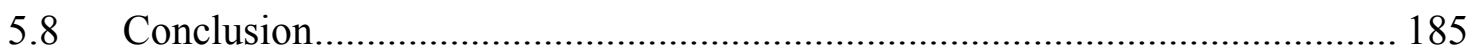

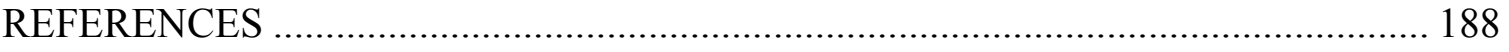

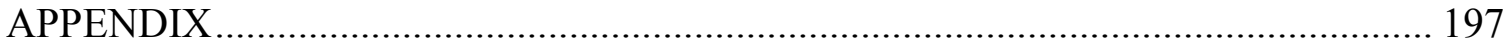

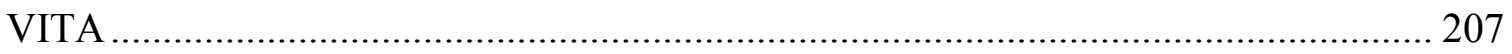




\section{LIST OF TABLES}

TABLE

PAGE

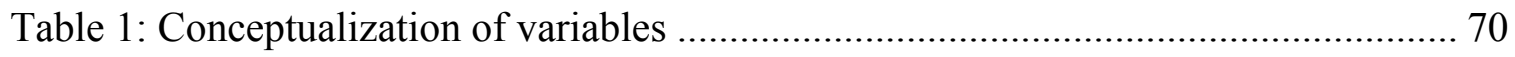

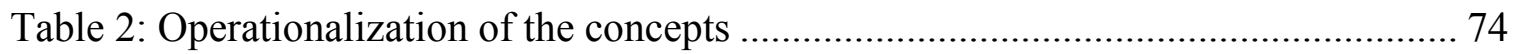

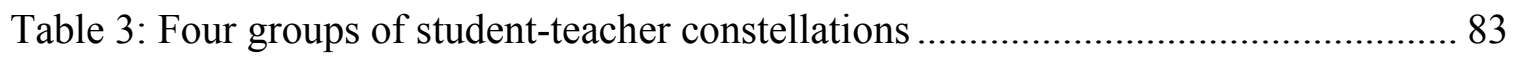

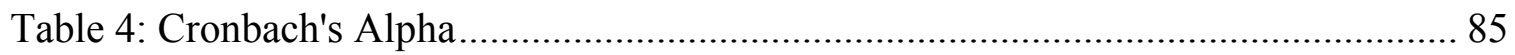

Table 5: Correlations, means, standard deviations and ranges of all variables used in

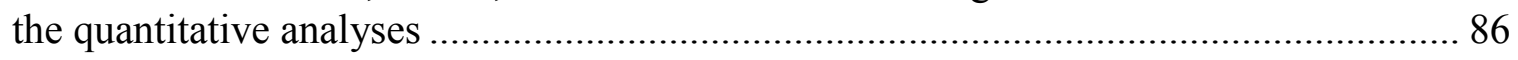

Table 6: Pearson's Correlations, Means, and Standard Deviations of the 4 mechanisms 95

Table 7: Pearson's Correlations, Means, and Standard Deviations of the 3 substantive effects

Table 8: One-way ANOVAs with 3 substantive effects as dependent variables and 4 representative bureaucracy group constellations as independent variables.

Table 9: One-way ANOVAs with 4 mechanisms as dependent variables and 4 representative bureaucracy group constellations as independent variables

Table 10: Differences in means across the four student groups for four significant variables 98

Table 11: Mediation results for the mechanism demand inducement as mediator, unstandardized coefficients

Table 12: Mediation results for the mechanism coproduction inducement as mediator 109

Table 13: Mediation results for the mechanism advocacy as mediator 112

Table 14: Mediation results for the mechanism values \& empathy as mediator 114

Table 15: Hypotheses with the findings from the quantitative analysis 117 


\section{LIST OF FIGURES}

FIGURE

PAGE

Figure 1: Simplified Model of Representative Democracy ...................................... 16

Figure 2: Simplified Model of a Representative Bureaucracy.................................... 20

Figure 3: Depiction of Factors and Indirect and Direct Sources ................................ 40

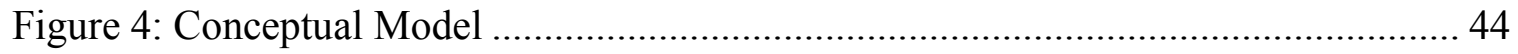

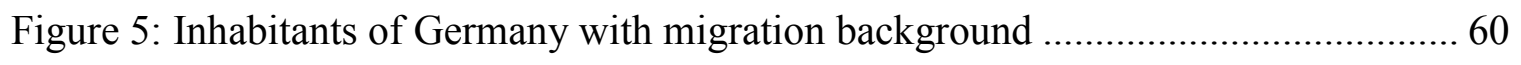

Figure 6: Conceptual model of quantitative analysis............................................... 73

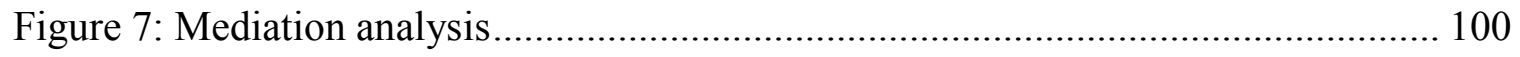

Figure 8: Relationship of Passive representation and grades through demand

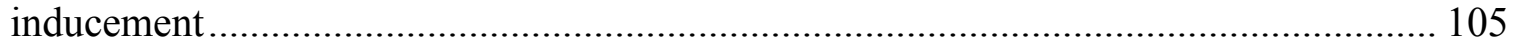

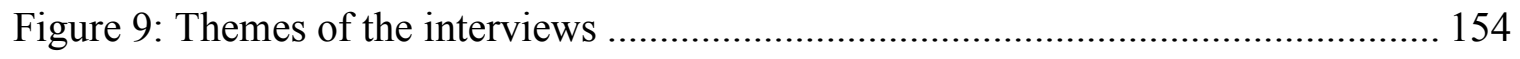




\section{INTRODUCTION TO THE STUDY}

\subsection{Introduction}

According to representative bureaucracy theory, a bureaucracy that mirrors the population it serves - in terms of demographic composition - is more responsive to the interests of all groups in the population. Donald J. Kingsley (1944) is commonly credited with coining the term "Representative Bureaucracy" in his work on the British Civil Service and sparking other scholars' interest in exploring the theory. Research in this area mainly focused on passive representation; scholars measured the degree to which an organization's bureaucracy was representative of the population it served - mostly in terms of gender and race (e.g., Dometrius \& Sigelman, 1984).

Mosher (1968) introduced the notions passive and active representation. Passive representation refers to the mere presence of minority bureaucrats in a bureaucracy, so that the demographic composition of a society is mirrored by the demographic composition of the bureaucracy. Active representation refers to the efforts of minority bureaucrats to pursue the interests of the individuals they represent. Following Mosher's (1968) work, scholars began focusing on the link between passive and active representation (e.g., Bradbury \& Kellough, 2008; Keiser, Wilkins, Meier, \& Holland, 2002; Meier, Wrinkle, \& Polinard, 1999). Most of these studies explored the factors that influence the attitude, values, and behavior of minority bureaucrats and eventually drive them to become active representatives of their minority group. These factors include demographic variables such as sex, race, ethnicity, sexual orientation, veteran status, language, and political affiliation (Gade \& Wilkins, 2003; Kelly, 1998; Kübler, Kobelt, \& Andrey, 2012; Selden, Brudney, \& Kellough, 1998; Slack, 2001). Researchers have also explored how minority bureaucrats 
are influenced by organizational factors, such as length of time working in the public sector, perceived work obligations, the organizational environment, the issue to be considered, organized employee groups, the bureaucrat's position in the organizational hierarchy and the physical location of the bureaucrat's office in the entity (Selden et al., 1998; Thompson, 1976). The outcomes of active representation tend to be measured as positive effects for minorities, such as improved academic performance among minority students in schools with more minority teachers or improved policy outcomes for minorities.

Recently, the research focus has slightly shifted, away from strong emphasis on the link between passive and active representation and toward a more comprehensive understanding of representative bureaucracy, its impacts, and the processes involved in such a bureaucracy. While several studies have focused on how passive representation may affect the population (e.g., Gade \& Wilkins, 2013; Meier \& Nicholson-Crotty, 2006; Theobald \& Haider-Markel, 2009, research in this area remains scarce.

\subsection{Statement of the Research Problem}

Passive representation leads to active representation. This process has been extensively examined over the past decades and several studies have indicated that a causal relationship exists between the two forms of representation (e.g., Selden et al., 1998; Sowa \& Selden, 2003; Wilkins \& Keiser, 2004). Lim (2006) contended that the strong research focus on the link between passive and active representation shifted attention away from investigating the different drivers of representation. He claimed that minority bureaucrats advocating for their minority group are not the sole source of presumed positive impacts 
of a representative bureaucracy. He suggested that there are different ways—namely, direct and indirect sources - in which a bureaucracy that passively represents the population it serves can impact the population. However, few studies have examined these indirect and direct sources.

Regarding methodological approaches, most studies on representative bureaucracy have applied quantitative methods with aggregate-level data. Studies with individual level data using qualitative research methods are rare in representative bureaucracy scholarship.

\subsection{Significance of the Study}

The purpose of the present study is to contribute to representative bureaucracy scholarship by exploring the mechanisms through which a representative bureaucracy can have substantive effects on the population it serves. Scholars have only recently begun to investigate the mechanisms behind representative bureaucracy. First, studies on the effects of passive representation have underlined the impact that passive representation alonewithout minority bureaucrats actively advocating for their minority groups - can have on the public (e.g., Atkins, Fertig, \& Wilkins, 2014; Gade \& Wilkins, 2013). This present study, which is a comprehensive examination of the relationship between representative bureaucracy and effects on the public - and considers the mechanisms behind this relationship - has the potential to substantively add to the representative bureaucracy literature. Furthermore, a better, more complete understanding of representative bureaucracy processes can also serve practitioners, equipping them with strategies (e.g., enhancing their services), which they can apply to more successfully serve the community, including minorities, or to become more responsive to the needs of the population. 
The present study focuses on teachers with migration background ${ }^{1}$ in German public schools. Germany has become a country of immigrants; the country must develop ways to successfully serve the needs of all, including its immigrant population. Along with this upsurge in immigrants, Germany has simultaneously experienced increases in immigrant representation in the public sector workforce, which will likely strengthen efforts to serve the entire population's needs. The German Federal Government and scholarly literature in this area have suggested that when the public sector workforce mirrors society, several positive outcomes result: more trust in the organization by the people, higher efficiency (due to increased trust), and increased responsiveness to the needs and wishes of the public (Bundesregierung, 2012; Kennedy, 2014; Kim, 1994; Mosher, 1968). Thus, the government has begun promoting and supporting intensified recruitment of people with migration background into the teacher workforce and the police force. Findings from the present study are of specific interest and great value to schools and statelevel school authorities; the findings provide novel insight into the effects of a representative teacher workforce and can help evaluate federal government efforts to increase representation of persons with migration background in the teacher workforce and in the entire public sector. Also, my findings elucidate which mechanisms are specifically useful in the school context to improve the situation in schools.

Data collection methods for this study include conducting questionnaires with students and interviews with teachers. Quantitative as well as qualitative analyses were conducted in a sequential mixed-methods approach. This enables triangulation of the

\footnotetext{
${ }^{1}$ The term is defined in Chapter 3.3.2.
} 
research findings and provides valuable insight into bureaucratic and community perspectives on specific issues. Additionally, as a mixed-methods study on representative bureaucracy, the present study contributes to the research literature - and is particularly important because it employs qualitative data analyses. This can provide deep insight that cannot be obtained when applying exclusively quantitative methods.

\subsection{Theoretical Framework}

The theoretical framework of this dissertation mainly draws from the work of Lim (2006) and Atkins et al. (2014). Lim (2006) closely examined how representative bureaucracy can have substantive effects on the people it serves. Instead of categorizing representative bureaucracy as passive and active, Lim claimed that there are direct and indirect sources of substantive effects of passive representation. Direct sources are those that influence the population directly through the bureaucrat's behavior. Indirect sources are produced through the behavior of other bureaucrats or of minority clients who are influenced by the minority bureaucrat's presence. Direct sources include advocacy, shared values and beliefs, and empathic understanding. Indirect sources that produce benefits through the behavior of non-minority bureaucrats include: minority bureaucrats expressing disapproval of discriminatory behavior by non-minority bureaucrats; prior restraint felt by non-minority bureaucrats if they are about to act on their bias due to the presence of a minority bureaucrat; and resocialization (i.e., the change in values and beliefs that a minority bureaucrat can provoke in a non-minority bureaucrat over time). Indirect sources that produce benefits through the behavior of minority clients include demand inducement (i.e., the minority bureaucrat's presence can be a stimulator for more applications or service 
demands from minorities) and coproduction inducement [i.e., a minority bureaucrat can stimulate clients from the same social group to work to enhance outputs and, thus, client outcomes] (Lim, 2006).

Atkins et al. (2014) investigated how passive representation among school teachers influences school connectedness and future expectations among students. They found that both connectedness and expectations increase for minority students with higher minority teacher rates. Atkins et al. (2014) provided a list of causal mechanisms—similar to Lim's (2006) direct/indirect sources:

1. Passive representation of minority bureaucrats affects the behaviour of minority clients by making the agencies' services more attractive to these clients.

2. The bureaucrat serves as a role model for the client.

3. Minority bureaucrats are more likely to assume a 'minority advocacy' or representative role for minority clients.

4. The presence of minority and female bureaucrats may lead to changes in the behavior of majority bureaucrats.

5. The increases in representation may shift the policies and/or priorities of the organization (Atkins et al., 2014, p. 506-507)

The present study examines the effects of passive representative bureaucracy by considering Lim's (2006) indirect and direct sources [i.e., Atkins et al.'s (2014) first four mechanisms]. When minority bureaucrats are present in a specific agency, they passively represent people in society who belong to the same minority group. Different demographic and organizational factors and the perceived role expectations of the minority bureaucrat impact the possibility of passive representation leading to substantive effects on the 
population. These factors include, among others: sex, race, ethnicity, education, length of time working in the public sector, perceived work obligations, and organizational rules and structures (e.g., Bradbury \& Kellough, 2008 Keiser et al., 2002; Krislov, 1974; Selden et al., 1998; Meier et al., 1999).

While most prior studies focused on the link between passive and active representative bureaucracy, my study follows Lim's (2006) view that passive representation can have effects on the population with the help of the direct and indirect sources. The findings indicate that Lim's suggested sources play an important role in the school setting.

\subsection{Research Questions and Hypotheses}

Building on the review of the representative bureaucracy literature, the present study focuses on the mechanisms behind a representative bureaucracy. The factors that turn a bureaucrat into a minority representative have been researched extensively; less attention has been focused on the different ways that passive representation can benefit the people. Mainly drawing from Lim (2006) and Atkins et al. (2014), the different sources, or causal mechanisms, that may enable a representative bureaucracy to have substantive effects are at the center of this dissertation; the present study examines these mechanisms by applying quantitative and qualitative methods. The objectives of this study are to:

1. Examine the mechanisms that make passive representative bureaucracy have substantive effects on the population without any direct influence of the minority bureaucrat on the people. The mechanisms that are investigated for 
this purpose are Lim's (2006) indirect sources "demand inducement," "coproduction inducement," and "peer influence."

2. Examine the role that Lim's (2006) direct sources "advocacy," "shared values and beliefs," and "empathic understanding," which involve direct influence of the bureaucrat on the population, play in the process of passive representation having substantive effects.

3. Explore the relationships between the factors that motivate bureaucrats to become representatives, with a special focus on Atkins et al.'s (2014) mechanisms and Lim's (2006) sources.

In this study, "passive representation" follows Mosher's (1968) description of the term (i.e., shared demographic characteristics between administrators and the public). The term "substantive effects" is adopted from Lim (2006), meaning a measurable or otherwise noticeable impact on people's lives. The different mechanisms are adopted from Lim (2006) and Atkins et al. (2014). Substantive effects are captured with three variables, which are further explained in Chapter 3.6: Research Design.

Research Question 1

Which mechanisms make a passive representative bureaucracy have substantive effects on the population it serves?

Hypothesis 1.1

Demand inducement plays a role in the relationship between passive representation and substantive effects on the population. 


\section{Hypothesis 1.2}

Coproduction inducement plays a role in the relationship between passive representation and substantive effects on the population.

\section{Hypothesis 1.3}

Advocacy plays a role in the relationship between passive representation and substantive effects on the population.

Hypothesis 1.4

Shared values and beliefs and empathic understanding play a role in the relationship between passive representation and substantive effects on the population.

\section{Research Question 2}

How do bureaucrats become representatives?

Direct and indirect sources (Lim, 2006) have the potential to influence a bureaucrat's representative function. Furthermore, additional factors and mechanisms may play a role and are explored to find an answer to Research Question 2.

Research Question 1 serves to address Objectives 1 and 2 and is tested with a quantitative analysis based on the student survey. Research Question 2 is more exploratory in nature and aims to respond to Objective 3 using qualitative methods, i.e., the analysis of 26 semi-structured interviews.

The findings of the quantitative analysis partially confirm hypotheses 1.1 and $1.2-$ a mediating effect of demand inducement and coproduction inducement on the relationship between passive representation and the three tested outcome variables, i.e., the substantive effects grades, career expectations, and classroom climate was found. Furthermore, 
hypothesis 1.4 was partially confirmed, as values and empathy mediate the relationship between representation and the classroom climate.

The findings of the qualitative analysis point to the important role of most investigated mechanisms. They also indicate that a teacher's personality is crucial for the mechanisms to occur, possibly more so than a common migration background. Empathic understanding is a particularly important mechanism and may lead to advocacy and peer influence. Furthermore, the findings highlight the importance of matching backgrounds and a critical mass of teachers with migration background in the workforce to overcome racism..

\subsection{Study Design}

This study focuses on German public schools. Public schools are an appropriate research setting for multiple reasons. First, they have similar regulations and objectives, teachers perform similar tasks and have comparable amounts of discretion (Keiser et al., 2002),. Second, their work occurs at the street-level, where bureaucrats interact most with citizens (Lipsky, 1980). Third, teachers often serve as role models (Cole, 1986), and students with migration background (MB) may identify more closely with teachers who also have an MB (Meier \& Bohte, 2001).

Furthermore, the location of the data collection, Germany, is particularly pertinent. The German government is currently supporting intensified recruitment of teachers with MB due to the following reasons. It assumes that increasing the number of school teachers with MB will increase motivation—and enhance the performance—of students who belong to the same minority group (Bundesregierung, 2012). Furthermore, teachers with MB are expected to be more empathic to students with MB and their parents; these parents will 
likely regard these teachers as especially trustworthy; these teachers will reflect cultural and ethnic diversity in classrooms and bring intercultural perspectives to the school and to teaching; and these teachers will represent equal opportunity, in terms of access, to the teaching workforce (Bundeskongress, 2010, p. 19).

The present study uses a sequential mixed-methods design with individual level data. The research questions are of such nature that a mixed-methods design is appropriate and necessary. An analytical survey, which collects a large amount of data for quantitative analyses, is an effective method for the first research question. Furthermore, data from indepth interviews has the potential to triangulate findings; for this study, qualitative data provides deep insight into the phenomenon under study, which would be difficult to obtain from exclusively quantitative methods. Moreover, Research Question 2 is exclusively addressed via qualitative methods since it assesses the motivation, viewpoints and feelings of the teachers.

First, the student questionnaire was designed and discussed in ten semi-structured interviews with German school teachers before implementation. In addition to discussing the survey, the interviews also provided the first set of qualitative data. Subsequently, a pilot study of the questionnaire with 45 students was carried out at Florida International University. Following this, 194 German public school students were surveyed. After the analysis of the survey data, 16 additional semi-structured interviews with teachers were conducted and analyzed. This was done with the purpose of also addressing any inconsistencies of the quantitative analysis. 


\subsection{Organization of Chapters}

Chapter 2 of this study includes a review of the representative bureaucracy literature. It first addresses traditional bureaucracy theories and their role in representative bureaucracy. Subsequently, the nature and historical development of representative bureaucracy theory are discussed, followed by an investigation of the extensive work on the link between passive and active representative bureaucracy. My criticism of the research literature's excessive focus on this link serves as the developmental starting point of this study's conceptual model. Normative considerations are also included in this chapter because discussions on whether bureaucrats should specifically serve certain groups and, thus, possibly disadvantage others are frequent and legitimate. Furthermore, I discuss different views on representation, as well as the most recent studies on representative bureaucracy. Finally, findings of previous studies that examined representative bureaucracy in schools are summarized.

Chapter 3 addresses the research methods applied in this study. First, theoretical support for the choice of methods is provided. Subsequently, the conceptual model, the research questions, and the hypotheses are discussed. After providing background information on immigration in Germany and the German school system, I describe the research design, including: designing the questionnaire, sampling, operationalization of variables, qualitative and quantitative data collection, and the quantitative analysis design. Finally, validity and reliability are addressed, followed by the conclusion of the chapter.

Chapter 4 describes the findings of the qualitative and quantitative analyses. The research design of this study is a sequential mixed-methods approach, first applying quantitative analyses, followed by a comprehensive qualitative analysis. The findings of 
both analyses are presented in the same chronological order. Finally, the conclusion summarizes the most important findings.

Chapter 5 contains the discussion and conclusions of this dissertation. First, I synthesize qualitative and quantitative findings for each of the hypotheses. Subsequently, I present the contributions to representative bureaucracy literature and I discuss findings of the quantitative and qualitative analyses and their implications for schools, school authorities, and governments. Finally, the study's limitations and its recommendations for future research on the mechanisms of representative bureaucracy are presented. 


\section{REPRESENTATIVE BUREAUCRACY - A LITERATURE REVIEW}

\subsection{Introduction}

This study draws from the theoretical concept of representative bureaucracy. The theory of representative bureaucracy is based on the idea that a bureaucracy that mirrors the population it serves - in terms of demographic composition — is more responsive to the interests of all groups in the population. Research on representative bureaucracy is extensive; however, there is no unanimous definition or interpretation of the term representative bureaucracy (Kennedy, 2014). Likewise, researchers and practitioners continue to debate the legitimacy, potential advantages and disadvantages, and consequences of representative bureaucracy. Additionally, there is no universal, common approach for testing and measuring representative bureaucracy, and the results of existing studies have been partially inconsistent.

Over time, research focus in the representative bureaucracy literature has shifted. Earlier studies concentrated on passive representation inside the organization (Kingsley, 1944; Levitan, 1946; Long, 1952; Van Riper, 1958); however, more recent studies have emphasized the link between passive and active representation (e.g., Bradbury \& Kellough, 2008; Gade \& Wilkins, 2013; Keiser et al., 2002; Meier \& Nicholson-Crotty, 2006; Selden, et al., 1998) and accounted for the effects of organizational culture and socialization (e.g., Meier, 1993; Meier \& Nigro, 1976; Saidel \& Loscocco, 2005; Selden, 2006; Sowa \& Selden, 2003). Different views on representation have been discussed (Pitkin, 1967) along with the sizable variety of characteristics in a society that can or should be represented by a representative bureaucracy. Recently, researchers have begun to investigate the effects 
of passive representation, which are also examined in the present study (Gade \& Wilkins, 2013; Meier \& Nicholson-Crotty, 2006; Theobald \& Haider-Markel, 2008).

This chapter focuses on addressing the public administration and organizational theory literature pertaining to representative bureaucracy — examining the complexities and inconsistencies within the entire body of literature on representative bureaucracy is beyond the scope of the present study. I first provide an overview of traditional bureaucracy theories and their role in representative bureaucracy. Then, I describe the nature and historical development of representative bureaucracy theory. Subsequently, the extensive work on the link between passive and active representative bureaucracy is examined. My criticism of the research literature's excessive focus on this link serves as the developmental starting point of this study's conceptual model. Normative considerations are also addressed, because discussions among scholars on whether bureaucrats should specifically serve certain groups and, thus, possibly disadvantage others are frequent and legitimate. Furthermore, I discuss different views on representation, as well as the most recent studies on representative bureaucracy and studies that examined representative bureaucracy in schools. Finally, the conceptual framework for this dissertation, developed based on the literature, is presented.

Most literature reviews on representative bureaucracy begin with Kingsley's (1944) foundational work. However, to understand how and why the concept of representative bureaucracy emerged, it is crucial to first examine the historical development of traditional bureaucracy and its flaws. 


\subsection{Traditional Bureaucracy and its Criticism}

Max Weber $(1922,1947)$ and his writings play a central role in the development of public administration theory-particularly in relation to the theory of traditional bureaucracy. He describes strictly hierarchical institutions as the most rational form of bureaucracy. Ideal public administrators perform their work on a value-neutral basis, treating every individual the same way. For Weber (1947), bureaucracy is a child of the democratization and rationalization of society, providing for equal treatment of all citizens. For a democracy to function well, the public must view the bureaucracy as a rational-legal authority. This authority obtains its legitimacy from legal order and laws. In simplified terms, in a representative democracy, the voting public elects officials, and those elected officials command and control the bureaucrats; the bureaucrats follow orders from the elected officials, and, thus, each bureaucrat is "a single cog in an ever-moving mechanism which prescribes to him an essentially fixed route of march" (Weber, 1947, p. 228), involving hierarchy, impersonality, professionalism, and value-neutrality.

Figure 1: Simplified Model of Representative Democracy

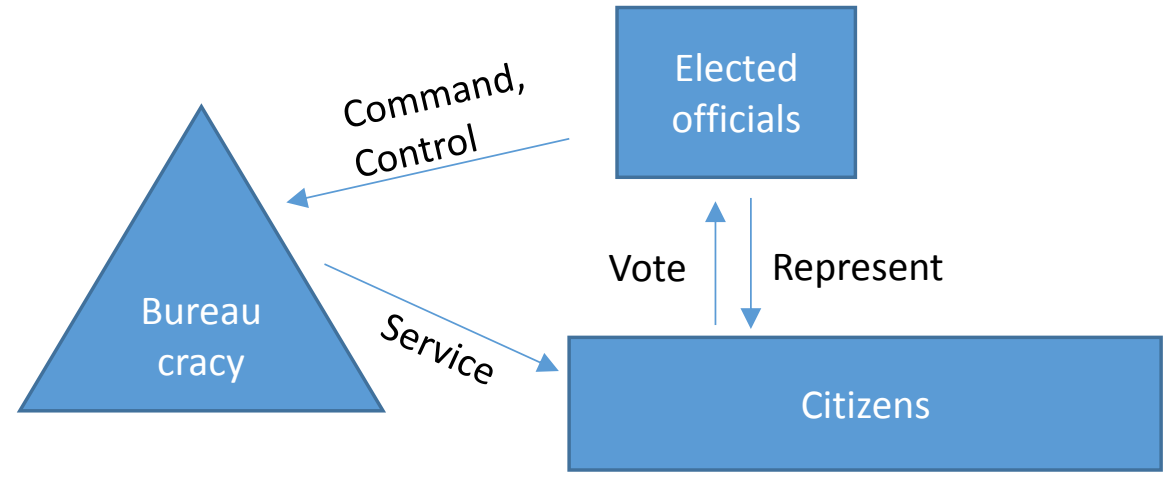

Weber (1947) recognized the problems that arise in the bureaucratic model presented in Figure 1; he acknowledged the negative impact of impersonality, as an 
instrument for dehumanization and depersonalization, and he also acknowledged that human beings are not entirely free of values. Humans have personal values, and they must be cognizant of this to establish value neutrality, which enables them to act impartiallywithout judging and without being biased. Furthermore, Weber (1947) expressed his concern about the representativeness of a representative democracy in the following way:

The demos itself, in the sense of an inarticulate mass, never governs large associations, rather, it is governed, and its existence only changes the way in which the executive leaders are selected and the measure of influence which the demos, or better, which social circles from its midst are able to exert upon the content and the direction of administrative activities by supplementing what is called public opinion. (p. 225)

Yet, of Weber's (1947) three types of authority (i.e., charismatic, traditional, and legal-rational), he viewed legal-rational authority as singularly and technically superior to any other form of organization.

The model displayed in Figure 1 has received various criticisms. For the purposes of this study, two dimensions of this overall criticism are specifically important: (a) criticism of the control of bureaucracy and (b) criticism of the representativeness of democracy.

Opponents of politics-administration dichotomy theory criticize the one-way relationship between elected officials and bureaucrats: do elected officials simply command and control bureaucrats? Dwight Waldo is generally recognized as hastening the end of the politics-administration dichotomy era and starting the administration-as-politics approach (Fry \& Raadschelders, 2008). He claimed that political control of bureaucracy is 
not only impossible due to the size and increasing complexity of government, but also undesirable, because it would deprive society of the knowledge of those who know best: the bureaucrats (Waldo, 1948). Bureaucrats, in many cases, make decisions on their own and sidestep the democratic process. This can happen due to information asymmetry, because, typically, the bureaucrat who is carrying out certain tasks every day is more experienced and knowledgeable than the elected official giving orders (Waldo, 1980, pp. 95-96).

At the street level, the control of bureaucracy is particularly difficult and sometimes undesirable; here, bureaucrats must sometimes act quickly—without asking supervisors how to proceed when there is no clear rule-leaving the bureaucrats to use their own judgement (Waldo, 1980, pp. 95,96). Lipsky (1980) argued that street-level bureaucrats can only perform their duties by circumventing and bending rules. Bureaucrats must often use their discretion to deliver certain public services.

The ethical, subjective responsibility of the bureaucrat was emphasized by Carl Friedrich (1940). According to Friedrich (1940), bureaucrats interpret each policy differently, depending on factors such as geographical, social, and cultural background. The relationship between elected officials and bureaucrats is a reciprocal, rather than a oneway, relationship. Friedrich proposed that bureaucrats be responsible to themselves and to public opinion rather than to elected officials and their bosses. Denhardt and Denhardt (2000) had a similar view: the public interest, the engaged community, and the ethical spirit of duty of the bureaucrat should be sufficient to hold him or her accountable. 
Weber himself had doubts about the representativeness of a representative democracy as the quote above shows. The people does not govern and is not represented, but merely certain social groups, oftentimes the more influential ones. In American history, events in the second half of the 20th century highlighted the distrust in government and the dissatisfaction of the people. The Civil Rights Movement signaled that representative democracy was not working effectively (i.e., neither the society in its diversity nor the interests of certain groups within the society were represented appropriately by elected officials). As a result of the increasing pressure from citizens, government became more responsive and more equitable.

To address the flaws of representative democracy, various approaches have emerged: The Minnowbrook Conference of 1968 brought about the New Public Administration era - with a focus on social equity. The Civil Rights Movement, women's rights movements, and gay rights movements were indicators of the distrust in government, the need for change, and the strong emphasis on social equity as the new ideal. The paradigm that then emerged — the New Public Management—-focused on lean government, outsourcing, treating citizens as clients, and adopting business values. Subsequently, the New Pubic Service, which can be regarded as a post-New Public Management paradigm, placed emphasis on serving people, valuing public opinion, and assigning the bureaucrat the role of ethical servant of citizens. Recently, the term Neo-Weberian State was introduced by Pollitt and Bouckaert (2004). For their model, they used Weber's description of bureaucracy and modernized it. Emphasis was shifted from focusing only on internal rules to focusing on meeting citizen needs with professionalism. They supplemented the role of representative democracy with consultation devices, which allowed for the direct 
representation of citizens' views. Furthermore, the bureaucrat is not only an expert of certain laws, but a manager who focuses on the needs of the citizens (Drechsler, 2009, p. 13). Notwithstanding the many differences between the abovementioned paradigms, there is one crucial commonality: They all strongly focused on more sensitivity and greater responsiveness toward citizens in which values and value-based treatment play an important role.

Various theoretical approaches have emerged to address modernization of traditional bureaucracy and adjusting it to the modern world; however, none has become widely recognized as the optimal solution for serving most or all people in a society. The present study suggests that representative bureaucracy can serve as a response to the criticisms of the representative democracy model described above. Democracy is desirable and vital. However, no politics-administration dichotomy exists, and it is indispensable in everyday life that bureaucrats make decisions on their own. Thus, a bureaucracy that represents society in terms of its demographic composition may represent citizens' needs better than a traditional one. Figure 2 presents, in simplified terms, how a representative bureaucracy can add to representative democracy.

Figure 2: Simplified Model of a Representative Bureaucracy

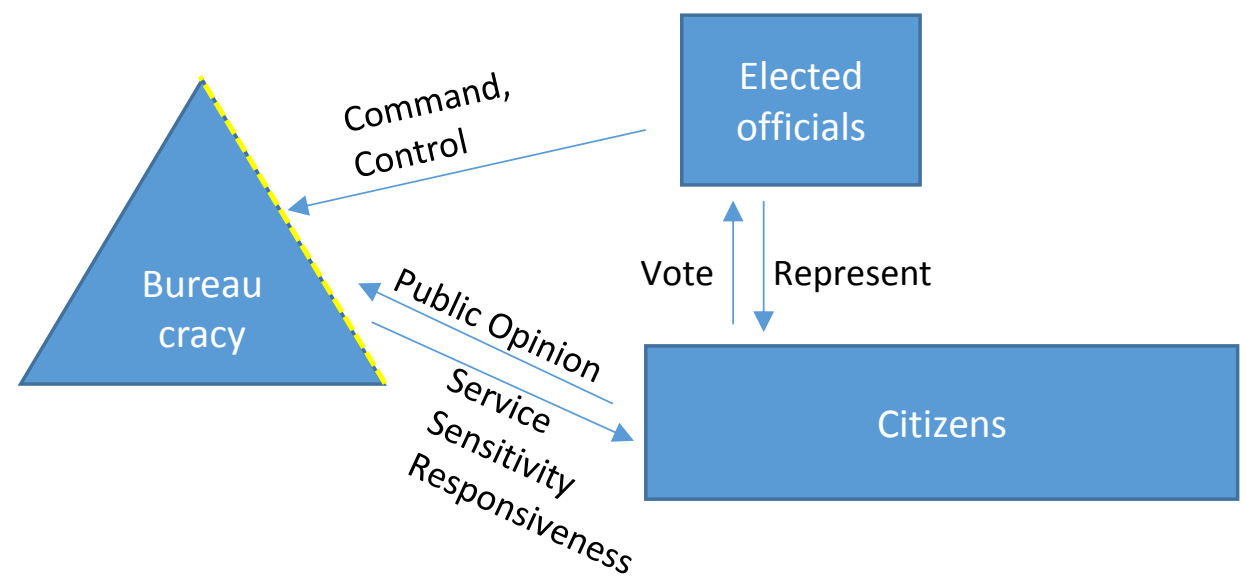




\subsection{The Nature and Development of Representative Bureaucracy Theory}

In the broadest sense, a bureaucracy is representative when its composition mirrors that of the society it serves. Kingsley's (1944) book "Representative Bureaucracy" is commonly regarded as the starting point of studies on representative bureaucracy. Kingsley coined the term representative bureaucracy while writing about the bureaucratic structures of the British Civil Service: "For bureaucracies to be democratic must be representative of the groups they serve" (p. 305). He expressed the need for a democratization of the administration, describing "the administrator [as], in fact, the representative figure of our times" (p. 262). He was most concerned with the representation of the dominant economic and social classes in a bureaucracy as a means to prevent irresponsible behavior, and he regarded a bureaucracy that represented the ruling middle class as appropriate.

Kingsley's study became the foundation of the research on representative bureaucracy theory, and subsequent scholars expanded on it. The notion of higher responsiveness in a representative bureaucracy played a role in the work by Levitan (1946) and Long (1952). Levitan (1946) claimed that in order to truly represent society, U.S. government had to become more representative of all members of society and of the values

the people hold. Such a representative bureaucracy could be perceived as more trustworthy by citizens. Similarly, Long (1952) emphasized composition—in terms of different social classes - and representation of different viewpoints and attitudes to achieve equality.

Early scholars promoted the importance of representation of values and Long (1952) introduced the notion of representation in terms of different attitudes. Van Riper (1958) then recognized that the behavior of bureaucrats, influenced by their attitudes and values, plays a crucial role for representative bureaucracy theory: 
A representative bureaucracy is one in which there is a minimal distinction between the bureaucrats as a group and their administrative behavior and practices on the one hand, and the community or societal membership and its administrative behavior, practices and expectations of government on the other. (Van Riper, 1958, p. 552)

By linking bureaucrats' attitudes with their behavior, Van Riper's (1958) work principally suggested a connection between passive representation and consequences of this representation for the people. This link was investigated by Mosher (1968), who is generally credited as the first person to differentiate between passive and active representative bureaucracy. Mosher (1968) highlighted several prerequisites for representative bureaucracy. He claimed that for passive representation to develop into active representation, variables such as individual characteristics of the bureaucrat and their socialization within the organization - as well as organizational variables - may play a role. His work laid the foundation for a large portion of the research literature investigating the link between passive and active representative bureaucracy.

\subsection{Passive and Active Representative Bureaucracy}

Mosher (1968) introduced the concepts of active and passive representation. A passive representative bureaucracy reflects the demographic composition of the people it serves. Active representation refers to the efforts of minority bureaucrats to pursue the interests of the individuals they represent. Krislov (1974) described passive and active representation as two different yet intertwined ways of regarding a bureaucracy as representative: "(1) It is seen as such in composition and in the manner of its selection, (2) 
it is judged in terms of substantive product and the quality of its decisions is evaluated in the light of their accord with what is assumed to be public opinion" (p. 37). Mosher (1968), defining his ideas, highlighted the importance of bureaucratic behavior in the link between passive and active representation: "the kinds of decisions and actions these officials take depend on their capabilities, their orientations, and their values; $[\ldots]$ and these attributes depend heavily upon their backgrounds, their training and education, and their current associations" (p. 3).

Building on Mosher's distinction between passive and active representation, the question of whether passive representation leads to active representation, and under which circumstances, became the major research focus in the field of representative bureaucracy research (e.g., Bradbury \& Kellough, 2008; Gibran, 2007; Keiser et al., 2002; Meier et al., 1999). Active representation has typically been measured in policy outputs or other substantive results favoring minorities.

Before addressing the different factors that were found to be conducive for passive representation to lead to active representation, I must highlight the role of administrative discretion in this process. Meier and Bohte (2001), summarizing Scott (1997), stated "that discretion varies with organizational factors, characteristics of the decision maker, and aspects of the decision (such as type of clientele)" (p. 457). Administrative discretion is often regarded as a precondition for the linkage between passive and active representation to occur. The bureaucrats must have a certain level of discretion so that their actions can have a (measurable) impact on certain groups (e.g., Gibran, 2007; Meier \& Bohte, 2001; Sowa \& Selden, 2003). However, this applies, foremost, to active representation in the form of a bureaucrat actively advocating for a group of people in society. Because the 
present study suggests that representative bureaucracy can have effects in different waysnot only through bureaucrats acting on behalf of certain groups - the necessity for discretion among bureaucrats is not as crucial as it was in previous studies. Discretion is a precondition for active representation in the form of advocacy, but does not play a major role when passive representation exerts an influence.

Most studies on the link between passive and active representation have focused on the factors that influence the attitude and values and, thus, the behavior of a bureaucrat. Both individual factors and organizational factors have been found to have an impact on bureaucrats' decisions to actively assist their respective minority members of society. When it comes to demographic factors, sex, race, and ethnicity are significant in explaining the linkage between passive and active representation (Bradbury \& Kellough, 2008; Keiser et al., 2002; Krislov, 1974). These are also the variables most commonly investigated by representative bureaucracy scholars. Recent studies have indicated that additional individual characteristics (e.g., age, disability, sexual orientation, veteran status, and language) should also be considered (Gade \& Wilkins, 2013; Kelly, 1998; Kübler et al., 2012; Lewis \& Ng, 2013; Slack, 2001; Thielemann \& Stewart, 1996). Additionally, level of education and party identification have been shown to affect bureaucrats' selfperceptions as minority representatives (Selden et al., 1998). Research on these individual factors and their effects has assumed that bureaucrats and people with the same demographic characteristics share the same values. Whether or not this is the case has been debated in the representative bureaucracy research literature. Kranz (1974) stated that minorities as "a group will more closely mirror the needs and wishes of their group, whether overtly or subconsciously, than non-minorities do" (p. 435). Several scholars have 
found indications for the existence of such group values (e.g., Selden, 1997; Selden et al., 1998; Thompson, 1976). Following this line of thought, passive representation seems to be regarded as a precondition for active representation. However, more recent studies have questioned this conclusion and asked if active representation can occur without passive representation (Kennedy, 2013; Dolan \& Rosenbloom, 2003).

Aside from demographic and other individual variables influencing the link between passive and active representation, organizational factors have been found to play a role. Significant organizational factors include length of time working in the public sector, perceived work obligations (Selden et al., 1998), the organizational environment, the issue under consideration, potential organized employee groups, the bureaucrat's position in the organizational hierarchy and the physical location of the bureaucrat's office in the entity (Thompson, 1976). The percentage of minority representatives can also be important: Thompson (1976) stated that a critical mass is needed for minority bureaucrats to become active representatives in an organization. Regarding the effects of serving in a certain organization, Meier and Nigro (1976) found that "Apparently, agency socialization tends to overcome any tendency for the supergrades to hold attitudes rooted in social origins" (p. 467). However, these findings might reflect the fact that they had investigated upper level officials (i.e., federal executives). To be promoted to senior positions or keep one's position, a bureaucrat must adapt to the organization's values and norms. At the street-level, where many bureaucrats are in steady and close contact with citizens, organizational socialization did not occur to the same extent; rather, individual characteristics seem to be the source of bureaucrats' values (Hindera, 1993; Meier, 1993; Thompson, 1976). 
In the context of organizational influence on representation, the organization's type and the policy area play a role. Considering Lowi's (1985) classification, the four agency types (i.e., regulatory, distributive, redistributive, and constituent) serve different purposes - but also have different organizational and political cultures and group relationships.

In addition to these individual and organizational factors, other concepts acting as mediating or intervening variables have been introduced and tested. Selden et al. (1998) assessed the concept of a minority representative role, i.e., representing one's minority group as a bureaucrat, that must be adopted for passive representation to translate into active representation. They tested whether adopting a minority representative role is dependent on demographic factors as well as on the bureaucrats' perceptions of the expectations by others regarding their role. The results showed that, contrary to Meier and Nigro's (1976) conclusions, ethnicity and race have a strong impact on bureaucrats' perceptions and their adoption of a minority representative role. Organizational factors did not counterbalance this effect to a significant extent. Building on those results, Gibran (2007) found that bureaucrats' perceived role expectations were a mediating factor, along with discretion. Furthermore, bureaucrats' role expectations and uncertainty are important to transform perceived discretion into active representation (Gibran, 2007).

The significance of all the variables, individual as well as organizational, is highly dependent on the context of the study. The link from passive to active representation does not only differ between organizations, it also varies among bureaucrats (Gibran, 2007; Kennedy, 2014). And, as noted above, the issue under consideration also influences bureaucrats' behavior (Thompson, 1976). 
Before describing recent trends in representative bureaucracy research, whichtogether with the abovementioned work on individual and organizational variables-are the foundation for this study, I will address the normative discussions on the topic. Given that bureaucrats should be value-neutral, the issue of whether a bureaucracy must be demographically representative of the people it serves is highly debated. The following section addresses this issue.

\subsection{Normative Considerations}

Many scholars have attempted to elaborate on the advantages of a representative bureaucracy and, thus, on the need to make bureaucracies more representative of the people they serve. Arguments in favor of a representative bureaucracy have ranged from simple fairness to being (more) democratic (Dolan \& Rosenbloom, 2003; Kingsley, 1944). A representative bureaucracy is business-like: efficient and effective. Moreover, a representative bureaucracy is responsive-embracing different perspectives based on experience and socialization (Rosenbloom \& Kravchuk, 2005). Through increased responsiveness, a representative bureaucracy promotes administrative responsibility. Representative bureaucracy is also regarded as more legitimate by minorities than one that is not representative of minorities (Theobald \& Haider-Markel, 2009). Kranz (1976), strongly advocating representative bureaucracy, suggested that it could benefit underrepresented groups as a whole (bureaucrats as well as citizens), racial/ethnic minorities and women, and other groups who might rely on particular public services, administrative organizations, and the government. 
Theorists who criticize representative bureaucracy mainly refer to active representation. However, passive representation is mostly regarded as positive because it is inherently open and "serves as an indicator of equality of opportunity and access" (Riccucci \& Saidel, 1997, p. 423). This openness, in turn, makes representative bureaucracies more legitimate in the eyes of minorities and eventually more responsive to the needs of all people. That is why passive representation plays a very important symbolic role (Ricucci \& Saidel, 1997). In his book, Mosher (1968) stated that:

1. governmental decisions and behavior have tremendous influence upon the nature and development of our society; our economy and our policy, 2. the great bulk of decisions and actions taken by governments are determined or heavily influenced by administrative officials, most of whom are appointed, not elected. (p.3)

He described passive representation as positive: "While passive representativeness is no guarantor of democratic decision-making, it carries some independent and symbolic values that are significant for democratic society" (Mosher, 1968, p. 17). With the help of passive representation, the range of norms and values in the society is represented. If passive representative bureaucracy is criticized then the contention is usually that passive representation does not necessarily lead to greater responsiveness (Kernaghan, 1991). Andrews, Boyne, Meier, O’Toole, and Walker (2005) presented such a study. Examining the connection between ethnic diversity and citizen satisfaction, they found that in administrations with a higher level of ethnic representation of the diverse public, citizen satisfaction declined. However, their investigation remains an exception among the studies on passive representation. 
While the concept of passive representation has not been excessively debated, active representation has been criticized in several ways. Mosher (1968), who established the concepts of passive and active representation, rejected active representation:

It may be noted that active representativeness run rampant within a bureaucracy would constitute a major threat to orderly democratic government. The summing up of the multitude of special interest seeking effective representation does not constitute the public interest. The strengths of different private interest groups within administration are vastly unequal, and the establishment of anything approaching equity would be nearly impossible. (p. 12)

Larson (1973) contended that it would be difficult to ensure that a representative bureaucracy would serve the interests of all different groups equally. Krislov (1974), in turn, highlighted the potential of active representative bureaucracy: "the human potentialities brought by bureaucrats to their jobs are inevitable and advantageous" (p. 81). Worthy of note: in their assessments of the links between passive and active representation, most of the abovementioned scholars did not explicitly elaborate on the potential negative connotation of active representation - when the actions of bureaucrats purposefully benefit their social or demographic groups. It is unfair when the needs and interests of disadvantaged minority groups in society are not represented in a bureaucracy; however, it may also be unfair if bureaucrats favor certain individuals or groups at the cost of others. Lim (2006) strongly rejected active representative bureaucracy in the form of bureaucratic partiality: "bureaucratic partiality should be clearly denounced, prohibited in practice, and curbed by appropriate measures if it is found to exist, regardless of which social group bureaucrats are from or partial toward." (p. 203) Lim (2006) suggested that in addition to 
partiality, other forms of representation can be considered active representative bureaucracy. Because Lim's work serves as the basis for this dissertation, his study and viewpoints will be discussed in detail in Chapter 2.7.

Although several scholars have rejected bureaucratic partiality, the discussion on whether or not it is fair is complicated-resembling the discussion on affirmative action. Treating a certain group of people favorably because they have been disadvantaged in the past has been and continues to be highly debated. However, the famous statement of President Lyndon Johnson, in a speech at Howard University, rightfully points to the need for measures that account for the discrimination of minorities in the past:

You do not take a person who, for years, has been hobbled by chains and liberate him, bring him up to the starting line of a race and then say, "you are free to compete with all the others," and still justly believe that you have been completely fair. Thus it is not enough just to open the gates of opportunity. All our citizens must have the ability to walk through those gates. This is the next and the more profound stage of the battle for civil rights. We seek not just freedom but opportunity. We seek not just legal equity but human ability, not just equality as a right and a theory but equality as a fact and equality as a result. (Lyndon Johnson, June 4, 1965)

Johnson's view on equality may apply to active representation in the form of partiality. How, without the help of such measures, will racial/ethnic minorities who were discriminated against in the past reach and compete at the same level as the dominant group in society? A discussion on the rightfulness of these forms of positive discrimination is not the focus of the present study and would go beyond its scope. Nevertheless, findings from 
the present study should be considered in the context of the ongoing debate: should historically disadvantaged groups receive preferential treatment?

\subsection{Different Views on Representation}

Noticeably, the development of representative bureaucracy research does not follow a clear trajectory. A common definition of representative bureaucracy is lacking. Moreover, empirical studies have focused on very different variables and partially contradict each other. This section addresses the multiple views on representative bureaucracy by elaborating on the term representation and its different classifications, and examining if active representation requires passive representation.

As stated earlier, scholars have not reached consensus on a common definition of representative bureaucracy; instead, they have chosen to define the term in each study—if they define it at all. As a result, major differences have emerged between the various definitions. Kranz (1974) defined passive representative bureaucracy as:

one in which the ratio of each minority in a particular government agency equals that group's percentage in the population in the area served by that office. $[\ldots]$ Moreover, it must include equitable distribution of minorities at all levels of appointive positions, not just at the low entry levels. (p. 435)

Although this constitutes a "true" passive representation, it is unlikely that a bureaucracy can be $100 \%$ representative of the citizens. The hiring process for such a bureaucracy may be excessively complicated or even unfeasible. Decisions on which variables should be considered when creating such a passive representative bureaucracy (e.g., sex, race, ethnicity, religion, nationality) would be very difficult and could be 
regarded as incorrect or unfair by some. Furthermore, a normative objection could be: more qualified applicants for certain positions might be rejected—weaker applicants would be hired instead to meet the representation requirement. As mentioned in the prior remarks on affirmative action, the rightfulness of such practices is prone to heated debate. An additional contention for representation in this stringent interpretation is the question of whether effective decision-making would still be possible in a bureaucracy that is as diverse as society.

Kingsley (1944) had suggested that the dominant classes in society be represented in bureaucracies. Today, this proposition would not be regarded as a suitable and fair solution. Another, possibly more feasible approach would be that a bureaucracy should resemble the people it serves to the greatest extent possible, but it does not have to be in exact proportions. Moreover, depending on the study, sometimes only one variable is of interest. In such a case (e.g., considering the descriptive representation of women or African Americans in a certain organization), aiming for exact proportions of representation is feasible and certainly desirable.

Thus, the way in which representation is defined and interpreted depends heavily on the context of each study, and-departing from some scholars' call for a common definition - it seems problematic, unnecessary, and undesirable to aim for one common definition.

Most of the abovementioned studies on the factors that link passive with active representation do not consider the possibility that passive representation might also affect the population with the help of mechanisms other than bureaucratic partiality. This omission has recently been criticized. Scholars have increasingly shifted their focus (back) 
to passive representation. While most of the early studies on passive representative bureaucracy measured the degree of representativeness of a certain bureaucracy without addressing potential effects of representation (e.g., Dometrius \& Sigelman, 1984), more recent studies on passive representation focus on its potential effects (Gade \& Wilkins, 2013; Meier \& Nicholson-Crotty, 2006; Theobald \& Haider-Markel, 2008). The mechanisms behind the effects are the base for the present study, and recent research on these mechanisms will be examined in the next section.

Regarding the development of research on representative bureaucracy theory, it is worth noting that — aside from the classic passive-active assumption—other classifications of representation were considered in the early stages of representative bureaucracy research. Pitkin (1967), for instance, described three views of representation: descriptive, symbolic, and substantive representation. Descriptive representation refers to the degree to which an organization mirrors the characteristics of the population (such as gender, race and ethnicity) as visible characteristics; more recent studies have also included characteristics such as sexual orientation, veteran status, and language (Close, Mason, Wilkins, \& Williams, 2011; Gade \& Wilkins, 2013; Kübler et al., 2012; Lewis \& Ng, 2013; Turgeon \& Gagnon, 2013). Symbolic representation refers to what a representative can embody for the people being represented. Substantive representation, in turn, refers to representatives' activities on behalf of those represented (Pitkin, 1967).

Similarly, Birch (1971) introduced three types of representation: delegated representation (a bureaucrat act on behalf of a group or person); microcosmic representation (a bureaucrat is representative of a larger group in certain ways - mirroring 
passive representation or Pitkin's descriptive representation); and, symbolic representation (a bureaucrat represents others symbolically).

Pitkin's (1967) substantive representation and Birch's (1971) delegated representation resemble Mosher's (1968) active representative bureaucracy. However, recent studies have suggested that substantive representation can have effects that mirror the effects of passive representation, and that the mere presence of minorities in the public sector can be influential—leading to substantive effects (Gade \& Wilkins, 2013; Meier \& Nicholson-Crotty, 2006; Theobald \& Haider-Markel, 2008). "With symbolic representation, then, attitudes and outcomes can change without any purposeful actions taken by the representatives other than holding a government office or position" (Theobald \& Haider-Markel, 2009, p. 410). In other words, symbolic representation as described by Pitkin (1967) and Birch (1971) can have substantive effects. It is noteworthy that these researchers investigated different types of representation 50 years ago, but empirical research on the different effects of these types of representation only began approximately ten years ago.

In addition to discussions on the effects of passive and symbolic representation, scholars have recently posed another question: for active (or substantive) representation to occur, is passive representation necessary? In one of the few studies that has investigated this question, Selden et al. (1998) found the adoption of a minority representative role to be crucial for active representation. As mentioned previously, ethnicity and race—as well as organizational factors - can influence the adoption of this role. In a subsequent study on attitude congruence, Bradbury and Kellough (2008) concluded that common attitudes 
among administrators and citizens is more influential on the adoption of a minority representative role than race.

A study on administrative role concepts by Selden, Brewer, and Brudney (1999) divided bureaucrats into five groups: stewards of the public interest, adapted realists, business-like utilitarians, resigned custodians, and practical idealists. Only one group, the resigned custodians, which includes the least satisfied bureaucrats, has a neutral competence role. A proactive administrative role is adopted by stewards of the public interest, who base their activities more on the public good than on efficiency and neutrality, as well as practical idealists and business-like utilitarians. Only adapted realists and resigned custodians consider themselves responsive to elected officials. The Selden et al. (1999) study showed that the five types are not determined by demographic variables.

\subsection{New Research Directions: Lim's (2006) Substantive Effects and Atkins, Fertig, and Wilkins's (2014) Causal Mechanisms}

Before examining empirical studies on the effects of passive representation, I will summarize the theoretical approaches of Lim (2006) and Atkins et al. (2014), which constitute the basis for this dissertation's conceptual model. Lim (2006) addressed the different ways through which representative bureaucracy can affect the population. Instead of categorizing representative bureaucracy as passive or active, he claimed that there are direct and indirect sources of substantive effects of passive representation. "Factors that produce benefits directly (i.e., through minority bureaucrats' direct influence on people) are called direct sources. Those that produce benefits indirectly (i.e., through the behavior of other bureaucrats and minority clients) are called indirect sources" (Lim, 2006, p. 195). 
The direct sources introduced by Lim (2006) are advocacy, shared values and beliefs, and empathic understanding. Advocacy includes bureaucratic partiality (i.e., pushing to secure advantages for a certain group). This partiality is rejected by Lim (2006) - just as it was by Mosher (1968). However, advocacy can also mean that a bureaucrat pushes to end discriminatory behavior against a certain group, thus promoting equal treatment. The direct source "shared values and beliefs" refers to the assumption that people from the same minority group share certain values and beliefs. Finally, empathic understanding means that bureaucrats can better understand an individual or a group because of a common cultural/ethnical/racial/professional background, even if there are no shared values and beliefs.

Indirect sources that produce benefits through the behavior of non-minority bureaucrats include: minority bureaucrats expressing disapproval of discriminatory behavior by non-minority bureaucrats; prior restraint felt by non-minority bureaucrats if they are about to act on their bias, due to the presence of a minority bureaucrat; and resocialization (i.e., the change in values and beliefs that a minority bureaucrat can provoke in a non-minority bureaucrat over time). Indirect sources that produce benefits through the behavior of minority clients are demand inducement and coproduction inducement. The former implies that the minority bureaucrat's presence can stimulate more applications or service demands from minorities, while the latter suggests that minority bureaucrats can stimulate clients from the same social group to work to enhance client outcomes (Lim, 2006). This is, according to Keiser et al. (2002), often the case in school settings-where students seek the approval of teachers. 
Most studies on the link between passive and active representation have attempted to prove this link by connecting it only to direct sources (i.e., "advocacy" and "partiality"). Aside from advocacy, research on the effects of representation remains scarce; however, the number of studies in this area is increasing. Most recent studies have focused on the influence of passive representation on clients' behavior [i.e., Lim's (2006) demand and coproduction inducement] (Atkins et al., 2014; Meier \& Nicholson-Crotty, 2006; Theobald \& Haider-Markel, 2008; Thielemann \& Stewart, 1996).

Atkins et al. (2014) investigated how passive representation among school teachers influences school connectedness and future expectations among students. They found that both connectedness and expectations increase for minority students with higher minority teacher rates. Atkins et al. (2014) provided a list of causal mechanisms—-similar to Lim's (2006) direct/indirect sources, which I used in the present study to develop my conceptual framework:

1. Passive representation of minority bureaucrats affects the behaviour of minority clients by making the agencies' services more attractive to these clients

2. The bureaucrat serves as a role model for the client

3. Minority bureaucrats are more likely to assume a 'minority advocacy' or representative role for minority clients

4. The presence of minority and female bureaucrats may lead to changes in the behavior of majority bureaucrats.

5. The increases in representation may shift the policies and/or priorities of the organization

(Atkins et al., 2014, pp. 506-507) 
The Atkins et al. (2014) mechanisms listed above partly parallel Lim's (2006) work in the following ways: Mechanism 1 is demand inducement; Mechanism 2 is a form of coproduction inducement; Mechanism 3 can be compared to Lim's direct sources as a whole; Mechanism 4 refers to the indirect sources that influence outcomes through nonminority bureaucrats' behavior, and Mechanism 5 connects representation with organizational change. Both Atkins et al. (2014) and Lim (2006) have stated that one or several of these mechanisms can occur simultaneously.

Atkins et al. (2014) found support for the first and second mechanisms-demand and coproduction inducement-in the form of increased perceived connectedness to the school and higher career expectations on the part of minority students in schools with more minority teachers. Demand inducement was also an outcome of a Meier and NicholsonCrotty (2006) study, which found a direct correlation between an increase in the number of reported sexual assaults and arrests and an increase in the number of female police offers. Addressing representative bureaucracy in high schools, Meier and Bohte (2001) and Meier et al. (1999) stated that students often regarded their teachers as role models. Focusing on the attitude of clients toward representative bureaucracy, Theobald and Haider-Markel (2009) found that African-Americans regard police stops and car searches as more legitimate when the officer is African-American, and found that Whites perceive them as more legitimate when the officer is White. This is an example of coproduction inducement. Similarly, Gade and Wilkins (2013) found evidence of demand and coproduction inducement when interviewing counselors of vocational rehabilitation services for veterans and surveying the clients. Veteran clients were more likely to succeed (coproduction inducement) and more likely to participate (demand inducement) when their counselors 
were veterans. Also, clients stated that communication was better and their satisfaction was higher when their counselor was a veteran. The perceptions and feelings of these clients can be the result of shared values and beliefs as well as empathic understanding.

In summary, these studies have attempted to show that the mere presence of minority bureaucrats can lead to substantive benefits for those being represented. However, active representation in the form of advocacy or partiality cannot always be excluded and may have played a role. While several researchers have criticized that earlier work on the link between passive and active representation did not control for sources other than advocacy, these researchers now admit that they cannot fully control for active representation, which might have also benefited the community, or fully control for mechanisms other than those being measured (Gade \& Wilkins, 2013; Theobald \& HaiderMarkel, 2009; Atkins et al., 2014).

Figure 3 below captures the propositions of Lim (2006) (i.e., the direct and indirect sources of passive representation) and includes factors that appeared to be significant in many studies on the link between passive and active representation. 
Figure 3: Depiction of Factors and Indirect and Direct Sources

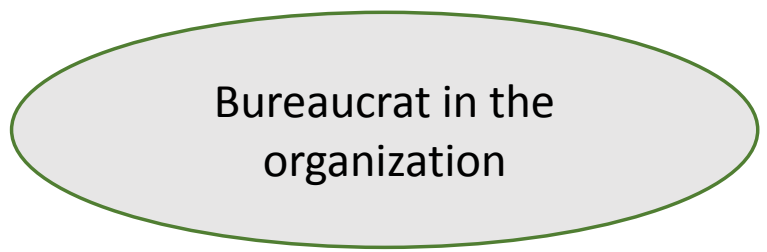

Personal factors:

- Minority status

- Ethnicity/race

- Age

- Sex

- Political viewpoints

- Religious viewpoints

- Veteran status

- sexual orientation

- language
Organizational

factors:

- Organizational goals and values

- Organizational rules and structures
INDIRECT SOURCES:

- Demand inducement

- Coproduction inducement

- Check/disapproval of non-minority bureaucrats' behavior

- Prior restraint

- Resocialization
Perceived role expectations:

- By public

- By organization

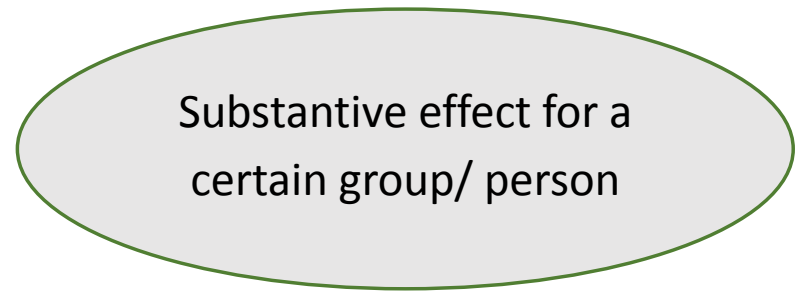

A bureaucrat in an organization is influenced by personal and organizational factors as well as by perceived role expectations. These factors may or may not turn the bureaucrat into an active representative of the people by advocating for them [Lim's (2006) direct source advocacy]. Furthermore, direct sources other than advocacy, as well as indirect 
sources, can lead to substantive effects for a person or a group of people. The conceptual model presented in Chapter 2.9 addresses these mechanisms in more detail.

\subsection{Representative Bureaucracy in Public Schools}

This dissertation focuses on representative bureaucracy in schools. Teacher-student relationships have been used in previous studies to measure the impact of representative bureaucracy. These studies used 'representative bureaucracy' as the independent variable - measured, for example, as the proportion of minority teachers a student has or whether or not they have minority or female teachers for certain subjects. The dependent variables included test scores, dropout rates, career expectations, and connectedness to the school; one study used a dependent variable that, at first glance, does not seem to be connected to the school setting: teenage pregnancy (Atkins \& Wilkins, 2013; Atkins et al., 2014; Keiser et al., 2002; Meier \& Bohte, 2001; Meier \& Stewart, 1992; Meier et al., 1999; Pederson, 2013; Pitts, 2005). Higher test scores for minority students as well as for White students were the outcome of an increased proportion of minority teachers (Meier et al., 1999). The increase in minority school-principals, however, did not have any significant effect on the students (Meier \& Stewart, 1992). This may be due to socialization by the organization, which caused the principals to identify more with the schools' values than with socio-cultural or ethnic values. It is also an indicator of the importance of direct clientcustomer contact for representative bureaucracy to work. Another effect of higher minority teacher rate was lower student dropout rate (Pitts, 2005). Meier and England (1984) studied the effects of African American school board members on policies in the educational arena 
that specifically affect African American students. They found higher rate of African American board members to be connected with more equitable educational policies.

Studies on the impact of gender found gender to be significant. Female math teachers and female teachers in general enhanced female students' math scores in Texas Schools (Keiser et al., 2002). Similarly, a study of Danish schools found that students with teachers of the same gender perform better in math and language arts (Pedersen, 2013). Another recent study focusing on African American teen pregnancy found that the presence of African American teachers lowered teen pregnancy rates among African American teenagers (Atkins \& Wilkins, 2013).

These studies all found that the presence of minority or female teachers had a significant impact on the different outcome variables. To date, only one study has investigated the mechanisms behind the outcomes (i.e., the question regarding the mechanisms via which passive representation led to substantive effects): Atkins et al.'s (2014) study included two of the mechanisms that cause passive representation to exert a substantive influence in the sphere of public schools. The dependent variables that they used-school connectedness and expectations for the future-have been previously researched in the educational setting. School connectedness leads to better results (Bond et al., 2007) and improves students' lives (Blum, 2005). Students with higher expectations for their professional future drop out of school less often than those who have lower expectations (Clark, Kim, Poulton, \& Milne, 2006). Moreover, those who have higher expectations have a healthier lifestyle (McDade et al., 2011). Atkins et al.'s (2014) study was the first to connect the two variables (i.e., connectedness and future expectations) to representative bureaucracy—finding positive results, including: higher minority 
representation rates among teachers enhanced connectedness and future expectations of students.

The following chapter presents the conceptual framework which was developed based on the foregoing review of the literature.

\subsection{Conceptual Framework}

This study focuses on the multiple ways that a representative bureaucracy can affect society. The model presented in Figure 4 is based on Lim's (2006) direct and indirect sources, but it also includes demographic and organizational factors—and the bureaucrat's perceived role expectations - that have been found to be significant in prior studies on representative bureaucracy. The model represents the conceptual framework for the entire study. A simplified conceptual model for the study's quantitative analysis is presented in Chapter 3.4. 
Figure 4: Conceptual Model

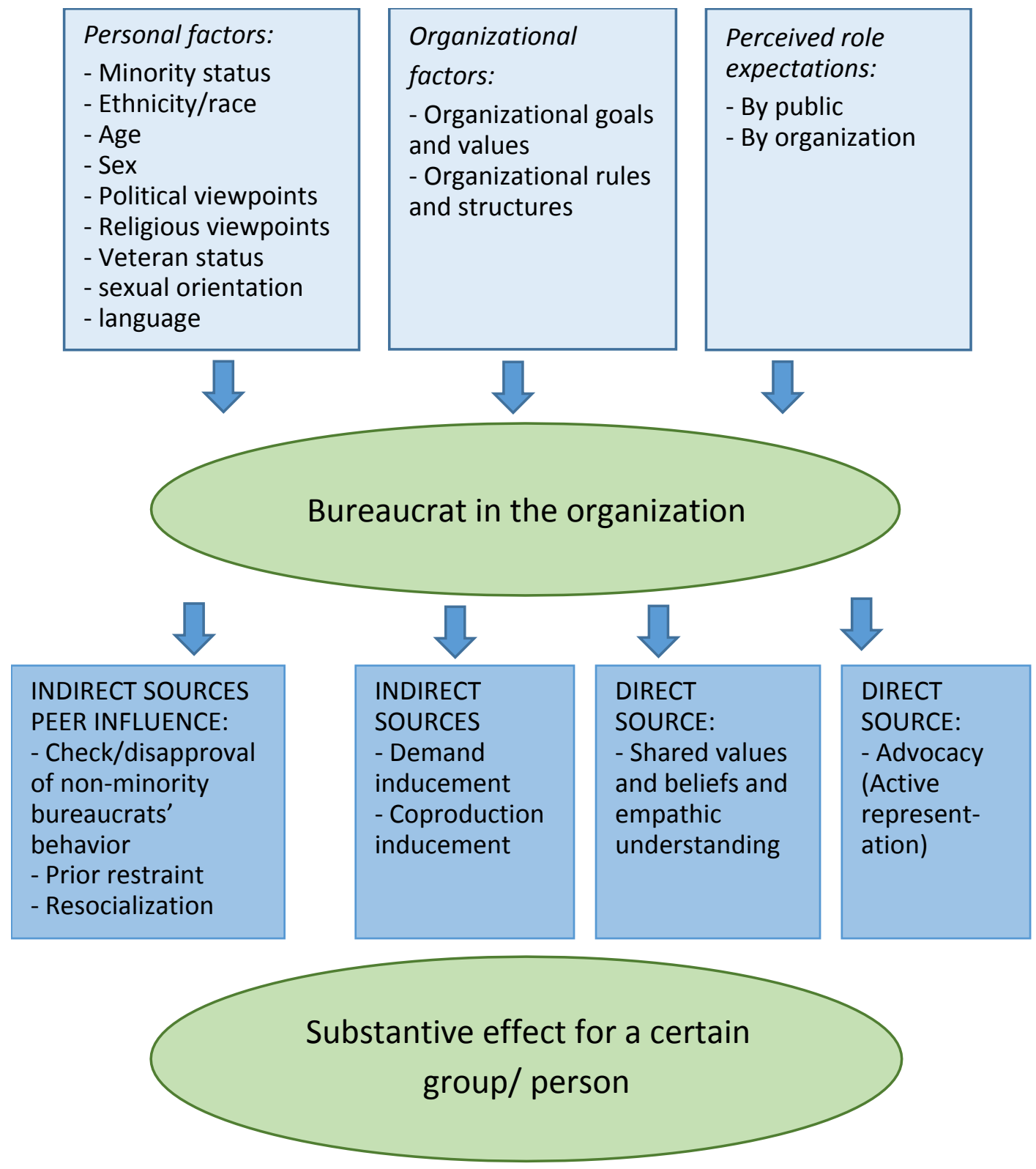

As depicted in Figure 4, various personal and organizational factors and perceived role expectations influence the bureaucrat in an organization. The indirect and direct sources are mechanisms through which passive representation can impact the population. 
Lim (2006) grouped three direct sources—advocacy/partiality, shared values and beliefs, and empathic understanding - into the same category because bureaucrats' behavior can directly lead to substantive effects for the people. He assumed that shared values and empathic understanding "lead minority bureaucrats to articulate the interests of their social groups as decision inputs and to take these interests into proper account in their own decisions and action" (Lim, 2006, p. 196). He regarded shared values and beliefs and empathic understanding as a "soft variation" of traditional active representation [as Mosher (1968) had framed it] in the form of advocacy.

In the conceptual model (Figure 4), the direct source advocacy is separated from shared values and beliefs and empathic understanding. Advocacy is an active and rather overt behavior of the bureaucrat, whereas shared values and beliefs and empathic understanding — even if they entail an active behavior of the bureaucrat — appear to be more covert mechanisms. Shared values and beliefs and empathic understanding, as covert direct sources that are both based on values and beliefs (either sharing them or understanding them), are grouped together as one mechanism for the quantitative part of this study.

The indirect sources in the conceptual model, as described by Lim (2006), are assumed to make representative bureaucracy have an impact without considering perceived role expectations because they do not involve the minority bureaucrat directly; but the behavior of majority bureaucrats (peer influence) and the public (demand and coproduction inducement). When interacting with a bureaucrat who has the same demographic characteristics, a client is motivated to engage in demand and coproduction inducement; thus, demand and coproduction inducement are likely to be connected to demographic variables and organizational settings. The indirect sources grouped under peer influence 
(check/disapproval, prior restraint, and resocialization), are produced by the presence of a minority bureaucrat in an organization and by their influence on non-minority colleagueswithout direct influence of the minority bureaucrat on the population.

The model depicts peer influence as distinct from the other sources. This emphasizes that peer influence is assumed to not interfere with the other sources. For the other three boxes (i.e., the two boxes depicting direct sources and the box depicting the other indirect sources), I assume that the boundaries dividing them can blur. One source may lead to another, and different sources can overlap. Demand inducement, for instance, may lead to shared values and beliefs or empathic understanding, when minority bureaucrats serve enough clients from their minority group. Also, empathic understanding and shared values and beliefs might lead to advocacy.

Lim (2006) argued that all indirect and direct sources can entail substantive effects. This can either occur with the help of one source, or several sources, which can affect outcomes for the people simultaneously. To understand these processes and make use of them, I investigate which sources, or mechanisms, are relevant to particular environments or settings, determine which sources are prevalent, and determine their effectiveness

This study examines how the abovementioned mechanisms influence the relationship between representation and substantive effects using quantitative methods; the relationships between the different mechanisms are explored with qualitative methods. The different approaches are explained in detail in Chapter 3.4. 


\subsection{Conclusion}

Over the past hundred years, researchers and practitioners have examined and discussed the role of bureaucracy in a society. Although Max Weber's (1922) essays were written nearly a century ago, his depiction of the value-neutral bureaucrat-who is bound to decisions made by politicians and serves to implement those decisions - is still prevalent today. Weber (1922) described the situation of his time: bureaucracy, based on legalrational authority, was the dominant form of organization in society, which was part of the unstoppable process of universal rationalization. However, the value neutrality of bureaucrats, and the assertion that they do not have any discretion regarding decisions they must make every day, was soon contested. Waldo (1948) claimed that political control of bureaucracy is not only impossible due to the size and increasing complexity of government, but also undesirable, because society would be deprived of the comprehensive knowledge of bureaucrats.

The theory of representative bureaucracy should not be regarded as a threat to traditional bureaucracy. Instead, it should be considered as a tool-a mechanism to improve and modernize the Weberian model of bureaucracy. The theory of representative bureaucracy may be used in combination with different theoretical approaches (e.g., New Public Management or the Neo-Weberian State). A representative bureaucracy strengthens the relationship between citizens and bureaucrats by being sensitive and responsive to public opinion.

Absolute value neutrality on the part of the bureaucrat, as described by Weber, is extremely difficult, if not impossible, to achieve. Throughout the lifespan, family, society and culture instill humans with values; our lives are heavily influenced and driven by those 
values, and excluding them entirely from our actions is impossible, if not undesirable. In a representative bureaucracy, different values are represented in the bureaucracy and can address a range of values in society.

Representative bureaucracy can complement Weberian bureaucracy by addressing some of the flaws of representative democracy. A representative bureaucracy establishes a stronger connection between bureaucracy and citizens. How does this work? Lim (2006) described several mechanisms that are helpful in making bureaucrats more responsive to their citizens. First, diversity within a bureaucracy increases the receptiveness for the diversity of public opinions. If bureaucrats are part of a diverse work atmosphere, they must clarify, discuss, and find compromises due to differences in values and opinions originating in different social, ethnical, regional, and national backgrounds. They, thus, communicate much more and are more aware of difficulties, but also of the advantages of a diverse environment. Aside from the changes that diversity can provoke inside the bureaucracy, which in turn have a positive impact on the bureaucrats that deal with citizens, a representative bureaucracy can also enhance citizens' perceptions of bureaucrats. When citizens see an individual who belongs to their (minority) group in a position of authority, they may be more likely to view the state as legitimate. Finally, minority bureaucrats can substantially influence other bureaucrats. When other bureaucrats are exposed to the viewpoints and actions of the minority bureaucrat, they are more likely to adopt their values, beliefs, and viewpoints and, thus, become more open-minded. By being more representative, the bureaucracy automatically becomes more receptive to its citizens' needs and wishes. 
In addition to the opportunities presented by representative bureaucracy theory, there are several aspects of representative bureaucracy theory that remain unclear and need to be addressed further. First, it seems difficult to make generalizations about the factors that help a minority bureaucrat become an active representative, as they can substantially vary in their significance depending on the situation, the persons involved, and the organization. It is crucial to keep this in mind, because research on the factors that make a bureaucrat a representative must account for the situational conditions in the given context.

Second, the option that active representation may occur without passive representation (i.e., that a bureaucrat becomes a representative for underprivileged people without matching those people in terms of race, ethnicity, sex, or other individual variables) should be taken into consideration. The drivers that turn a bureaucrat into an active representative can be difficult to detect and to measure. Even the bureaucrats themselves may not be aware of the feelings, values, and stimuli that make them defend or support certain people, as this may occur at a subconscious level. The inclusion of qualitative methods to research these drivers (e.g., in the form of interviews, story-telling, or observation) is likely to lead to more nuanced results in comparison to the exclusive use of quantitative methods.

Third, although the narrow view focusing only on the link between passive and active representation has been overcome and the recent research includes passive representation as well as its effects, one crucial question deserves more attention: how, and with the help of which mechanisms, does passive representation have effects on the population? Previous studies focusing on the effects of passive representation have found that effects do indeed exist, but most either completely omit the question of "how" or 
address it only marginally, with the exception of Atkins et al. (2014). Lim (2006) and Atkins et al. (2014) highlighted mechanisms involved in representative bureaucracy and the dearth of research on them. Representative bureaucracy researchers must investigate these mechanisms to uncover potentially valuable results for the public sector.

Referring to the methods applied in representative bureaucracy research, the vast majority has relied on quantitative methods - most often using data at the aggregate level (Kennedy, 2013). Data at the individual level is difficult to obtain. Another challenge is matching data from citizens' and bureaucrats' perspectives, which would allow for a valuable triangulation of findings. To date, this has not been accomplished, although scholars have acknowledged that it would be an interesting research topic (e.g., Atkins et al., 2014). In addition to the triangulation, individual level data can help isolate the effect of each different mechanism better than data at the organizational level. The next chapter discusses the methodological approach that is used in this dissertation. 


\section{CONTEXT AND RESEARCH METHODS}

\subsection{Introduction}

Chapter 3 describes the research methods used in this dissertation and provides sociodemographic and historical background information on the context of the study (i.e., research location Germany). First, theoretical support for the choice of methods is provided, followed by information on immigration in Germany and the German school system. Subsequently, I describe the research design, including: designing the questionnaire, sampling, operationalization of variables, qualitative and quantitative data collection, and the quantitative analysis design. Finally, validity and reliability are addressed, followed by the conclusion of the chapter.

\subsection{Ontological and Epistemological Considerations}

The principal objective of this dissertation is to examine how a representative bureaucracy can impact the people it serves. As mentioned in Chapter 2, most scholars have used quantitative research methods to examine the effects of representation. In previous research, the impact of representative bureaucracy has mostly been measured as policy outputs on the aggregate level. These studies have contributed significantly to representative bureaucracy research. However, individual level data may be more appropriate for comprehensive examination of the many impacts of representative bureaucracy. Thus, the present study uses individual level data for quantitative analysis. Some of the recent studies examined in the literature review (Chapter 2) also used individual level data (e.g., Atkins et al., 2014; Meier \& Stewart, 1992; Meier et al., 1999; 
Selden et al., 1998; Theobald \& Haider-Markel, 2009)—providing more nuanced details on the factors that lead to substantive effects of a representative bureaucracy.

In addition to the frequent use of aggregate level data, quantitative methods are more prevalent than qualitative methods in representative bureaucracy research (Kennedy, 2014; Lim, 2006). However, a research model that is exclusively based on quantitative methods may be less likely to capture factors that are not easily measurable. In the context of representative bureaucracy in schools, a crucial factor that is likely to influence the student-teacher relationship and may impact the (perceived) representative role of the teacher is the personality of the teacher-the teacher's willingness to help, to work extra hours, to help students with problems, etc. Although extensive teacher surveys may be able to capture such phenomena, personal interviews are invaluable in efforts to gain a deeper, more detailed understanding of the issue. Using qualitative methods, I can more comprehensively examine the factors that make a teacher become — or be perceived as - a representative for students compared to investigations using purely quantitative methods. Hence, the present study uses both qualitative and quantitative methods. Guba and Lincoln (1994) stated that

[p]recise quantitative approaches that focus on selected subsets of variables necessarily "strip" from consideration $[\ldots]$ other variables that exist in the context that might, if allowed to exert their effects, greatly alter findings. Further, such exclusionary designs, while increasing the theoretical rigor of a study, detract from its relevance, that is, its applicability or generalizability, because their outcomes can be properly applied only in other similarly truncated or contextually stripped 
situations (another laboratory, for example). Qualitative data, it is argued, can redress that imbalance by providing contextual information. (p. 106)

For the reasoning of the chosen research methods, it is important to include epistemological considerations. The validity of combining quantitative and qualitative research methods has long been contested; opponents have argued that the two approaches are linked to different epistemological backgrounds. Quantitative research methods have been traditionally linked to the positivist paradigm. "Hard data" in the form of numbersquantifiable and objective — can produce explanatory and generalizable results. Common research approaches in the positivist paradigm, such as rational choice theory, behavorialism, and institutional analysis, are all based on the assumption of causality and an objective, value-free reality that is measurable (McNabb, 2013).

Post-positivists, in turn, contend that objective reality exists, but cannot be fully known, because researchers' experience, knowledge, and values always influence their observations. Human rationality is limited; therefore, objective measurement of reality is not possible (McNabb, 2013). Bevir and Rhodes (2002) introduced the term "interpretive theory" for the different post-positivist approaches that have emerged and the use of "subjective narrative" (i.e., the researcher is part of the research process—not an objective observer who does not influence occurrences in the research). Robson (2002), in turn, divided non-positivist approaches into three types: post-positivist, constructivist, and interpretive research, also named critical or emancipatory research. While post-positivists agree with positivists that an objective truth exists, they contend that it is impossible to know it due to human limitations. Constructivists claim that reality is a social construct 
established by the researcher rather than an objective fact. Interpretive research has included other types, including feminist and Marxist research approaches (McNabb, 2013).

While positivism has been traditionally linked to quantitative methods, nonpositivist approaches have gravitated toward qualitative methods. A combination of different methods has long been regarded as complicated, if not unfeasible, when different paradigms are involved. The "paradigm wars" in the 1980s made proponents of quantitative methods and proponents of qualitative methods become entrenched in their positions (Reichhardt \& Rallis, 1994). Guba and Lincoln (1994) considered the different paradigms, their assumptions, and implications. They distinguished positivism, postpositivism, critical theory, and constructivism and claimed that to resolve the paradigm debate, supporters of the different viewpoints should have a constructive dialogue instead of merely defending their "own" paradigm.

Research on representative bureaucracy mostly draws from the "traditional" postpositivist paradigm: objective reality is not entirely comprehensible, but it exists; researchers must continually strive to reach objectivity. In more recent studies, researchers have not specifically designated a certain paradigm; they are open to more interpretive approaches, acknowledging the central role of different perspectives. Feminist theory, for instance, provides a valuable theoretical lens, as it takes into consideration different perspectives on phenomena. People with different (ethnic, religious, economic, or social) backgrounds have different versions of reality. In the case of bureaucrats, their subjective views balance out the subjective views of the groups already entrenched in the bureaucracy. Bureaucrats' life experiences will shape their perspectives and finally influence their behavior. This can occur subconsciously. To serve citizens fairly and effectively, a 
bureaucracy must involve the perspectives of people from different backgrounds, which can be achieved with a diverse workforce.

Moving from theoretical considerations to methodological approaches, observing and measuring the complex phenomena behind representative bureaucracy theory using exclusively quantitative data may be, depending on the research questions, insufficient and undesirable. This approach does not capture the meaning and impact of variables that are not measurable with quantitative data. Recent studies have acknowledged these difficulties by including different or additional methods or different types of data into the representative bureaucracy research (Atkins et al., 2014).

The present study builds on current efforts to combine mixed methods to study representative bureaucracy. The study aims to reveal the mechanisms behind the representative bureaucracy phenomenon, thereby providing support for the importance of different perspectives by conducting in-depth interviews. I utilize a mixed-methods approach for two reasons. First, the nature of the research questions and hypotheses are such that both quantitative and qualitative methods are not only appropriate but necessary. A study design utilizing a single method would be less comprehensive and incomplete and would not advance knowledge of the phenomenon under study. Second, the use of mixed methods allows for the triangulation of findings - which results in more accurate findings because different kinds of data are collected and analyzed (Jick, 1979). Olsen (2004) stated that triangulation "is not aimed merely at validation but at deepening and widening one's understanding" (p.130). Due to the complexity of human attitudes and behavior, even the most appropriate research method can often only capture a small portion of the phenomena 
of interest. Triangulation with the help of mixed methods is likely to enhance the overall findings of the present study.

The analysis technique employed in this dissertation is a sequential mixed-methods approach. It is described in detail in Chapter 3.4. Since the data for the present study were collected in Germany, information on the sociodemographic and historic background of the study location is necessary and provided in the following chapter, Chapter 3.3.

\subsection{Location of the Study: Germany}

This study focuses on German public schools and uses data collected in Germany. Before describing the data collection process, the following two sections provide an overview of the German public school system and immigration in Germany. This background information provides insight into why I chose to focus on these research subjects, and explains why the topic is important for Germany.

\subsubsection{German Public School System}

This study focuses on public schools as key point of interaction between citizens and bureaucrats. Public schools serve as ideal places for studying representative bureaucracies for several reasons. First, schools as organizations have similar if not the identical rules, regulations, and objectives. Teachers in different schools perform similar tasks and have similar amounts of discretion: "School systems vest a great deal of autonomy in these street-level personnel who come to the organization as trained professionals. Administrators only rarely visit individual classrooms and, thus, do not closely monitor the interactions between teacher and student" (Keiser et al., 2002, p. 558). 
The work on the "street-level" is another important reason why examining student-teacher relationships matters. It is at the street-level where bureaucrats interact most with citizens (Lipsky, 1980); hence, street-level bureaucrats are likely to be more aware of the problems and needs of the community they serve.

As this study uses data collected in Germany, it is important to briefly review the school system in Germany - as it differs from systems in the US and other countries. In Germany, education is administered at the state level. Germany has 16 states (Bundesländer) and each state has an agency for school authority (Landeschulbehörde), which is the employer of the teachers at public schools. ${ }^{2}$ The students attend elementary school (Grundschule) for four years (grades 1-4), usually from six to ten years of age. After those four years, they are divided into three groups, and each group will attend one of three different secondary school forms. Teachers provide recommendations to parents on which school form is appropriate for their children. The parents then decide which form the child will attend (including a school form that differs from teachers' recommendations). Students with good grades attend "Gymnasium" for eight to nine years (grades 5-12 or 5-13; depending on the state), usually from 10 to 18 or 19 years of age. Students whose grades were not sufficient for a Gymnasium recommendation attend Realschule (grades 5-10) or - with lower grades - to Hauptschule (grades 5-9). Students who finish Gymnasium can then study at university; those who finish Realschule or Hauptschule can either attempt to join Gymnasium to eventually receive admission to university (if their grades are good enough) or begin an apprenticeship. An apprenticeship lasts three years and usually

\footnotetext{
${ }^{2}$ Private schools function differently, but they are accredited and monitored by the school authority agencies. They were not part of this study, though, and thus need not be explained further.
} 
consists of on-the-job-training paired with Berufsschule - a special school that focuses on the different professions. ${ }^{3}$

This traditional three-tier system has frequently been criticized for its rigidity and the difficulty for students to switch from a "lower" school form to Gymnasium. Consequently, several "Oberschulen" and "Gesamtschulen" have been founded, which combine the three secondary school forms. So-called "berufsbildende Schulen" are similar-they combine the three-tier system into one. Students at these schools are typically grouped into different tracks (depending on academic performance-level) in the last two or three school years; in general, a transition from one track to another is easier to achieve - and also less socially strenuous - for these students compared to students in the traditional three-tier system.

\subsubsection{Immigration in Germany}

In the past 60 years, Germany has become a country of immigrants. Compared to traditional immigrant countries such as the United States, Canada, or Australia, Germany's immigration history is young. Thus, there is a need to address new, emerging issues, which may originate from socio-cultural, traditional, or religious differences, among the inhabitants of Germany. This section provides: an overview of immigration in Germany, including the most recent data; a summary of the country's immigration history, which will illustrate the urgent need for constructive dialogue between government and citizens; and

\footnotetext{
${ }^{3}$ Apprenticeships are a common form of education for all kinds of skilled manual professions in Germany (e.g., carpenters, hair-cutters, nurses, plumbers, car repairmen, salesmen, IT-system assistants, etc.)
} 
a description of the situation today and the assumed implications of diversity in the public sector workforce - particularly in terms of workers with migration background.

Germany is home to over 17 million people with migration background. According to the official definition of migration background, those meeting criteria for migration background are "all who migrated to today's territory of the Federal Republic of Germany after 1949, as well as all foreigners born in Germany, and all born in Germany as Germans with at least one parent who migrated to Germany or was born as a foreigner in Germany"4 (Statistisches Bundesamt, 2005, p. 6). In an effort to shorten the definition, the Federal Statistical Office then introduced the following, slightly different definition: "A person has a migration background if she or he or at least one parent was born without German citizenship"5 (Statistisches Bundesamt, 2016, p. 2). ${ }^{6}$

According to Germany's 2015 Census, 17.1 million of the 81.4 million inhabitants in Germany have a migration background- $-21 \%$ of the population $(23.9 \%$ in former West Germany; 5.3\% in former East Germany). Of these individuals with migration background (MB), 7.8 million (9.5\%) are foreigners and 9.3 million (11.5\%) are Germans. Two-thirds

\footnotetext{
${ }^{4}$ German original: ,alle nach 1949 auf das heutige Gebiet der Bundesrepublik Deutschland Zugewanderten, sowie alle in Deutschland geborenen Ausländer und alle in Deutschland als Deutsche Geborenen mit zumindest einem zugewanderten oder als Ausländer in Deutschland geborenen Elternteil.“

${ }^{5}$ German original: „Eine Person hat einen Migrationshintergrund, wenn sie selbst oder mindestens ein Elternteil nicht mit deutscher Staatsangehörigkeit geboren wurde.“

${ }^{6}$ Due to limited data collection procedures in the German yearly sample census, the terms "migration background in the narrower sense" and "migration background in the wider sense" were introduced. In the yearly census, people are not asked questions about their parents. As all members of one household fill out the census surveys, only those who live in one household with their parents can be identified as people with migration background due to their parents' attributes. Thus, those who are counted in the yearly census as people with migration background are those with migration background in the narrower sense. Only in the years 2005, 2009, and 2013 were people asked about their parents' migration background. Hence, in those years, individuals with migration background in the wider sense could be identified (Statistisches Bundesamt, 2016).
} 
(11.5 million) of the people with MB personally experienced migration (6.4 million foreigners, 5 million Germans), whereas one-third (5.7 million) were born in Germany (1.3 million foreigners, 4.3 million Germans). ${ }^{7}$ Figure 5 provides an overview of the numbers and percentages of people with and without migration background in Germany.

Figure 5: Inhabitants of Germany with migration background (in absolute numbers and as percentage of total population)

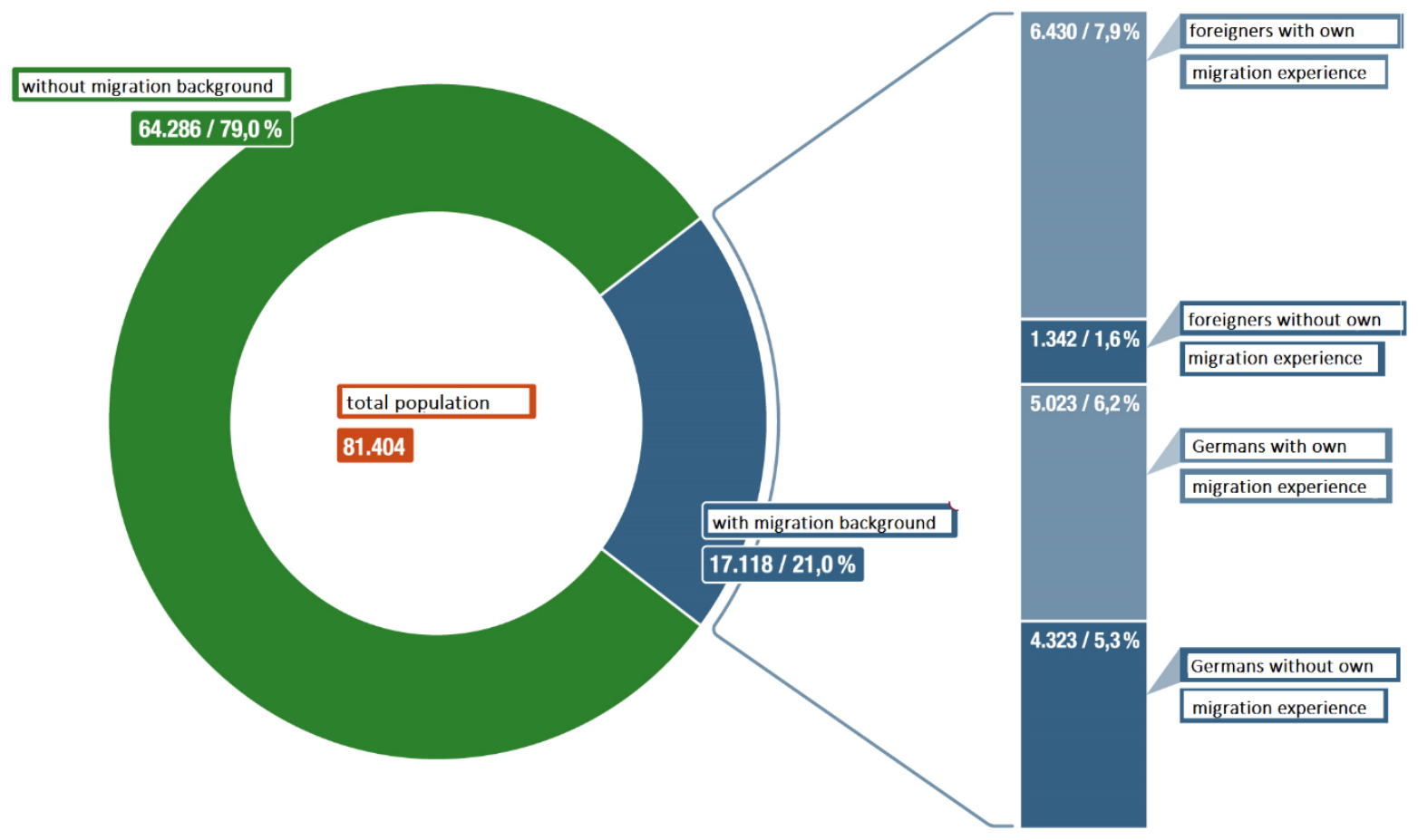

Source: Adopted from Statistisches Bundesamt, 2016

People with MB are younger than those without MB (36 years compared to 47.7 years on average). Among all children in Germany under five years of age, $36.5 \%$ have a migration background (Statistisches Bundesamt, 2016). The numbers have been increasing steadily over the past years. The percentage of teachers with MB cannot be determined

\footnotetext{
${ }^{7}$ Due to Ius Sanguinis, citizenship is not acquired through birth in Germany. The many Germans with own migration experience are mostly so-called Spätaussiedler, repatriates, who were born in the former Soviet Union on soil that was historically German and who then moved to today's German territory.
} 
exactly, as no data were collected on a large scale, but it is estimated to be approximately two percent (Trenkamp, 2014).

The largest group of persons with MB originate from Turkey (16.7\%), followed by those of Polish origin (9.9\%) and Russian origin (7.1\%), and those who originate from Kazakhstan (5.5\%) (Statistisches Bundesamt, 2016, p. 8).

Germany is also home to an unknown number of asylum seekers and unregistered immigrants. Due to the current situation in the Middle East, the number of those seeking help in Germany is likely to have increased drastically in the last 1.5 years.

People with MB are disadvantaged in several ways. They perform worse in school (9.9\% of people with MB have not finished any form of secondary school, compared to $1.5 \%$ without $\mathrm{MB}$ ) and are more likely to be unemployed; thus, people with $\mathrm{MB}$ are more likely to receive long-term social security benefits (7.4\% people with $\mathrm{MB}$ receive such benefits compared to $2.7 \%$ without $\mathrm{MB}$ ). Also, the average household income is significantly lower if at least one family member in the household has a migration background (Statistisches Bundesamt, 2016).

The reasons for these inequalities can be connected to the way that immigration was handled in Germany historically; below, I summarize German immigration history to help explain why this country was chosen for the present study. Although some immigration to Germany occurred before World War II, mass immigration began after the war. The shortage of manpower compelled the government to recruit workers from abroad to meet the demands of a growing economy. The first treaty was signed in 1955 with Italy. In the following years, agreements were established with Greece, Spain, Turkey, Morocco, Portugal, Tunisia, and Yugoslavia (Fassmann, Münz, \& Seifert, 1999). The work 
contracts — and thus the guest workers' stay in Germany—were designed to be for a limited amount of time. The work consisted mostly of industrial jobs, often in the form of assembly-line activities that did not require highly qualified labor. Social integration of the foreigners was not considered to be important at that time (Herbert, 2001). When the contracts of the workers neared expiration, many were extended - the need for manpower remained high for more than another decade. The percentage of foreigners in Germany had grown from $1.2 \%$ in 1960 to $4.9 \%$ in 1970 (Bade \& Oltmer, 2004). In 1973, during the first oil crisis, government imposed a ban on the recruitment of foreign workers. However, the number of foreigners living in Germany continued to increase as those who had been living in Germany (for more than a decade in many cases) did not have positive economic opportunities in their home countries and, thus, they settled down. Many brought their families to Germany (Bade \& Oltmer, 2004).

With the second generation of immigrants, problems in school led to the first integration debates involving foreign children. In 1979, the first official commissioner of foreigner issues in the federal government, Heinz Kühn, demanded the government's acknowledgement of Germany as an immigration country and urged for equal rights regarding education, work, and housing, especially for the second generation of immigrants. ${ }^{8}$ However, the few changes that were implemented only targeted temporary integration. Emphasis was put on maintaining the original culture and language of the children with MB, "premised on the assumption that education in the mother tongue would facilitate the eventual return of the foreigners to their home countries" (Joppke, 1996, p.

\footnotetext{
${ }^{8}$ The first time that an individual with migration background (Aydan Özoğuz) was appointed to that postwhich was created to represent the interests of people with migration background - was four years ago, in 2013.
} 
469). All integration measures occurred at the local level and were generally uncoordinated and unstructured.

The first progressive step toward addressing the immigration issue, which entailed major changes, was the Naturalization Law enacted in 2000, which aimed to facilitate the acquisition of German Citizenship. Minimum residency to apply for naturalization was reduced, a modified version of Ius Soli was implemented, ${ }^{9}$ and the option of having dual citizenship was facilitated (Storz \& Wilmes, 2007). The subsequent Immigration Law, 2005, emphasized successful integration of immigrants (BAMF, 2011a). So-called integration courses were introduced and made obligatory for those who did not have work and did not participate in another language training (BAMF, 2011b). In 2008, more courses were introduced, such as special courses for women, parents, and youth, as well as intensive courses and alphabetization courses (BAMF, 2013). Further measures to support integration were introduced with the National Integration Plan 2007, the Nationwide Integration Program 2010, and the National Action Plan for Integration 2012. Similar in content, these programs focus on individual support for — and increasing recognition of the potential of - children, teenagers, and young adults; improving recognition of university and technical diplomas received abroad; and increasing the number of immigrants in the public sector workforce at the federal and state level. Measures with the aim of improving integration, to be taken at all levels of government, were defined in the plans. Additionally,

\footnotetext{
${ }^{9}$ Instead of acquiring citizenship only through inheritance (Ius Sanguinis), a modified version of the Ius Soli was implemented: Children born in Germany become Germans if at least one parent had a legal residency permit for eight years or an unlimited residency permit for three years. However, the restrictions listed under $\mathrm{N}^{\circ} 1$ also apply here for the children's parents. All in all, about $40 \%$ of foreign children benefited from this change and obtained German citizenship.
} 
the programs suggested that: individuals with MB should be encouraged to join the public sector workforce, human resources personnel should be trained to reduce barriers that impede hiring people with $\mathrm{MB}$, and public sector employees should be sensitive to intercultural diversity (Bundesregierung, 2012).

The historical development of immigration to Germany shows that the country was not prepared for mass immigration and all the repercussions it entailed (e.g., increases in ethnic, religious, economic, and social diversity). The government was not successful in its initial responses to tensions that arose due to outdated immigration laws at the political/administrative level and closed-mindedness and rejection at the sociodemographic level. Chancellor Angela Merkel (Spiegel, 2010, Oct. 16) stated in a speech in 2010 that "multiculturalism has failed utterly"10 in Germany, in the sense that people of different social, ethnic, or religious backgrounds had experienced difficulty next to each other in peace. The above mentioned National Action Plan for Integration 2012 emphasized the important role that people with $\mathrm{MB}$ in the public sector can play. By increasing the number of people with MB in the public sector at all levels, specifically in the teacher workforce and the police force, the government aimed to integrate people with MB more successfully (Bundesregierung, 2012). Including migrants in the public sector can be specifically valuable because these workers provide broader, multisided understanding of different cultures and traditions.

Regarding the teacher workforce in Germany, public school teachers are civil servants employed at the state level who obtain a stable and secure income that is equal for

\footnotetext{
${ }^{10}$ German original: "Multikulti ist gescheitert, absolut gescheitert."
} 
all teachers in each state and increases commensurately with increasing work experience. The German government assumes that increasing the number of school teachers with MB is likely to enhance the performance of students who belong to a certain minority population by increasing their motivation in the classroom (Bundesregierung, 2012). Teachers often serve as role models (Cole, 1986), and students with MB may identify with teachers who also have a migration background (Meier \& Bohte, 2001). Furthermore, teachers with $\mathrm{MB}$ are expected to be more empathic to students with immigrant backgrounds and their parents; these parents will likely regard these teachers as especially trustworthy; these teachers will reflect cultural and ethnic diversity in classrooms and bring intercultural perspectives to the school and to teaching; and these teachers will represent equal opportunity, in terms of access, to the teaching workforce (Bundeskongress, 2010, p. 19). In addition to the assumed benefits for students with $M B$ and their parents, the aspects of equal opportunity, open access, and ethnic diversity should be emphasized. In a country - and a world - whose population is increasingly splitting into opposing groups, fueled by diverging political and social attitudes, it is critically important to engage in an open dialogue and to clearly show that all humans are equal by providing equal access to equal opportunities.

Thus, from a practical perspective, learning about the effects of a representative teacher workforce will be of great value not only for schools, state governments, and the federal government, but also for the all people. The results of the present study help elucidate the significance of teachers with MB; the study aims to evaluate the impact and meaning of these teachers. 


\subsection{Research Design}

The majority of research on representative bureaucracy uses quantitative methods - with data aggregated at the organizational level in most cases. This approach is appropriate when the goal is to determine whether representative bureaucracy has led to a specific policy; however, to investigate the mechanisms that motivate individual bureaucrats to become representatives, data at the individual level is necessary. With individual level data, effects of individual as well as organizational level variables can be examined (Atkins et al., 2014). Also, the scarcity of qualitative data in the representative bureaucracy literature has often been criticized-indicating a need for more qualitative research in this area (Lim, 2006; Kennedy, 2014).

The present study responds to both issues (i.e., need for qualitative data, lack of qualitative data) by using a sequential mixed-methods design with individual level data. Due to diversity in nature among the research questions, a mixed-methods design was appropriate and necessary. An analytical survey was an effective method for Research Question 1, and obtained a large amount of data from many respondents. Research Question 2, which is more exploratory in nature, was effectively addressed with qualitative data from in-depth interviews to gain deep insight into the phenomena; it is unlikely that such insight would have been gained from exclusively quantitative methods. Furthermore, by addressing issues that remained unclear after the quantitative analysis - using data collected from the in-depth interviews - I was able to triangulate findings.

The data collection took place in three phases. First, the questionnaire design for the student survey (designed to assess research question 1) was discussed in ten semistructured interviews with ten German school teachers. Simultaneously, those ten 
interviews were used to collect the first round of qualitative data to assess research question 2. Subsequently, a pilot study of the questionnaire, with 45 students, was carried out at Florida International University, Miami, FL. Following this, 194 German public school students were surveyed. After the analysis of the survey data that assessed research question 1, 16 additional semi-structured interviews with teachers were conducted to expand on the date gathered in the first round of interviews. The following sections explain the order and choice of methods in more detail.

\subsubsection{Questionnaire Design}

To investigate the mechanisms behind a representative bureaucracy, primary data from students was collected using a questionnaire. The questionnaire design was based on the reviewed literature and the research questions; before starting the data collection, ten semi-structured interviews with German school teachers (six with migration background; four without migration background) were conducted to discuss the content and the composition of the questionnaire. Because data collection occurred in Germany, verified whether items in the questionnaire that were mainly based on U.S. (American) research literature were suitable for the German public school context. Simultaneously, the interviews also included questions to address Research Question 2 (further explained in Chapter 3.6.2).

The questionnaire was purposely kept short (one Din A4 page, similar to US American letter format) to prevent students from losing interest while completing it. The time span needed to complete the questionnaire was estimated at ten minutes (maximum). A short questionnaire was important to facilitate student participation, and as an obligation 
from the school authorities to take the least time possible away from students' classwork. It was designed in English and then translated to German.

A questionnaire for the teachers, asking the same questions but from their perspective, was also developed. Initially, statistical analyses with the teacher questionnaires were planned as well, but due to small sample size, the statistical analyses were completed with data from the student surveys. However, the demographic section of the teacher questionnaire was important in that it provided details about teachers' migration backgrounds. Also, to obtain descriptive data for the sample, the teacher questionnaire included questions on (estimated) number of teachers with migration background at the school and number of students with migration background per class.

The questionnaire contained 27 questions - all but three (i.e., those asking for the student's and student's mother's and father's country of birth) were closed-ended. It started with a set of demographic items (7), followed by six sets of items to address the criterion variables and the mediators.

\subsubsection{Sampling}

The targeted respondents were public school students aged 15 years and older; younger students might have had problems understanding the content of the questions (regardless of the questions' formulation). The sample did not have restrictions regarding the geographical location within Germany, but a permit from German school authorities at the state level for each state in which questionnaires would be completed was obligatory. For obtaining the permit, the questionnaire had to be slightly adapted to the regulations of the states (i.e., questions on political and religious viewpoints had be deleted). Upon 
permission from two states, Lower Saxony and Bremen, the survey was conducted. To avoid systematic bias, it was important to keep the type of school (see Chapter 3.3.1) constant. However, with Germany's three-tier system, choosing one of those three types would skew the results, because a disproportionate number of students with migration background (MB) attend the two lower tier schools: Realschule and Hauptschule (Statistisches Bundesamt, 2016). Thus, Gesamtschulen, Berufsbildende Schulen, and Oberschulen were selected as the most suitable school forms - they combine the three-tier system in one school form and attract a heterogeneous group of students. Also, because the underlying concept of these school forms is comparatively new and the number of these schools is increasing steadily, the results of the present study will be relevant for evaluating the impacts of a representative bureaucracy overall, and be particularly valuable to the three included new school forms.

As stated in Chapter 3.3.2, 21\% of Germany's inhabitants have a migration background (MB). Among the children under five years of age, 36.5\% have an MB. For this study, 194 students in seven schools were surveyed. Although the sample is somewhat smaller than originally planned, it is sufficiently large for statistical analyses and can thus provide an insight into the role of the mechanisms of representative bureaucracy in the school context.

\subsubsection{Conceptualization and Operationalization of Variables}

The first step in the questionnaire design was to conceptualize the variables, followed by their operationalization. For the present study, the process of conceptualization and operationalization is based on several studies (mainly Lim, 2006; Atkins et al., 2014; 
Tower, Bowen, Alkadry, 2011). Table 1 below presents the conceptualization of the main variables.

Table 1: Conceptualization of variables

\begin{tabular}{|l|l|}
\hline Assumption & $\begin{array}{l}\text { Representative bureaucracy has substantive effects through various } \\
\text { mechanisms }\end{array}$ \\
\hline Concepts & Predictor: \\
& $-\quad$ Representative bureaucracy (RB) \\
& Criterion: \\
& $-\quad$ Substantive effects \\
& $-\quad-$ Grade (Grade) \\
& $-\quad$ - Classroom Climate (CC) \\
& - - Career Expectations (CE) \\
& Mechanisms: \\
& $-\quad$ Demand inducement (DI) \\
& $-\quad$ Coproduction inducement (CI) \\
& $-\quad$ Advocacy (Adv) \\
& $-\quad$ Values \& Empathy (VE) \\
\hline
\end{tabular}

\section{Predictor: Representation}

Because the present study focuses on the difference that representation makes, the main predictor variable is representation. I assume that teachers with and without migration background will have different effects on students.

Atkins et al. (2014) measured the outcome variable at the individual level, but their independent variable-representation-was measured at the school level. They acknowledged that "purely individual level data would be preferable for some analyses" (p. 521), but asserted that the data they used were suitable for capturing how students' expectations and feelings of connectedness to the school were affected by the presence of teachers who resembled the students. For the present study, individual level data are most suited. 


\section{Criterion: Substantive effects}

Representation may have substantive effects on the population. The government aimed to improve these substantive effects by promoting the increase of people with MB in the teaching workforce (Bundeskongress, 2010). Also, more trust on the part of the parents was noted as a positive outcome, as well as the reflection of equal opportunity (access) and ethnic and cultural diversity in the classrooms (Bundeskongress, 2010), whereas trust by the parents and the reflection of equal access and cultural diversity are part of the qualitative study.

For the present study's questionnaire, substantive effects were operationalized as three criterion variables: grades, social climate, and career expectations. Students' performance has been a commonly used variable to measure the effect of representative bureaucracy in the school setting (Keiser et al., 2002; Pedersen, 2013; Meier et al., 1999). In the present study, it was operationalized as the student's most recent grade in the subject, measured as a category question from 1 (best) to 4 or more (worst) ${ }^{11}$.

Career expectations is the second criterion variable. In the questionnaire of this study, career expectations contain four items. One of them is adopted from Atkins et al.' (2014) study which used a question regarding the student's estimation on the likelihood of them graduating from college. While that item was included in this study, one item on the likelihood of a successful graduation from high school and two items on the chance to find suiting and a well-paid employment were also added. Since in Germany a college degree is not necessary for a great variety of jobs, graduating from college should not be the only

\footnotetext{
${ }^{11}$ Grades range from 1 (best) to 6 (worst). The grades 5 and 6 are both failing grades. Since students may feel uncomfortable when they have to admit that their grades are 5 or 6 , the worst grade that could be checked in the questionnaire was " 4 or more".
} 
indicator for one's perception of career expectations. Believing in one's chance to obtain well-paid employment that one likes serves as additional appropriate indicator.

The third criterion variable is classroom climate. Classroom climate is a less common outcome variable in the representative bureaucracy literature. However, to address the propositions of the German government and to capture the mood in the classroom, I include social climate as a criterion variable. The five items used in the questionnaire to obtain students' perceptions of the classroom climate are adopted from the Tower et al. (2011) study on organizational climate of Extension faculty. The items chosen for this study - safety, unity, belongingness, pride, friendship - seem particularly appropriate in the high school context and regarding the objective of this study. Atkins et al. (2014) used connectedness as the dependent variable in their study on the effects of representative bureaucracy which was operationalized with the survey item "I feel like I am a part of this school" (p. 510). This item is similar to the belongingness item in this study. According to the government, the tensions among students of different ethnic backgrounds may entail an agitated, uneasy social climate in the classrooms and schools. Representative bureaucracy has the potential to change the perception of the social climate and thus has an impact on the students.

\section{Mediators: Mechanisms}

The different mechanisms, or direct and indirect sources, are assumed to be mediating the relationship between representative bureaucracy and substantive effects. Hypotheses 1 and 2 involve the indirect sources demand inducement and coproduction inducement, while hypotheses 3 and 4 include the direct sources advocacy and shared 
values and beliefs and empathic understanding. Figure 6 depicts the assumed mediation of the relationship of representative bureaucracy and the substantive effects.

Figure 6: Conceptual model of quantitative analysis

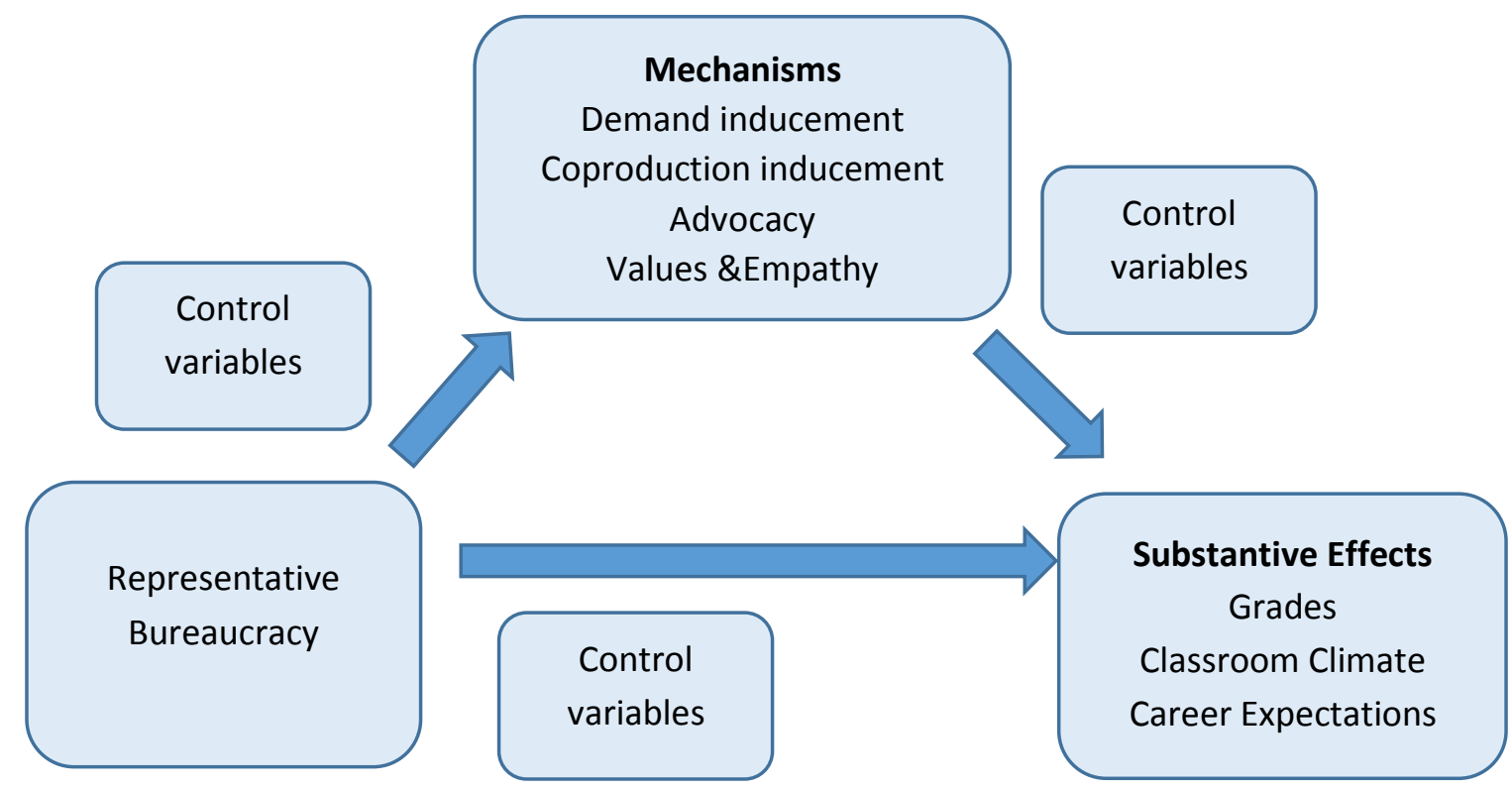

The items for the four mechanisms (demand inducement, coproduction inducement, advocacy, and values and empathy) were designed based on Lim's (2006) description of those sources. Asking the teacher for advice in and after class and identifying with them are indicators for demand inducement. Regarding the teacher as a role model (as a person who motivates the student), working hard to satisfy the teacher, and admiring the teach indicate coproduction inducement. The direct source advocacy was operationalized with the items "teacher stands up for student" and "teacher makes decisions that particularly benefit this student." These items correspond to the "traditional" active representative bureaucracy, as a bureaucrat, (i.e., the teacher actively benefits the population). The fourth mechanism (values and empathy) is also a direct source, but less 
active than advocacy. It is measured with two items asking for the student's perception of shared values and of empathic understanding.

\section{Demographic variables}

Demographic items of the questionnaire included age (ranging from 15 to 19 and older), sex (m/f), country of birth of student and the year they moved to Germany (in case student was not born in Germany) and country of birth of both parents (open-ended with a space to write the country's name), and educational level of both parents (did not graduate from school/graduated from high school/graduated from college). ${ }^{12}$ The questions about countries of birth of students and their parents provided for the calculation of the predictor variable representative bureaucracy; the others served as control variables. Sex, age, and education of mother and father may influence the relationship between the predictor, mechanisms, and criterion variables - and were, thus, controlled for.

The operationalization of the variables, including the survey items for each, is summarized in Table $2^{13}$.

Table 2: Operationalization of the concepts

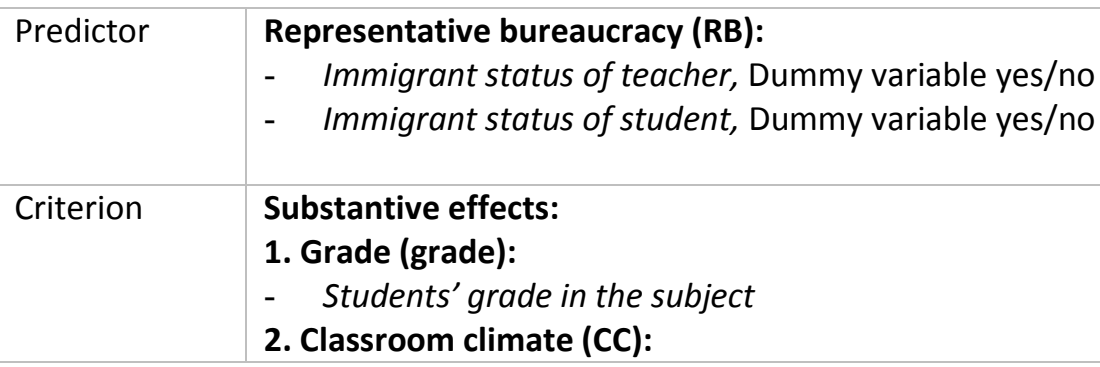

\footnotetext{
12 Two additional items on the students' political standpoints and their religious beliefs were eliminated from the questionnaire as they were not approved by the German school authorities with the reasoning that revealing this kind of information may be a violation of privacy.

${ }^{13}$ See Appendix A for the student questionnaire in German.
} 


\begin{tabular}{|c|c|}
\hline & $\begin{array}{l}\text { - } \quad \text { I feel safe in this class } \\
\text { - } \quad \text { There is a feeling of unity and group spirit in this class } \\
\text { - } \quad \text { There is a feeling of belongingness in this class } \\
\text { - } \quad \text { I am proud to be part of this class } \\
\text { - } \quad \text { This class is a good place to make friends } \\
\text { 3. Career expectations (CE): } \\
\text { - It is likely that I will finish high school successfully } \\
\text { - It is likely that I will graduate from college } \\
\text { - It is likely that I will have a job that pays well } \\
\text { - It is likely that I will get the job that I want }\end{array}$ \\
\hline Mechanism & $\begin{array}{l}\text { 1. Demand inducement (DI): } \\
\text { - } \quad \text { I usually ask my teacher for advice } \\
\text { - } \quad \text { I identify with my teacher } \\
\text { 2. Coproduction inducement (CI): } \\
\text { - I want my teacher to be satisfied with my performance } \\
\text { - } \quad \text { My teacher motivates me to work harder } \\
\text { - My teacher is a role-model for me } \\
\text { - } \quad \text { I look up to my teacher } \\
\text { 3. Advocacy (A): } \\
\text { - My teacher stands up for me } \\
\text { - My teacher makes decisions that benefit particularly me } \\
\text { 4. Shared values and beliefs and empathic understanding } \\
\text { - My teacher and I share similar values and beliefs } \\
\text { - My teacher understands me and my problems }\end{array}$ \\
\hline
\end{tabular}

\subsubsection{In-depth Interview Schedule Design}

The in-depth interview schedule's objective was to explore the factors that make teachers turn into representative of their students. For that purpose, Lim's (2006) direct and indirect sources were explored on one hand and additional potential factors were explored on the other hand. The interviews were designed as semi-structured face-to-face interviews, allowing for unexpected information — valuable to the present study — to be discussed in detail. After a brief introduction summarizing the purpose of the study (all participants knew beforehand what the study was about), the interview schedule started with a broad opening question: "Has there been a situation in your time as a teacher when your migration 
background has played a role? Please tell me about it." For teachers without MB, the question was "Do you remember a situation here in school when the migration background of one of your colleagues has played a role? Please tell me about it." According to Mayer (2012), it is useful to design the first item with particular care. The initial question should motivate respondents to continue; it should be relevant and comprehensible and not have the potential to scare-off or discourage the respondent in any way. Also, a broad opening question motivates the participant to share their story while emphasizing the points that they perceive to be of importance, without being drawn into any particular direction by the interviewer.

The following sets of questions asked for teachers' impressions, attitudes, and thoughts on Research Question 2. First, the four mechanisms that were analyzed in the quantitative study were addressed using four sets of questions (listed below) to investigate which role they play in the school context—aside from having substantive effects.

1. Do students approach you to ask you for (educational or non-educational) advice? Are those proportionately more students who also have a migration background/ who have the same background? (demand inducement)

2. Do the students make an effort to satisfy you with their performance? Do you think that you motivate them to work harder? Do you think that you are a role model for the students? Are those proportionately more students who also have a migration background/ who have the same background? (coproduction inducement)

3. Did you ever stand up for a certain student with a migration background? Do you make decisions that benefit particularly those students? (direct sources: advocacy) 
4. Do you think that you share similar values with your students? Do you understand the problems of your students? Better than teachers without migration background? (direct sources: shared values and beliefs, empathic understanding)

Following those four sets, a fifth set of questions addressed the teachers' role perceptions:

5. Do you see yourself as a representative of your ethnic, religious or cultural group? Why/why not? Does the community expect you to represent your group? Does the school advocate your representative function? (representative role perception) The last set of questions pertained to the fifth mechanism, peer influence. This mechanism was discussed in detail during the interview because it was not possible to address it in the student questionnaire.

6. Do you think that you influence other teachers, for example their behavior? Do you think that your presence has made other teachers more sensitive towards people with an ethnic/ religious/ cultural background different from theirs? Has your presence ever stopped a teacher without migration background acting biased? Are there any tensions between teachers with and without migration background? (peer influence)

After I conducted the first four interviews, two topics that had emerged during those interviews were added to the interview questions: (1) students' and parents' trust in teachers and (2) the importance of matching migration backgrounds.

1. Do you think that parents of students with migration background trust you more than other teachers? Likewise, do you think that parents of students without migration background trust you less than other teachers? 
2. Which role does it play which migration background a person has? Do backgrounds have to match in order for representation to make a change? Which characteristics have to match? (Religion/ethnicity/ nationality) $)^{14}$

\subsubsection{Data collection: First Set of Interviews}

The first set of interviews had three objectives:

1. Discuss the questionnaire's applicability and adequacy for German students;

2. Collect data to address the Research Question 2;

3. Ask teachers to refer potential participants (other teachers) to complete the survey and participate in the second set of interviews.

The potential participants included all teachers working in the chosen three school forms, regardless of age or sex. To obtain insight into their different perspectives, I interviewed teachers with and without migration background. I began the search for interviewees by contacting networks for teachers with migration background in four states. ${ }^{15}$ I assumed that members of those networks might be particularly interested in participating in the study. The network in Bremen responded immediately and the first interview with a teacher from an Oberschule was conducted. Then, that interviewee forwarded an e-mail message with information on the study and the researcher's contact details ${ }^{16}$ to all members of the Bremen and Hamburg network (roughly 150 people), to

\footnotetext{
${ }^{14}$ See Appendix B for the interview schedule in German.

${ }^{15}$ Websites of the networks: Hamburg: http://li.hamburg.de/netzwerk/, Berlin: http://www.berlin.de/sen/bildung/bildungswege/nach-der-schule/lehrernetzwerk.html, Lower Saxony: http://www.nibis.de/nibis.phtml?menid=2800, Bremen: http://netzwerk.schule.bremen.de/.

${ }^{16}$ See Appendix C for the information letter in German.
} 
which four teachers from Bremen responded who were then interviewed. When nobody else responded to the e-mail messages, all teachers in Gesamtschulen and Oberschulen in (Hannover the capital of Lower Saxony) were contacted via e-mail and phone calls and two more teachers responded and forwarded the information to colleagues-five more interviews were conducted.

Altogether, ten teachers ( 5 female; 5 male) from six different schools participated in the first set of interviews. Six teachers had a migration background and four did not. The teachers were between 32 and 47 years of age. Two of the six teachers with migration background had immigrated themselves, three had parents who had both immigrated, and one teacher had one parent who had immigrated and one who was born in Germany. Four of the interviews were audio-recorded; the other six teachers preferred not to be audiorecorded, so hand-written notes were taken during the interviews. The interview-duration varied substantially, with the shortest interview lasting 17 minutes and the longest 67 minutes. On average, interviews with teachers with migration background were 41 minutes long, while those with teachers without migration background were 23 minutes long.

Some interviewees provided detailed responses to the opening question, giving real-life examples. If they mentioned a certain topic during that answer, I accordingly modified the order of the subsequent sets of questions to enhance the flow of the discussion. Although Gray (2009) contended that changing the order of the questions in an interview schedule may skew the results, it seemed to be the best solution for the present study. Maintaining the same order would have made the interviews less fluid and artificial in some cases; interviewees may have perceived that the interview schedule was mechanicallacking consideration for interviewees' responses. 
Focus was directed on creating a comfortable environment during the interviews. The interviews occurred either in the schools of the participants or at their private homes, based on the preference of the interviewee. Creating a relaxed environment and building rapport (e.g., explaining the interview process, guaranteeing confidentiality, and answering interviewees' questions) contributed to the success of the interviews (Gray, 2009). All participants seemed to be comfortable and eager to share their stories and answer the questions. They were all interested in the study and requested copies of the dissertation after it is completed.

Following the interview schedule with the nine sets of questions, the validity of the survey in the German school context was discussed with the interview participants. The teachers' comments were then incorporated into the survey instrument. The wording of several items was improved as the translation from English to German had slightly distorted the meaning of those items. Also, the teachers had suggested to use more "youthfriendly vocabulary" (i.e., age-appropriate wording) in several cases and to keep the items as short and easily understandable as possible.

\subsubsection{Data Collection: Student Survey}

Before data collection started, a pilot study was conducted at Florida International University and Miami-Dade College. The questionnaire was distributed to 45 B.A. students across three courses to test the validity of the questionnaire items. Focus was directed on the clarity of the questions and the time needed to complete the questionnaire. Only two minor alterations concerning more-appropriate wording were necessary. 
Permits from German school authorities in Bremen and Lower Saxony were obtained to conduct the student surveys. The five interview participants from the Hannover schools agreed to participate in the survey with their classes. An additional permit had to be obtained from each school principal and from the parents of all children under 18 years of age. Obtaining the parent's permit proved to be one of the most formidable challenges in the data collection process. Although parental consent forms were distributed to students - who were asked to obtain parent signatures on the forms - according to the teachers, many might not have presented the forms to their parents; thus, in the first surveys, only five to eight students participated of the 20 to 30 students per class (except for one class with 15 participating students). Thus, after receiving only 34 completed questionnaires from the first four classes, I focused on finding $12^{\text {th }}$ and $13^{\text {th }}$ grade student participants, who are mostly 18 years and older. After a presentation of the present study. at a conference for teachers with migration background, two conference participants agreed to participate in the survey and convince colleagues from their schools to also participate with their classes. Thus, nine more classes participated with students that were mostly 18 years and older.

The questionnaires were completed during regular school hours. It took the students between five and ten minutes to complete the questionnaire. I visited each class, explained the study and the questionnaire, and answered students' questions. This allowed me to observe the dynamics between students and teacher and between the students. In five classes, I remained in the classroom for the entire length of the class (i.e., 90 minutes) after having collected the completed questionnaires. The teachers filled out their questionnaires at the same time. 
Altogether, 194 questionnaires were completed in 13 school classes. Although this number is not as high as anticipated, it is sufficiently large to conduct quantitative analyses. Because only 13 teachers filled out the teacher questionnaire, statistical analyses with that data were not possible. However, demographic data (i.e., data on their migration background) were needed for the analyses and thus their completed questionnaires were important as well. An online version of the survey-to increase the number of observations - was considered due to the difficulty to find participants; however, the researcher's presence was an important factor in participation. That is, because the researcher was present and able to communicate with the class, teachers and students were motivated to participate in the study. I determined an online survey would not have been feasible - particularly if the teachers had to explain the study to the students and motivate them to complete the questionnaire. Moreover, the response rate would have been extremely low.

To guarantee anonymity, questionnaires were separated from the consent forms immediately after the documents were collected from the students. Both questionnaires and consent forms are stored in a locked cabinet at the researcher's house. The collected data were transferred to a Microsoft Excel spreadsheet, then coded and transferred to SPSS 18. The data are stored on the researcher's laptop, secured with a password, and only available to the researcher.

\subsubsection{Quantitative Analysis Design}

The quantitative data analysis addresses Research Question 1 and its four hypotheses: (1) Demand inducement plays a role in the relationship between passive 
representation and substantive effects on the population; (2) Coproduction inducement plays a role in the relationship between passive representation and substantive effects on the population; (3)Advocacy plays a role in the relationship between passive representation and substantive effects on the population; and (4) Values and empathy play a role in the relationship between passive representation and substantive effects on the population .

The data analyses were conducted in SPSS 18. Before starting the statistical analyses, the first step involved the creation of the main predictor variable: representative bureaucracy. In the questionnaires, the students specified whether they (and/or one or both of their parents) were born outside of Germany. The teachers also provided this information in their questionnaires. If the student/teacher, or at least one parent, was born outside of Germany, they had a migration background. Two dummy variables for representative bureaucracy were created for the mediation analyses: "Both MB": 1=student and teacher both have a migration background, $0=$ only one, either student or teacher has a migration background, or none has a migration background. "Both no MB": $1=$ Teacher and students both have no migration background, $0=$ at least one has a migration background or both.

Furthermore, a categorical variable measuring representative bureaucracy, MB_const (Constellation of migration backgrounds), was created for the MANOVA, including the four categories presented in Table 3:

Table 3: Four groups of student-teacher constellations

\begin{tabular}{|l|l|l|}
\hline & \multicolumn{2}{|l|}{ Migration background student } \\
\hline $\begin{array}{l}\text { Migration background } \\
\text { teacher }\end{array}$ & $\begin{array}{l}\text { (1) Teacher yes } \\
\text { Student yes }\end{array}$ & $\begin{array}{l}\text { (3) Teacher no } \\
\text { Student yes }\end{array}$ \\
\hline & $\begin{array}{l}\text { (2) Teacher yes } \\
\text { Student no }\end{array}$ & $\begin{array}{l}\text { (4) Teacher no } \\
\text { Student no }\end{array}$ \\
\hline & & \\
\hline
\end{tabular}


(1) Teacher and student both have a migration background, $0=$ all other constellations; (2) Teacher has a migration background, student does not, $0=$ all other constellations; (3) Teacher does not have a migration background, student has migration background, $0=$ all other constellations; and (4) Teacher and student both have no migration background, $0=$ all other constellations .

Unfortunately, different national or ethnic backgrounds could not be incorporated into the quantitative analysis. This was due to the sample size, but also due to theoretical considerations, as it would be superficial and prone to bias to assume that everybody who has the same national, ethnical, or religious background behaves in a similar way or believes in the same things. Thus, the importance of different backgrounds is addressed extensively in the qualitative analysis.

The operationalization of the variables, as explained in Chapter 3.4.1.2, was designed such that-except for the demographic variables and the criterion variable "grades"- each concept was measured by several items in the questionnaire. Those items were indexed according to the concepts they measure and a new variable was created of the mean of the respective items. Altogether, six indices were created: The criterion variables "classroom climate" and "career expectations" and the mechanisms "demand inducement," "coproduction inducement," "advocacy" and "values and empathy." To test the reliability of the indices, Cronbach's alpha was calculated for each index to assess the internal consistency of the subscale. The results are presented in Table 4: 
Table 4: Cronbach's Alpha

\begin{tabular}{|l|l|}
\hline Index & Cronbach's Alpha \\
\hline Classroom climate (5 items) & .86 \\
\hline Career expectations (4 items) & .65 \\
\hline Demand inducement (2 items) & .81 \\
\hline Coproduction inducement (4 items) & .71 \\
\hline Advocacy (2 items) & .70 \\
\hline Values \& Empathy (2 items) & .83 \\
\hline
\end{tabular}

For three indices, internal consistency is high, with Cronbach's alpha above .80 . Coproduction inducement and advocacy have Cronbach's Alpha values around 0.70, which are regarded as acceptable (Blanz, 2015). Career expectations, with a Cronbach's Alpha value of .65, is less internally consistent; however, it is usually still accepted.

Subsequently, one-way multivariate analyses of variance (MANOVA's) were executed to compare the means of the answers of the four student-teacher constellations. Following this, mediation analyses were conducted to explain the impact of the four mechanisms on the relationship between representative bureaucracy and the grades, career expectations of the students, and the perceived classroom climate.

The following table, Table 5, includes the correlations, means, standard deviations, and ranges of all variables that were included into the statistical analyses ${ }^{17}$.

\footnotetext{
${ }^{17}$ See Appendix D for a list of all variables used in the quantitative analyses.
} 
Table 5: Correlations, means, standard deviations and ranges of all variables used in the quantitative analyses

\begin{tabular}{|c|c|c|c|c|c|c|c|c|c|c|c|c|c|c|c|c|c|}
\hline & Sex & Age & $\begin{array}{l}\text { Edu } \\
\mathrm{m}\end{array}$ & $\begin{array}{l}\text { Edu_ } \\
f\end{array}$ & $\begin{array}{l}\mathrm{MB}_{-} \\
\text {const } \\
\end{array}$ & $\begin{array}{r}\text { Both } \\
\text { MB } \\
\end{array}$ & $\begin{array}{l}\text { Both_ } \\
\text { no_MB }\end{array}$ & $\begin{array}{l}\text { Grad } \\
\mathrm{e}\end{array}$ & CE & $\mathrm{cC}$ & DI & $\mathrm{Cl}$ & Adv & VE & Mean & SD & $\begin{array}{l}\text { Ran } \\
\text { ge }\end{array}$ \\
\hline Sex (Sex) & 1 & & & & & & & & & & & & & & .50 & .50 & 1 \\
\hline Age (Age) & .07 & 1 & & & & & & & & & & & & & 17.59 & 1.75 & 7 \\
\hline $\begin{array}{l}\text { Edauction mother } \\
(\text { Edu_m })\end{array}$ & .01 & .06 & 1 & & & & & & & & & & & & 1.05 & .45 & 2 \\
\hline Education father (Edu_d) & .10 & .12 & $.44^{* *}$ & 1 & & & & & & & & & & & 1.16 & .48 & 2 \\
\hline $\begin{array}{l}\text { Migration background } \\
\text { constellation (RB_const) }\end{array}$ & .02 & $.42^{* *}$ & .05 & .04 & 1 & & & & & & & & & & 2.49 & 1.10 & 3 \\
\hline $\begin{array}{l}\text { Both have migration } \\
\text { background (Both_MB) }\end{array}$ & .00 & $-.23^{* *}$ & -.11 & -.11 & $-.72^{* *}$ & 1 & & & & & & & & & .22 & .41 & 1 \\
\hline $\begin{array}{l}\text { Both have no migration } \\
\text { background } \\
\text { (Both_no_MB) }\end{array}$ & .00 & $.31^{* *}$ & .04 & .03 & $.81^{* *}$ & $-.31^{* *}$ & 1 & & & & & & & & .26 & .44 & 1 \\
\hline Grade (Grade) & .02 & .06 & $.16^{*}$ & .10 & $.18^{*}$ & .03 & $.22^{* *}$ & 1 & & & & & & & 2.88 & 1.51 & 5 \\
\hline Career expectations (CE) & .04 & -.03 & $.19^{* *}$ & $.24^{* *}$ & -.05 & .07 & -.00 & $.34^{* *}$ & 1 & & & & & & 5.31 & 1.10 & 5.25 \\
\hline Classroom climate (CC) & .03 & $-.16^{*}$ & .06 & .12 & $-.26^{* *}$ & $.17^{*}$ & -.13 & .06 & .12 & 1 & & & & & 5.18 & 1.20 & 5.20 \\
\hline Demand inducement (DI) & -.04 & -.04 & -.14 & -.08 & -.02 & .14 & .11 & $.28^{* *}$ & .05 & $.26^{* *}$ & 1 & & & & 3.30 & 1.67 & 6.00 \\
\hline $\begin{array}{l}\text { Coproduction inducement } \\
\text { (Cl) }\end{array}$ & -.11 & .04 & -.01 & .02 & .10 & .08 & $.15^{*}$ & $.36^{* *}$ & $.15^{*}$ & $.18^{*}$ & $.55^{* *}$ & 1 & & & 4.93 & 1.16 & 5.50 \\
\hline Advocacy (Adv) & -.08 & -.06 & -.09 & -.12 & .10 & .01 & $.15^{*}$ & $.25^{* *}$ & .01 & .13 & $.49^{* *}$ & $.63^{* *}$ & 1 & & 4.50 & 1.44 & 6.00 \\
\hline Values and empathy (VE) & -.11 & -.00 & -.07 & -.11 & .05 & .04 & .12 & $.24^{* *}$ & .05 & $.23^{* *}$ & $.60^{* *}$ & $.59^{* *}$ & $.64^{* *}$ & 1 & 4.20 & 1.36 & 6.00 \\
\hline
\end{tabular}


Comparing the table above to the conceptual model (Chapter 2.9), the following variables are missing from the analysis: political and religious viewpoints, organizational factors, and perceived role expectations and peer influence. Political and religious viewpoints could not be included because collection of those data was prohibited by school authorities due to protection of privacy. The organizational factors are considered to be constant in this study due to the study context: German public schools of the same type (i.e., Oberschulen and Gesamtschulen). The rules and structures as well as the goals and values are very similar among schools. The amount of discretion is dependent on the organizational factors and important for active representation to occur. It is considered to be constant for this study, because teachers have the same level of discretion - they are in classrooms with students without any further supervision, but they must all follow the same regulations. The perceived role expectations and the peer influence variables could not be addressed in the student survey; they must be examined using questionnaires directed at teachers. However, these variables were explored using qualitative analysis.

\subsubsection{Data Collection: Second Set of In-depth Interviews}

After analyzing quantitative data collected with the questionnaires, a second set of in-depth interviews was conducted. The interview questions from the first set were revised and special focus was directed on inconsistent survey results. Moreover, continued focus was directed on addressing the mechanism "peer influence" and the perceived representative role expectations.

In the second set of interviews, the participants consisted of 16 teachers: nine with migration background and seven without migration background. The teachers ( 8 male; 8 
female) were between 30 and 52 years old. The interviews were conducted in the interviewees' respective schools and lasted between 24 and 53 minutes.

Altogether, 26 teachers participated in the two sets of interviews ${ }^{18}$. Information saturation was reached after completing ten interviews in the second set; however, six more interviews were conducted to ensure that no major new viewpoints were left out. The interviews were transcribed verbatim and then coded and analyzed with the help of NVivo 11. NVivo, a qualitative data analysis software, supports the collection and organization of different kinds of data sources. With its word search, query, and visualization tools, it is particularly useful for the analysis of the interviews of this study.

\subsection{Validity and Reliability}

Addressing validity and reliability is crucial for both quantitative and qualitative methods. To make inferences, the research tools must be internally valid and reliable. Internal validity is met when a research instrument measures those phenomena that the researcher intended to measure (Gray, 2009). The questionnaire, for instance, should cover the content of the research issues, but it should also refrain from asking extraneous questions. For interviews, internal validity is strengthened by: (a) encouraging participants to explain their views in detail and to expand on interesting answers, (b) building rapport and trust, (c) adding questions to the interview schedule after reviewing the first interview results, and (d) allotting sufficient time for the interview, so that all issues can be discussed

\footnotetext{
${ }^{18}$ See appendix E for a list of interview participants.
} 
without time pressure (Arksey \& Knight, 1999; Gray, 2009). I implemented these techniques to enhance internal validity for both the questionnaire and the interviews.

External validity commonly refers to the generalizability of a study. Although the sample of the quantitative part of this study is small compared to the population, its results may serve as an indicator of the effects and mechanisms of representative bureaucracy in schools in the entire country. It would be difficult, however, to transfer these results to other types of organizations - some mechanisms (e.g., coproduction inducement) might be particularly important in the educational (school) context because teachers often serve as role models, but might be less effective in other contexts. This constraint originates from the research topic rather than the choice of methodology of this study. Nevertheless, certain aspects of these findings are likely to be transferable to other organizations. Regarding the qualitative part, external validity depends on the transferability of the results. Reaching a saturation point makes a study more transferable (Arksey \& Knight, 1999). A saturation point has been reached in the qualitative part of this dissertation.

Reliability refers to the consistency of a measure. It can be achieved by applying two measures to a phenomenon - for example, measuring a phenomenon at different points in time or using different instruments to measure the same concept. Triangulation, the combination of quantitative and qualitative methods, is a procedure that improves the reliability of a study. In the present study, the methods to address the first research question are triangulated. Regarding the qualitative methods that were used in this study to answer Research Question 2, consistency can be improved following the same procedures when conducting the interviews. Because one person conducted these interviews, interviewer bias remained minimal and consistency in the interview procedure was met. 


\subsection{Conclusion}

Representative bureaucracy research is primarily set in the "traditional" postpositivist paradigm. Regarding the nature of representative bureaucracy theory, however, it is valuable to also consider different non-positivist paradigms. Feminist theory, for instance, which emphasizes individuals' different perspectives and subjective realities, can help to acknowledge the importance of having a bureaucracy that is representative of the population it serves. The bureaucrats' life experiences shape their perspectives and finally influence their behavior. Thus, minority bureaucrats and their subjective views balance out the subjective views of the groups already entrenched in the bureaucracy.

The present study attempts to capture the different perspectives on different phenomena and their significance by using a sequential mixed-methods design. The objective is to understand the mechanisms that make a representative bureaucracy have substantial effects, thereby addressing the questions "How, with the help of which mechanisms, does passive representation have substantive effects on the population it serves?" and "How do bureaucrats become representatives?" Hypotheses 1, 2, 3, and 4 of Research Question 1 involve the mechanisms "demand inducement," "coproduction inducement," "advocacy," and "shared values and beliefs and empathic understanding" and the substantive effects "grades," "classroom climate," and "career expectations." They are examined using quantitative methods. Research Question 2 is more exploratory; data were collected with the help of semi-structured interviews. It also addresses the four mechanisms (i.e., demand inducement, coproduction inducement, advocacy, and values and empathy) plus the fifth mechanism "peer influence" but without connecting them to substantive effects. 
First, ten interviews were conducted with high school teachers to: (a) discuss the validity of the student questionnaire design and (b) collect data to address Research Question 2. Subsequently, Research Question 1 was examined with quantitative methods. The surveys collected data from 194 students. The analyses techniques include One-Way MANOVA, multiple regression, and mediation analyses. Finally, a second round of interviews was conducted to address Research Question 2 and to explore details that remained unclear after the quantitative analysis. This allowed research findings to be triangulated, which helps improve reliability. 


\section{THE MECHANISMS OF REPRESENTATION - FINDINGS}

\subsection{Introduction}

This chapter presents findings from the qualitative and quantitative analyses described in Chapter 3. A sequential mixed-methods approach was used-beginning with quantitative analyses, followed by a comprehensive qualitative analysis. The overall finding is that the personality of a teacher plays a major role, particularly regarding those mechanisms that involve an activity of the teacher. First, the results of the quantitative analyses are presented and discussed. Subsequently, findings from the qualitative analysis are reviewed. Finally, the conclusion provides are summary of all findings.

\subsection{Quantitative Analysis}

The quantitative analysis of this study consists of two sets of analyses, namely MANOVA's and multiple regressions. To begin the analytical process, I conducted two separate One-Way MANOVAs to compare the means of the four teacher-student constellations [i.e., (1) teacher and student both have a migration background; (2) teacher has a migration background, student does not; (3) teacher does not have a migration background, student has migration background; and (4) teacher and student both have no migration background]. Subsequently, I tested the mediating influence of four mechanisms (i.e., demand inducement, coproduction inducement, advocacy, and values and empathy) on the relationship between representative bureaucracy and three substantive effects: grades, classroom climate, and career expectations. I used four sets of mediation analyses - one for each mechanism. Following a description of the study sample below, I present the statistical analyses used in this study. 


\subsubsection{Sample Demographics}

Data was collected from 194 student-participants who completed the survey. The sample included 97 female (50\%) and 97 male participants. The ages ranged between $14^{19}$ and 19 years and older (39\% of the participants). Among the fathers of the students, 138 (71\%) finished high school, 38 (20\%) obtained a university degree, and 9 (5\%) did not finish high school. Among the mothers of the students, 150 (77\%) finished high school, 24 $(12 \%)$ graduated from university, and $15(8 \%)$ did not finish high school.

In the sample, 80 students $(41.2 \%)$ have a migration background (MB). Of those, 21 students $(26 \%)$ have only one parent who was born outside of Germany; for 59 students (74\%), both parents were born abroad. Only 12 students (15\%) have personally experienced migration; those students have spent 12 years in Germany, on average (ranging from 2 to 19 years).

Out of the 13 teachers, 7 (54\%) have an MB. The percentage of students with MB in the sample $(41.2 \%)$ is higher than that of people with MB in Germany $(21 \%)$. However, the share of people with MB is higher among the younger generation and is increasing steadily; for example, among children under five years of age, $36 \%$ have an $\mathrm{MB}$ (Statistisches Bundesamt, 2016, Sep 16). The sample of students, with regard to their MB, was random - the number of students with $\mathrm{MB}$ in the surveyed classes was not known prior to data collection. However, I did use purposive sampling for teachers of the participating classes; for the statistical analysis, purposive sampling was necessary to ensure recruitment of a large enough group of students with teachers with MB. Thus, the percentage of

\footnotetext{
${ }^{19}$ Only grades 9 and higher were asked to participate in the survey with the objective that all participants be 15 years and older. Only 2 students were 14 years old, but they completed the survey together with their older classmates without any problems and were thus included in the analysis.
} 
teachers with $\mathrm{MB}$ in the sample is $54 \%$, whereas that of the population is estimated at $2 \%$ (Trenkamp, 2014). The classes that participated in the survey are from seven different schools. The percentage of teachers with MB per school ranges between 4.8 and $7.4 \%$, while the percentage of students with MB per class varied substantially with percentages between 26.3 and 71.4 .

\subsubsection{One-way MANOVA Results}

Two one-way multivariate analyses of variance (MANOVA) were conducted to obtain an insight into the means of the students' responses. The one-way MANOVA is used to detect statistically significant differences among the means of two or more groups. For the MANOVA, the categorical variable "migration background constellation" MB_const is used as a factor for which the respondents are divided into four groups: (1) teacher and student have a migration background $(n=42) ;(2)$ only teacher has a migration background ( $n=63$ ); (3) only student has a migration background ( $n=37)$; and, (4) both have no migration background $(n=50)$. The number of observations is relatively evenly spread across the four groups, which is one of the assumptions needed to use MANOVA. The three substantive effects-grades ${ }^{20}$, classroom climate, and career expectations-were tested in the first MANOVA and the four mechanisms - demand inducement, coproduction inducement, advocacy, and values and empathy-were addressed in the second MANOVA.

\footnotetext{
${ }^{20}$ The variable grades was recoded such that higher values represent better grades to make interpretation simpler.
} 
In addition to comparing the means, MANOVA can be used to determine if one group outperforms all others across the three substantive effects and/or across the four mechanisms.

Before conducting the MANOVAs, two assumptions are tested. One MANOVA assumption is that dependent variables should be correlated moderately (Meyers, Gampst, \& Guarino, 2006). Tables 6 and 7 show that most correlations are significant and moderate (i.e., not higher than 0.7) and, thus, appropriate for MANOVA.

Table 6: Pearson's Correlations, Means, and Standard Deviations of the 4 mechanisms

\begin{tabular}{|c|c|c|c|c|c|c|}
\hline & 1 & 2 & 3 & 4 & Mean & $S D$ \\
\hline 1. Demand Inducement & 1 & & & & 3.30 & 1.67 \\
\hline 2. Coproduction Inducement & .55 & 1 & & & 4.93 & 1.16 \\
\hline 3. Advocacy & .49 & .63 & 1 & & 4.50 & 1.44 \\
\hline 4. Values \& Empathy & .60 & .59 & .64 & 1 & 4.20 & 1.37 \\
\hline
\end{tabular}

Note: $n=193$, Correlations greater than .10 are significant $(\mathrm{p}<.01)$

Table 7: Pearson's Correlations, Means, and Standard Deviations of the 3 substantive effects

\begin{tabular}{|c|c|c|c|c|c|}
\hline & 1 & 2 & 3 & Mean & $S D$ \\
\hline 1. Grade & 1 & & & 2.88 & 1.51 \\
\hline 2. Career Expectations & .34 & 1 & & 5.31 & 1.10 \\
\hline 3. Classroom Climate & .06 & .12 & 1 & 5.18 & 1.20 \\
\hline
\end{tabular}

Note: $n=193$, Correlations greater than .10 are significant $(\mathrm{p}<.01)$

Subsequently, Box's Tests were conducted to examine whether the covariance matrices between the groups were equal, which is an additional assumption of MANOVA. The Box's M values of 35.85 for the mechanisms and 24.79 for the criterion variables have $\mathrm{p}$ values of .27 and .15 , respectively, suggesting that they are not significant and covariance matrices between groups are equal (Huberty \& Petoskey, 2000). 
Two one-way MANOVAs were then conducted to examine the differences between the evaluations of the mechanisms and criterion variables among the four groups of teacher-student constellations. For the mechanisms, the MANOVA effect was significant at .10 level, with Pillai's trace $=.10, \mathrm{~F}(12,561)=1.610, \mathrm{p}=.09$. The value of $\eta^{2}$ is .03 , suggesting that $3.3 \%$ of the variance among the dependent variables is associated with being part of any of the four teacher-student constellations. For the substantive effects, Pillai's trace $=.20, \mathrm{~F}(9,555)=4.46, \mathrm{p}<.001$. The value of $\eta^{2}$ was .07 , associating $6.7 \%$ of the variance among the dependent variables with the differences among the four groups.

Before MANOVAs were followed-up with ANOVAs, Levene's tests of equality were performed for each variable to test the homogeneity of variance assumption (see Tables 8 and 9). The test is significant only for one variable, classroom climate, suggesting that the variance associated with it is not homogenous (see Table 8). However, an examination of the standard deviations of classroom climate among the four groups revealed that none is four times larger than the smallest, which suggests that ANOVA is robust (Howell, 2009). Thus, two series of one-way ANOVAs for each of the dependent variables were conducted. Table 8 and 9 show that the ANOVAs for grade, classroom climate, demand inducement, and coproduction inducement are significant, with effect sizes ranging from 4.7 to $10.4 \%$. For the other three variables-career expectations, advocacy, and values and empathy—no significant differences between the four constellations of teacher-students were found. 
Table 8: One-way ANOVAs with 3 substantive effects as dependent variables and 4 representative bureaucracy group constellations as independent variables

\begin{tabular}{|c|c|c|c|c|c|c|c|c|c|c|c|c|c|}
\hline & \multicolumn{2}{|c|}{ Levene's } & \multicolumn{3}{|c|}{ ANOVAs } & \multicolumn{2}{|c|}{$\begin{array}{c}\text { Group } 1 \\
\text { Both have } \\
\text { MB }\end{array}$} & \multicolumn{2}{|c|}{$\begin{array}{c}\text { Group } 2 \\
\text { Only } \\
\text { teacher has } \\
\text { MB }\end{array}$} & \multicolumn{2}{|c|}{$\begin{array}{c}\text { Group } 3 \\
\text { Only } \\
\text { student has } \\
\text { MB }\end{array}$} & \multicolumn{2}{|c|}{$\begin{array}{c}\text { Group } 4 \\
\text { Both have } \\
\text { no MB }\end{array}$} \\
\hline & $\begin{array}{l}F_{(3,} \\
185)\end{array}$ & $p$ & $\begin{array}{l}F_{(3,} \\
185)\end{array}$ & $p$ & $\eta^{2}$ & $M$ & SD & $M$ & SD & $M$ & SD & $M$ & SD \\
\hline Grade & 1.87 & .14 & 5.44 & .00 & .08 & 2.97 & 1.51 & 2.34 & 1.21 & 2.97 & 1.59 & 3.45 & 1.6 \\
\hline $\begin{array}{l}\text { Classroom } \\
\text { Climate }\end{array}$ & 3.61 & .01 & 7.17 & .00 & .10 & 5.55 & .91 & 5.49 & .98 & 4.56 & 1.37 & 4.96 & 1.32 \\
\hline $\begin{array}{l}\text { Career } \\
\text { expectations }\end{array}$ & .47 & .70 & .41 & .74 & .01 & 5.45 & .97 & 5.34 & 1.07 & 5.18 & 1.13 & 5.32 & 1.17 \\
\hline
\end{tabular}

Table 9: One-way ANOVAs with 4 mechanisms as dependent variables and 4 representative bureaucracy group constellations as independent variables

\begin{tabular}{|c|c|c|c|c|c|c|c|c|c|c|c|c|c|}
\hline & \multicolumn{2}{|c|}{ Levene's } & \multicolumn{3}{|c|}{ ANOVAs } & \multicolumn{2}{|c|}{$\begin{array}{c}\text { Group } 1 \\
\text { Both have } \\
\text { MB }\end{array}$} & \multicolumn{2}{|c|}{$\begin{array}{c}\text { Group } 2 \\
\text { Only } \\
\text { teacher has } \\
\text { MB }\end{array}$} & \multicolumn{2}{|c|}{$\begin{array}{c}\text { Group } 3 \\
\text { Only } \\
\text { student has } \\
\text { MB }\end{array}$} & \multicolumn{2}{|c|}{$\begin{array}{c}\text { Group } 4 \\
\text { Both have } \\
\text { no MB }\end{array}$} \\
\hline & $\mathrm{F}_{(3,188)}$ & $p$ & $\begin{array}{l}F_{(3,} \\
188)\end{array}$ & $p$ & $\eta^{2}$ & $\mathrm{M}$ & SD & M & SD & M & SD & $\mathrm{M}$ & SD \\
\hline $\begin{array}{l}\text { Demand } \\
\text { Inducement }\end{array}$ & .53 & .66 & 3.08 & .03 & .05 & 3.74 & 1.72 & 3.10 & 1.56 & 2.78 & 1.61 & 3.61 & 1.72 \\
\hline $\begin{array}{l}\text { Coproduction } \\
\text { Inducement }\end{array}$ & 1.57 & .20 & 3.36 & .02 & .05 & 5.11 & 1.08 & 4.6 & 1.15 & 4.93 & .95 & 5.23 & 1.26 \\
\hline Advocacy & .06 & .98 & 1.74 & .16 & .03 & 4.55 & 1.41 & 4.26 & 1.43 & 4.34 & 1.43 & 4.85 & 1.45 \\
\hline $\begin{array}{l}\text { Values and } \\
\text { Empathy }\end{array}$ & .20 & .90 & 1.4 & .25 & .02 & 4.3 & 1.47 & 4.07 & 1.31 & 3.95 & 1.37 & 4.48 & 1.32 \\
\hline
\end{tabular}

The ANOVAs showed that at least one of the differences in means among the 4 groups is significant for the four dependent variables (i.e., demand inducement, coproduction inducement, grades, and classroom climate). By comparing the means presented in Tables 8 and 9, the question of whether one group outperforms the others across all mechanisms or substantive effects was addressed. Then, two series post-hoc tests were conducted to determine, among the means of the 4 groups, which differ significantly. Regarding the substantive effects, no single group has higher means across all variables. 
For grades, the group of students without migration background (MB) who have teachers without MB outperforms the others; however, for the other two variables (i.e., classroom climate and career expectations), the group of students with MB who have teachers with MB outperforms the others.

Referring to the four mechanisms, the same two groups outperform the others: students with $\mathrm{MB}$ who have teachers with $\mathrm{MB}$ ranked demand inducement higher than all others, and students without MB who have teachers without MB evaluated the other three mechanisms — coproduction inducement, advocacy, and values and empathy—higher. It is striking that the two "mixed groups"-in which only one, either student or teacher, has an MB - ranked all four mechanisms worse than the two "homogenous" groups.

The last step of the MANOVA involved two series of post-hoc analyses. The significant findings are presented in Table 10.

Table 10: Differences in means across the four student groups for four significant variables

\begin{tabular}{|c|c|c|c|c|c|c|}
\hline & \multicolumn{2}{|c|}{$\begin{array}{l}\text { Both have no } \\
\text { MB } \rightarrow \\
\text { only teacher } \\
\text { has MB }\end{array}$} & \multicolumn{2}{|c|}{$\begin{array}{l}\text { Only teacher } \\
\text { has MB } \rightarrow \\
\text { Only student } \\
\text { has MB }\end{array}$} & \multicolumn{2}{|c|}{$\begin{array}{l}\text { Both have MB } \\
\rightarrow \\
\text { Only student } \\
\text { has MB }\end{array}$} \\
\hline & MD & $\mathbf{p}$ & MD & $\mathbf{P}$ & MD & $\mathbf{p}$ \\
\hline Grade & 1.11 & .00 & & & & \\
\hline Classroom climate & & & .99 & .00 & .93 & .00 \\
\hline Coproduction inducement & .67 & .02 & & & & \\
\hline Demand inducement & & & & & .96 & .08 \\
\hline
\end{tabular}

The means differ significantly $(\mathrm{p}<.05)$ for grades, classroom climate, and coproduction inducement. When both teacher and student have no MB, the student's grade is 1.1 units better (out of six) compared to cases in which the teacher has an MB and the 
student has none. This indicates that the matching of migration backgrounds - in this case, the matching of not having migration backgrounds - is important for a student's grade.

The students with $\mathrm{MB}$ who have a teacher with MB evaluate the classroom climate .93 units better (out of seven) than students with MB who have a teacher without MB. Also, students without MB who have teachers with MB evaluate the classroom climate .99 units better than students with MB in a class with a teacher without MB. These two findings correspond to the assumption of the German government that teachers with MB, symbolizing equal access, diversity, and legitimacy, may contribute to a better atmosphere in the classroom (Bundesregierung, 2012). It is noteworthy that students with and without MB perceived the classroom climate to be better when they had a teacher with MB rather than one without.

Finally, students without MB who have teachers without MB evaluate coproduction inducement .67 units better than students without MB who have a teacher with MB. This points to the assumption that students without MB want to work hard to appease their teachers and regard them as role models e when those have no MB either.

A difference in means between two groups for demand inducement was significant at the .1 level. Students with MB who have a teacher with MB evaluate demand inducement .96 units higher than students with MB who have a teacher without MB, suggesting that they ask for personal advice and identify with their teacher more often when both have an MB.

The MANOVAs provide a first impression of the four groups' perceptions on the tested variables. In summary, the differences between the four constellations of teacherstudents are significant for four variables: for the substantive effect grades between one 
pair of groups, for the substantive effect classroom climate between two pairs of groups, for the mechanism coproduction inducement for one pair of groups, and finally, at a $10 \%$ level, for the mechanism demand inducement between one pair of groups.

\subsubsection{Mediation Analysis Results}

The main quantitative analysis of this dissertation comprises four sets of multiple regression analyses. Their main purpose is to test the four hypotheses of Research Question 1 [i.e., the role of the four mechanisms (direct and indirect sources) in the relationship between passive representation and the three substantive effects-grades, career expectations, and classroom climate]. I assume that the four mechanisms mediate the effect of passive representation on the variables that represent the three substantive effects. To calculate potential mediation effects, the individual relationships between the different variables are tested with multiple regressions. Figure 7 depicts the steps of the mediation analysis with the variables of this study.

Figure 7: Mediation analysis

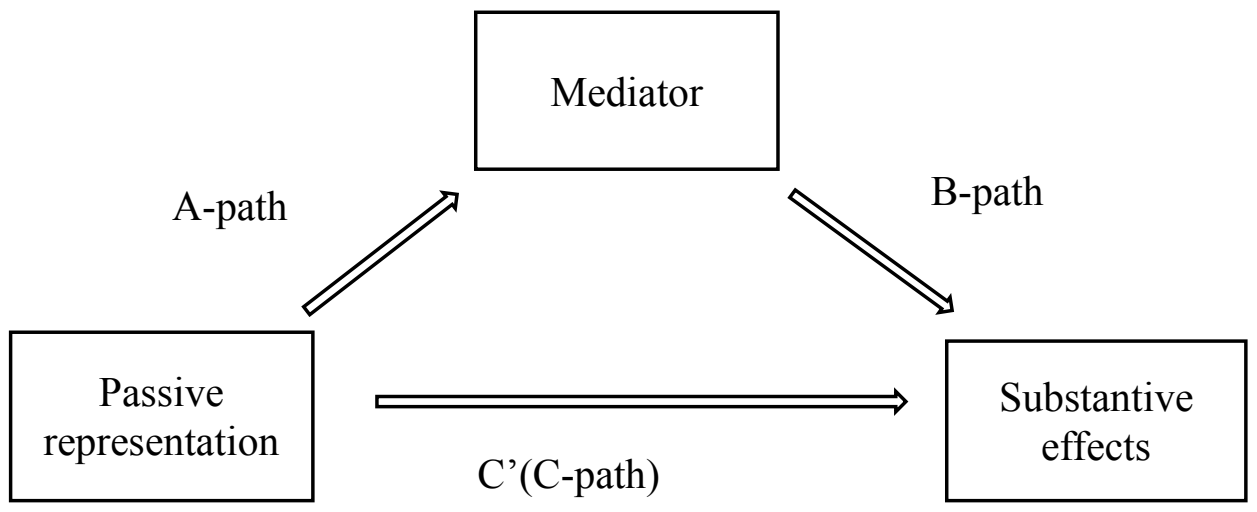

Source: Adopted from Hayes' (2009) simple mediation model, p. 409 
The C-path, or total effect, refers to the causal relationship between passive representation and substantive effects without controlling for any potential mediator. The A-path is the relationship between passive representation and the mediator, while the Bpath uses both mediator and passive representation as predictors (passive representation is controlled for) and substantive effects as criterion. Together, they constitute the indirect effect of the predictor $\left(\mathrm{a}^{*} \mathrm{~b}\right)$. Finally, the $\mathrm{C}^{\prime}-\mathrm{Path}$, or direct effect, measures the effect of passive representation on substantive effects while controlling for the mediator. Thereby, the total effect of the predictor on the criterion is equal to the sum of the indirect and direct effect of $X: c=c^{\prime}+a^{*} b$.

Mediation was "traditionally" most often calculated following Baron and Kenny's (1986) causal-steps-model. However, recent scholarship on mediation modeling has criticized the sole reliance on Baron and Kenny's (1986) model, particularly the assumption that the relationship between predictor and criterion (C-path) must be significant for mediation to occur (Hayes, 2009; Zhao, Lynch, \& Chen, 2010). Also, the assumption that mediation is either present or absent is outdated; it is currently regarded as a continuum (MacKinnon, 2008). To test the significance of mediation (i.e., the indirect effect), bootstrapping has become the method that appears to have the highest power and is least prone to type I errors (Hayes, 2009). Being a non-parametric measure, bootstrapping uses random sampling with replacement to assign a confidence interval to the indirect effect (Preacher \& Hayes, 2004).

For the present study, the analyses were conducted using the PROCESS Macro for SPSS created by Hayes. For each mediation analysis, the macro calculates four regressions (A-Path, B-Path, C-Path, and C'-Path, depicted in Figure 7). Furthermore, it uses 
bootstrapping with bias corrected confidence estimates to estimate the significance of the indirect effect (i.e., the mediation). The $90 \%$ confidence interval of indirect effects was obtained with 1000 bootstrap resamples.

Tables 11-14 present the findings of mediation analyses for the four potential mediators (i.e., the mechanisms demand inducement, coproduction inducement, advocacy, and values and empathy). The analyses were conducted with control variables age, sex, education of the student's mother, education of the student's father, and twelve dummy variables to control for class fixed effects (i.e., the effects of variables not accounted for in the models that are specific to each of the 13 surveyed school classes or their teachers). ${ }^{21}$ The predictor variable is passive representation but because it cannot be measured as it was in the MANOVAs (i.e., as a categorical variable), two dummy variables were created to capture the effects of passive representation: "Both MB", coded as $1=$ both, teacher and student have a migration background and $0=$ all other constellations; and "Both no MB" coded with $1=$ both, student and teacher have no migration background and $0=$ all other constellations. ${ }^{22}$ Thus, for each mechanism and each criterion variable, there are two mediation analyses: one with the predictor "Both MB" and one with the predictor "Both no MB".

Because mediation is tested for three criterion variables, $6(3 \times 2)$ mediation analyses were conducted for each mediator. The results listed in the tables show the

\footnotetext{
${ }^{21}$ The analyses were also run without control variables. Many more mediators led to significant indirect effects, but the goodness of fit of the model was substantially lower.

${ }^{22}$ This was preferred to using only one dummy variable with $1=$ backgrounds match (i.e., both have or do not have a migration background). With this variable, it would be impossible to obtain specific results due to both student and teacher having a migration background.
} 
unstandardized beta coefficient, standard error, and $\mathrm{R}^{2}$ for each single regression (i.e., each path of the mediation). The results of the single regressions were included for two reasons: First, to comprehend the mediation analysis process, it is more convenient for the reader to see the single results at a glance than only having the estimates of the indirect effect. Second, aside from providing information on the mediation, results of the single regressions provide information on the impact of the predictors on the mediator, of the predictors on the criterion, and of the mediator on the criterion — even when no mediating effect was found.

Table 11 presents the results for the mechanism demand inducement. The analyses that found significant indirect effects of the mediators on the relationship between predictor and criterion variables are interpreted below each table. Furthermore, significant paths of analyses for which the indirect effect was insignificant are also interpreted if their interpretation is meaningful for this study. 
Table 11: Mediation results for the mechanism demand inducement as mediator, unstandardized coefficients

\begin{tabular}{|c|c|c|c|c|c|c|c|c|c|c|c|c|c|}
\hline & \multicolumn{3}{|c|}{ C-Path - Total Effect } & \multicolumn{3}{|c|}{ A-Path } & \multicolumn{3}{|l|}{ B-Path } & \multicolumn{2}{|c|}{$\begin{array}{l}\text { C'-Path - Direct } \\
\text { Effect }\end{array}$} & \multicolumn{2}{|c|}{ Indirect effect } \\
\hline & $\mathrm{B}$ & SE & $\mathrm{R}^{2}$ & B & SE & $\mathrm{R}^{2}$ & B & SE & $\mathrm{R}^{2}$ & B & SE & B & $\mathrm{Cl}$ \\
\hline Grades, both MB & $.68 * * *$ & .29 & .35 & .48 & .33 & .30 & $.13^{*}$ & .07 & .37 & $.61 * *$ & .29 & .06 & -.01 to .24 \\
\hline Grades, both no MB & .23 & .29 & .34 & $.59^{*}$ & .32 & .31 & $.14 * *$ & .07 & .35 & .14 & .29 & $.08^{+}$ & .02 to .25 \\
\hline Career Expectations, both MB & .27 & .22 & .29 & .47 & .33 & .29 & $.11 * *$ & .05 & .31 & .22 & .22 & .04 & -.00 to .17 \\
\hline Career Expectations, both no MB & .03 & .22 & .28 & .53 & .32 & .30 & $.11 * *$ & .05 & .30 & -.03 & .22 & $.06^{+}$ & .01 to .18 \\
\hline Classroom Climate, both MB & .10 & .26 & .21 & .50 & .33 & .29 & $.16 * * *$ & .06 & .24 & .02 & .25 & .08 & -.00 to .24 \\
\hline Classroom Climate, both no MB & .17 & .25 & .21 & .53 & .32 & .29 & $.16 * * *$ & .06 & .24 & .08 & .25 & $.09^{+}$ & .02 to .22 \\
\hline
\end{tabular}

Note: $\quad *$ Significant at .1; **significant at .05, *** significant at $<.01$

${ }^{+}$Significant at .1, referring to bias-corrected bootstrapping, $90 \%$ confidence interval (CI) 


\subsubsection{Results of the Mechanism Demand Inducement as Mediator}

The second row of Table 10 presents the results from a mediation analysis with the predictor "Both no MB", the criterion grades, the mediator demand inducement and the control variables. As an example of interpretation, the results were added to the mediation model in Figure 7 to create the following figure, Figure 8:

Figure 8: Relationship of Passive representation and grades through demand inducement

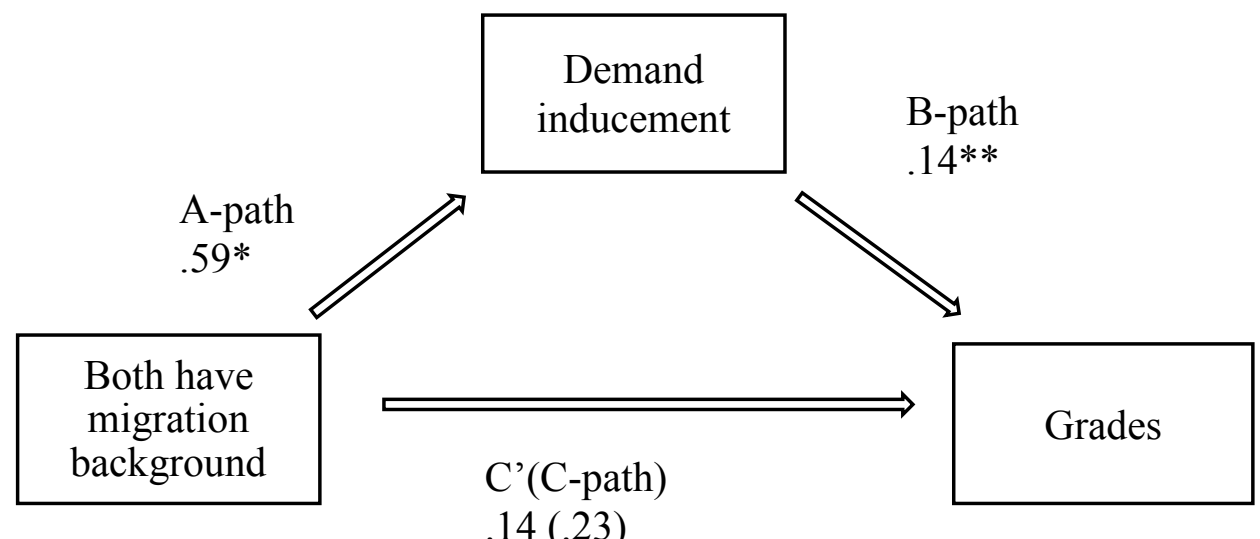

Note: ${ }^{*} p<.1 ; * * p<.05$

If neither teacher and nor student have a migration background (MB), demand inducement is evaluated 0.59 units (out of 7) higher than if one of them or both have MB (a-Path). Also, with each one-unit increase in the evaluation of demand inducement, the grade of the student was 0.14 units (out of 6) higher (B-path). The no-migrationbackground predictor does not significantly influence the grade when only the two variables are included (C-path) or when demand inducement is controlled for (C'-path). However, the indirect effect, measured with bootstrapping, can still be significant if the Cpath is not. This is the case here; the lower limit of the confidence interval is 0.02 , and the 
upper limit is 0.25 . With the confidence interval chosen at $90 \%$, the likelihood of the true indirect effect ranging from 0.02 to 0.25 is $90 \%$, Because the range does not contain the value zero, the null hypothesis that the indirect effect is zero can be rejected. Thus, demand inducement mediated the causal relationship between passive representation and grades. The beta coefficient of the indirect effect quantifies how much two students, one without $\mathrm{MB}$ who has a teacher without $\mathrm{MB}($ "Both no $\mathrm{MB}$ " =1) and the other having a different background combinations ("Both no $\mathrm{MB}$ " $=0$ ), are estimated to differ in their grades, as a result of their background's influence on demand inducement, which in turn influences the grade (Hayes, 2013). The indirect effect is relevant if the effect of both having MB on the grade of the student can be said to be transmitted through demand inducement (A-path $\mathrm{x}$ B-path) (Hayes, 2013). Here, the true indirect effect is estimated at $0.59 \times 0.14=0.08$ and is, following bias-corrected bootstrapping, significant. The ratio of the indirect to the total effect is 0.37. However, Hayes (2013) as well as MacKinnon (1995) do not recommend using the ratio of the indirect to the total effect as a measure of effect size, as it can adopt values below 0 and above 1 , which is problematic for a ratio that, by definition, has values between 0 and 1 . Thus, the effect size is interpreted throughout the analyses with the unstandardized coefficient of the indirect effect.

Zhao et al. (2010) provided a framework to assess the different types of mediation:

1. Complementary Mediation: Mediated effect $\left(a^{*} b\right)$ and direct effect $c$ both exist and point at the same direction;

2. Competitive Mediation: Mediated effect $\left(a^{*} b\right)$ and direct effect $c$ both exist and point in opposite directions; 
3. Indirect-Only Mediation: Mediated effect $\left(a^{*} b\right)$ exists, but not direct effect;

4. Direct-Only Non-Mediation. Direct effect $c$ exists, but no significant indirect effect $a * b$;

5. No-Effect Non-Mediation. Neither direct nor indirect effect exists.

(Zhao et al., 2010, p. 200)

In the case of the first mediation analysis above, the result is an indirect-only mediation, because the indirect effect is significant, but the direct effect is not. According to Zhao et al. (2010), this shows that the "mediator is consistent with [the] hypothesized theoretical framework" (p. 201).

For the remaining results presented in Table 11, I will first discuss the significant indirect effects. For the relationship between the predictor "Both no MB" and the criterion variables career expectations and classroom climate, the mechanism demand inducement serves as a mediator. The indirect effect of demand inducement on the relationship between "Both no MB" and career expectations was 0.06 . Thus, a student who has no MB with a teacher who has no MB has a grade that is 0.06 units higher than a student without those features - their different backgrounds influence demand inducement, which in turn influences career expectations. Because the c-Path is not significant in this case, it is also indirect-only mediation.

The third criterion variable was classroom climate. Here, demand inducement again had a significant indirect effect on the relationship between "Both no MB" and classroom climate, with an unstandardized coefficient of .09 The mediation is an indirect-only mediation. 
Following the above report of significant indirect effects, I will now review the other relationships. When considering the two paths that are multiplied to obtain the indirect effect (i.e., the A-path and the B-path), it is worth noting that of the three significant indirect effects, only one had a significant A-path AND a significant B-path. In the other two cases, only the B-path is significant. According to bias-corrected bootstrapping, the indirect effects of those two cases are also significant, but their beta coefficient is somewhat smaller or their lower confidence interval closer to 0 . Thus, I assume that for the significant indirect effect that has both, a significant A-path and significant B-path, the indirect effect is stronger.

The variance in the criterion variables explained by the models ( $\mathrm{R}$ squared) ranged from $24 \%$ and $37 \%$ (referring only to significant regressions). 
Table 12: Mediation results for the mechanism coproduction inducement as mediator

\begin{tabular}{|c|c|c|c|c|c|c|c|c|c|c|c|c|c|}
\hline & \multicolumn{3}{|l|}{ C-Path } & \multicolumn{3}{|c|}{ A-Path } & \multicolumn{3}{|l|}{ B-Path } & \multicolumn{2}{|c|}{$C^{\prime}$-Path } & \multicolumn{2}{|c|}{ Indirect effect } \\
\hline & B & SE & $\mathrm{R}^{2}$ & B & SE & $\mathrm{R}^{2}$ & B & SE & $\mathrm{R}^{2}$ & B & SE & B & $\mathrm{Cl}$ \\
\hline Grades, both MB & $.68^{* *}$ & .29 & .35 & $.41 *$ & .24 & .25 & $.23 * *$ & .09 & .38 & $.58 * *$ & .29 & $.09^{+}$ & .01 to .26 \\
\hline Grades, both no MB & .23 & .29 & .34 & .16 & .24 & .24 & $.25 * * *$ & .01 & .36 & .19 & .29 & .04 & -.04 to .16 \\
\hline Career Expectations, both MB, & .27 & .22 & .29 & .37 & .25 & .22 & $.13^{*}$ & .07 & .30 & .22 & .22 & $.05^{+}$ & .01 to .16 \\
\hline Career Expectations, both no MB & .03 & .22 & .28 & .12 & .24 & .21 & $.14^{*}$ & .07 & .30 & .01 & .22 & .02 & -.03 to .12 \\
\hline Classroom Climate, both MB & .10 & .26 & .21 & .40 & .24 & .22 & $.27 * * *$ & .08 & .26 & -.01 & .25 & $.11^{+}$ & .02 to .25 \\
\hline Classroom Climate, both no MB & .17 & .25 & .21 & .12 & .24 & .21 & $.27 * * *$ & .08 & .26 & .14 & .24 & .03 & -.07 to .15 \\
\hline
\end{tabular}

Note: $\quad *$ Significant at .1; **significant at .05, *** significant at $<.01$,

+Significant at .1, referring to bias-corrected bootstrapping, $90 \%$ confidence interval (CI) 


\subsubsection{Results of the Mechanism Coproduction Inducement as Mediator}

The second mechanism that is assumed to mediate the relationship between passive representation and substantive effects is coproduction inducement. Table 12 includes the mediation analysis results for the six analyses conducted with the mediator coproduction inducement. Coproduction inducement has a significant indirect effect in three of the six analyses. The indirect effect of coproduction inducement is significant in the relationship between "Both MB" and all three criterion variables: grades, career expectations, and classroom climate.

In the analysis with the criterion grades, the unstandardized coefficient of the indirect effect is 0.09 . All three paths were significant. This points to a complementary mediation following Zhao et al.’s (2010) framework.

For the criterion variable career expectations, the mediation is indirect-only, with the C-path being insignificant. The regressor "Both MB" had a significant indirect effect of 0.05 on career expectations, attributed to its influence on coproduction inducement, which in turn influences career expectations.

Finally, the classroom climate is influenced significantly by passive representation through the mediator coproduction inducement. The indirect effect with the predictor "Both MB" is 0.11 . The mediation is an indirect-only mediation.

Aside from the indirect effect of coproduction inducement, it is worth noting that the B-path of all six mediation analyses in the table were significant. This points to the importance of coproduction inducement (i.e., the need to appease the teacher by working hard; student's perception of the teacher as a role-model) for influencing all three criterion 
variables - regardless of the migration background of student and teacher. R-squared ranged from $25 \%$ to $38 \%$ for all models in Table 12 . 
Table 13: Mediation results for the mechanism advocacy as mediator

\begin{tabular}{|c|c|c|c|c|c|c|c|c|c|c|c|c|c|}
\hline & \multicolumn{3}{|c|}{ C-Path } & \multicolumn{3}{|c|}{ A-Path } & \multicolumn{3}{|c|}{ B-Path } & \multicolumn{2}{|c|}{$C^{\prime}$-Path } & \multicolumn{2}{|c|}{ Indirect effect } \\
\hline & B & SE & $R^{2}$ & B & SE & $\mathrm{R}^{2}$ & B & SE & $R^{2}$ & B & SE & B & $\mathrm{Cl}$ \\
\hline Grades, both MB & $.68 * *$ & .29 & .35 & -.00 & .30 & .27 & .11 & .08 & .36 & $.68 * *$ & .30 & .00 & -.09 to .06 \\
\hline Grades, both no MB & .23 & .29 & .33 & .33 & .29 & .27 & .11 & .08 & .34 & .19 & .29 & .04 & -.01 to .18 \\
\hline Career Expectations, both MB & .28 & .22 & .29 & -.05 & .30 & .28 & .09 & .06 & .30 & .28 & .22 & -.01 & -.10 to .03 \\
\hline Career Expectations, both no MB & .03 & .22 & .28 & .35 & .29 & .29 & .09 & .06 & .29 & -.00 & .22 & .03 & -.00 to .16 \\
\hline Classroom Climate, both MB & .01 & .26 & .20 & -.03 & .30 & .28 & $.15^{* *}$ & .07 & .23 & .11 & .26 & -.00 & -.10 to .07 \\
\hline Classroom Climate, both no MB & .17 & .25 & .21 & .35 & .28 & .28 & $.15^{* *}$ & .07 & .23 & .12 & .25 & .05 & .00 to .18 \\
\hline
\end{tabular}

Note: $\quad *$ Significant at $.1 ; * *$ significant at $.05, * * *$ significant at $<.01$,

+ Significant at .1, referring to bias-corrected bootstrapping, $90 \%$ confidence interval (CI) 


\subsubsection{Results of the Mechanism Advocacy as Mediator}

The third mechanism that was assumed to mediate the relationship between passive representation and substantive effects is advocacy. Table 13 presents the mediation analysis results for the six analyses conducted with the mediator advocacy.

None of the six mediation analyses for the mediator advocacy found a significant indirect effect of advocacy on the relationship between the migration background and the three criterion variables.

The B-path was significant in two cases; advocacy is a significant predictor for the classroom climate, which increased by 0.15 units when advocacy increased by one unit and "Both MB" was held constant. In the second analysis, classroom climate increased by 0.15 units with each unit increase of advocacy when "Both no MB" was held constant (besides the other control variables).

R-squared ranged between 0.23 and 0.36 ; thus, between $23 \%$ and $36 \%$ of the variance in the substantive effects are explained by the model. 
Table 14: Mediation results for the mechanism values \& empathy as mediator

\begin{tabular}{|c|c|c|c|c|c|c|c|c|c|c|c|c|c|}
\hline & \multicolumn{3}{|l|}{ C-Path } & \multicolumn{3}{|c|}{ A-Path } & \multicolumn{3}{|l|}{ B-Path } & \multicolumn{2}{|c|}{$C^{\prime}$-Path } & \multicolumn{2}{|c|}{ Indirect effect } \\
\hline & B & SE & $R^{2}$ & B & SE & $\mathrm{R}^{2}$ & B & SE & $\mathrm{R}^{2}$ & B & SE & B & $\mathrm{Cl}$ \\
\hline Grades, both MB & $.68 * *$ & .30 & .35 & .12 & .27 & .29 & .10 & .09 & .36 & $.67^{* *}$ & .30 & .01 & -.01 to .13 \\
\hline Grades, both no MB & .26 & .29 & .34 & .35 & .26 & .30 & .10 & .09 & .34 & .22 & .29 & .04 & -.01 to .16 \\
\hline Career Expectations, both MB & .28 & .22 & .29 & .07 & .27 & .28 & $.12^{*}$ & .06 & .31 & .27 & .22 & .01 & -.04 to .10 \\
\hline Career Expectations, both no MB & .04 & .22 & .29 & .37 & .26 & .29 & $.12^{*}$ & .06 & .30 & -.01 & .22 & .05 & .00 to .17 \\
\hline Classroom Climate, both MB & .10 & .26 & .21 & .05 & .27 & .28 & $.23 * * *$ & .07 & .26 & .09 & .25 & .01 & -.09 to .13 \\
\hline Classroom Climate, both no MB & .20 & .25 & .21 & .37 & .26 & .29 & $.23 * * *$ & .07 & .26 & .11 & .25 & $.09^{+}$ & .01 to .22 \\
\hline
\end{tabular}

Note: $\quad *$ Significant at .1; ** significant at .05, *** significant at $<.01$,

${ }^{+}$Significant at .1, referring to bias-corrected bootstrapping, $90 \%$ confidence interval (CI) 


\subsubsection{Results of the Mechanism Values and Empathy as Mediator}

Table 14 presents the mediation analysis results for the twelve analyses conducted with values and empathy - the fourth mechanism that was assumed to mediate the relationship between passive representation and the three criterion variables.

The variable values and empathy has a significant indirect effect on the relationship between predictor and criterion in one case. The predictor is "Both no MB" and the criterion variable is classroom climate. The indirect effect of values and empathy on the relationship between those two variables is significant, with an effect-size of 0.09. Because, —aside from the mediating effect — only the B-path is significant, the mediation is indirectonly.

The B-path, depicting the influence of values and empathy on the criterion variables, is significant for career expectations and for classroom climate; when values and empathy increase by one unit, career expectations increase by 0.12 and the classroom climate increases by 0.23 units.

The C-path describes the relationship between predictors and criterion variables without accounting for the mediating variables. Hence, the results for the C-path (first column) are similar across Tables 11-14. One of the six regressions has a significant Cpath (total effect). When both teacher and student have a migration background, the student's grades are estimated to be higher than when at least one has no migration background. 


\subsubsection{Summary and Discussion of Quantitative Findings}

The objective of the quantitative analyses was to address the indirect and direct sources that can have a mediating effect on the relationship between passive representation and substantive effects. The research question was: Which mechanisms make a passive representative bureaucracy have substantive effects on the people it serves? Four hypotheses were tested, each addressing one of the four mechanisms. Table 15 below presents the hypotheses with the main findings from the quantitative analysis. 
Table 15: Hypotheses with the findings from the quantitative analysis

\section{Hypothesis \\ H 1.1: \\ Demand inducement plays a role in the relationship between passive representation and substantive effects on the people.}

\section{H 1.2:}

Coproduction inducement plays a role in the relationship between passive representation and substantive effects on the people.

\section{H 1.3:}

Advocacy plays a role in the relationship between passive representation and substantive effects on the people.

\section{H 1.4:}

Values and empathy play a role in the relationship between passive representation and substantive effects on the people.

\section{Findings}

- MANOVA: Students with migration background (MB) with teacher with MB rate demand inducement 0.96 units higher than student with $\mathrm{MB}$ with teacher without MB.

- Influence of Demand Inducement on criterion variables (b-path of mediation) is significant for all three: When demand inducement is higher, classroom climate improves by 0.16 units and career expectations and grades increase by 0.14 and 0.11 units, respectively.

- Mediation: Demand inducement mediates the relationship between "Both no MB" and all three criterion variables positively, with effect sizes (unstandardized coefficients) of 0.08 (grades), 0.06 (career expectations), and 0.09 (classroom climate).

- MANOVA: Students without MB with teacher without MB evaluate coproduction inducement 67 units higher than students without MB who have a teacher with MB.

- Influence of Coproduction Inducement on criterion variables is significant for all three: When coproduction inducement is higher, grades and career expectations increase (by 0.24 and 0.13 units respectively) and the classroom climate improves by 0.26 units.

- Mediation: Coproduction inducement mediates the relationship between "Both MB" and all three criterion variables positively, with effect sizes (unstandardized coefficients) of 0.09 (grades), 0.05 (career expectations), and 0.11 (classroom climate).

- MANOVA: No significant differences between the means of the four groups were found in regard to advocacy.

- Influence of Advocacy on criterion variables is significant for classroom climate: When advocacy is higher, the classroom climate improves by 0.25 units.

- Mediation: Advocacy does not mediate the relationship between any of the tested predictors and criterion variables.

- MANOVA: No significant differences between the means of the four groups were found in regard to values and empathy.

- Influence of Values and Empathy on criterion variables is significant for classroom climate and career expectations: When advocacy is higher, career expectations increase by 0.12 units and classroom climate increases by 0.23 units.

- Mediation: Values and empathy has a positive mediating effect on the relationship between "Both no MB" and classroom climate with an effect size of 0.09 . 
Overall, seven of the 24 tested mediations were significant. The effect sizes are relatively small, varying between 0.04 and 0.106 units (out of 6 units for grades and 7 for career expectations and classroom climate). Of the seven mediations, demand inducement and coproduction inducement are responsible for six. While demand inducement mediates the relationship between "Both no MB" and all criterion variables, coproduction inducement mediates the relationship between "Both MB" and all criterion variables. This indicates that for students without migration background (MB) who have teachers without $\mathrm{MB}$, demand inducement plays a larger role as a mediator of their grades, career expectations, and their perception of the classroom climate compared to teacher-student groups where at least one has an MB. In turn, coproduction inducement plays a larger role for students with $\mathrm{MB}$ who have teachers with $\mathrm{MB}$, mediating their grades, career expectations, and perception of the classroom climate compared to groups where at least one has no MB.

Furthermore, values and empathy mediate the relationship between "Both no MB" and the classroom climate. Thus, the mediators are slightly more likely to have significant effects with the predictor "Both no MB" (4 significant mediations) than with the predictor "Both MB" (3 significant mediations). The reason for this may be that in the quantitative analyses, MBs could not be matched by country, ethnicity, or other demographic characteristics. The qualitative analysis in the subsequent section addresses this and provides insight into the importance of matching MBs.

The four mechanisms have a positive significant effect on most of the three criterion variables (b-path of the mediation analyses). Demand inducement and coproduction inducement influence all three criterion variables, advocacy influences the classroom 
climate, and values and empathy influences classroom climate and career expectations. The concepts behind the four mechanisms capture either active behavior of the teacher (advocacy and values and empathy) or of the students (demand inducement and coproduction inducement). Becoming active as a student is, thus, important for all the criterion variables, while becoming active as a teacher is important for the classroom climate and, through values and empathy only, for career expectations.

The reason that only 7 of the 24 mediations have a significant indirect effect is the weak link between the predictors and the four mechanisms (a-path of the mediation analyses). The migration backgrounds and whether both teacher and student have—or both do not have - a migration background have a significant impact in two occasion. When both have no MB, demand inducement is 0.59 units higher than when at least one has an MB. In turn, when both teacher and student have MB, coproduction inducement is 0.41 units higher than when at least one does not have an MB. The few significant links between predictors and the mechanisms point to the conclusion that the influence of the teacher (direct sources advocacy and values and empathy) and the influence of the student (indirect sources coproduction inducement and demand inducement) are mostly due to factors other than MB. However, the indirect effect of the mechanisms was significant in seven cases, although the a-path was significant only in two cases. This shows that the b-path has a strong relationship in the five cases that found a positive indirect effect of the mediators without a significant a-path. The qualitative analysis aims to provide deeper insight into the importance of migration backgrounds for the mechanisms. 


\subsection{Qualitative Findings}

The second part of this study's analytical approach to the research questions consists of comprehensive qualitative analysis. The qualitative data were collected through 26 semi-structured interviews to address Research Question 2 on one hand and to assess uncertainties of the quantitative analysis on the other hand. The first ten interviews were conducted with three objectives in mind: collect data to address Research Question 2, obtain information on the validity of the survey instrument for the quantitative data collection, and become familiar with teachers who are interested in participating in the study and might refer colleagues to participate in the study—-thus snowball sampling to find participants. As previously discussed in Chapter 3, the recruitment of participants was challenging. Snowball sampling was the only feasible way to obtain a sufficiently large number of interviewees and teachers who agreed to participate in the analytical survey with their classes. The disadvantage of this approach is that only people who were very interested in the topic — and wanted to contribute to this study's significance — participated in the interviews. Also, it is likely that those teachers who chose to participate in the interviews may be particularly interested in their students' well-being. To counterbalance this bias and to obtain insight into the broader teaching workforce, the interview participants were asked about their colleagues and about the relationship they have with these colleagues. Most of the participants provided insights into the perceptions and behavior of their colleagues, which make it possible better understand the work environment of the teachers and the role of colleagues, other personnel, and parents.

Altogether, 26 teachers ( 13 female; 13 male) were interviewed. They were between 30 and 52 years old. Eleven had no MB and 15 had MB. Of those 15, seven had immigrated 
to Germany themselves; the others were born in Germany. Of the eight born in Germany, two had one parent with MB and one without. Six of the 15 teachers with MB have a Turkish background, two have a Polish background, and two have a Spanish background. The remaining 5 teachers with $\mathrm{MB}$ respectively have the following backgrounds: Ukrainian, Czech, Egyptian, Russian, and Macedonian. For the analysis of the interviews, they were assigned the numbers 1 to 26 .

Of the 26 interviews, ten were not audio-recorded because the participants felt more comfortable not being recorded. For those interviews, notes were written and uploaded to NVivo together with the transcribed interviews that were audio-recorded.

\subsubsection{Results for Research Question 2}

Research Question 2 of this study is: "How do bureaucrats become representatives?" Prior research has addressed this question extensively, though most often with quantitative methods. Several factors have been found to influence a bureaucrat's representative function - including demographic factors (e.g., race, ethnicity, age, sex, political affiliation, educational level) and organizational factors (e.g., length of time working in the public sector, perceived work obligations, organized employee groups, the position of the bureaucrat in the entity) (e.g., Selden et al., 1998). In the qualitative part of this study, however, the aim was to go beyond attributes that are easily measurable with quantitative methods. The objective was to obtain insight into viewpoints, perceptions, feelings, and fears that have the potential to form a person's role perception and, influence their behavior. Thus, focus was pointed toward Lim's (2006) direct and indirect sourceswith the aim of obtaining information on their meaning and usefulness in the school setting. 
During the data collection process, emerging themes that seemed important to teachers' representative role perception were added to the interview schedule (see description in Chapter 3).

The data were coded and analyzed in NVivo 11. I began the coding process by creating a mind map to help organize the themes that were addressed in the interviews. The first themes added to the map correspond directly to Lim's (2006) direct and indirect sources: (1) Demand inducement; (2) Coproduction inducement; (3) Advocacy; (4) Shared values and beliefs; (5) Empathic understanding; and (6) The three "peer influence" sources—Prior restraint, Check/disapproval, and Resocialization. Furthermore, "perceived representative role and role expectations" was added, corresponding to the $5^{\text {th }}$ set of questions in the interview schedule. Those themes were then used as nodes in the coding process, during which sub-nodes were created when appropriate.

The sets of questions in the interview schedule corresponded to the themes listed above; however, most interviews digressed from the schedule in terms of the order of questions. The broad opening question prompted most participants to tell one or more stories; the interviewees, via their responses, helped guide the interview, which likely stimulated their interest and openness - allowing for the collection of better quality data deep insights into the phenomena. Information on a certain theme or several themes was often obtained throughout the interview and not specifically when the corresponding question was asked. This did not hinder the analysis, as the data were structured during the coding process.

In the coding process, several additional nodes were created for themes that either played a major role for several of the existing nodes or could not be easily added to another 
node. These included: (1) Role of parents, (2) Language and other competencies of teachers with migration background, and (3) The term migration background and its interpretation. After the coding of the interviews, the experiences and viewpoints of the different participants regarding each theme were studied in detail and compared. Common as well as opposed perceptions were highlighted and opinions or stories of particular importance were chosen to be quoted. These findings are presented below.

\subsubsection{Demand Inducement}

Lim (2006) described demand inducement in the following way: "The presence of minority bureaucrats can stimulate more applications or service demand from minority clients" (p. 197). In the school context, more service demand is likely to be created by students asking for advice. Thus, the questions in the interview schedule that addressed the role of demand inducement in the school context were: Do students approach you to ask you for (educational or personal) advice? Are those proportionately more students who also have a migration background/ who have the same background?

The themes discussed most in the interviews that were linked to demand inducement included, "asking for advice," "identification with teacher," and "increased interest." Identifying with the teacher appeared to be a catalyst for demand inducementstudents asked for advice or showed increased interest because they identified with the teacher. Thus, identification with the teacher can-though not necessarily-be a precondition for students to increase demand.

Of the 15 teachers with migration background, 13 recalled situations when students with migration background asked them for advice based on the fact that both student and 
teacher have a migration background. Of those 13, six teachers said that this occurs regularly. The majority of this advice was practical in nature (e.g., help with official documents). However, advice of more personal nature was also solicited sometimes, as six teachers recalled.

Interviewee \#22, having one parent with German and one with Turkish background, once faced a situation in which a female student with MB, who had been hit by her father, asked how to make her father understand and accept that she wants to "live like the others" (i.e., the same way her friends live). Later in the interview, this teacher stated that the situation with the girl was the only one he remembered (in terms of demand inducement) and he explicitly stated that although students come to him for advice regularly, this does not happen due to his or their backgrounds. This statement indicated that situations in which a student asks for advice due to common migration background are rare, and he feels that students solicit his advice because of his position as teacher and his personality—not because he has an MB. However, what he said next was interesting and showed that demand inducement may occur more often than he thinks: "Well, actually they do come, like the girl, they come to me. And I have the impression, that they trust me quicker than they trust my German colleagues. Above all because I can deal with them differently"23 (Interviewee \#22). When asked what he meant by that, he responded that he knows how different family life can be with its different role allocations and different styles of raising children - based on different cultural heritage. At first glance, those statements seem to

\footnotetext{
${ }^{23}$ German original: "Also sie kommen, wie mit dem Mädel, die kommen dann schon. Und ich habe auch den Eindruck, dass die schneller Vertrauen zu mir finden, als zu deutschen Kollegen. Das finde ich schon. Vor allem, weil ich auch anders mit ihnen umgehen kann".
} 
belong to the node "empathic understanding" as they involve an active behavior by the teacher (i.e., understanding what is occurring rather than provoking certain behaviors in students merely through his presence). However, students may come to ask for advice more often because they think that the teacher is more understanding, but this does not necessarily have to be the case. Thus, perceived empathic understanding can provoke demand inducement, regardless of whether it really exists.

Among the teachers without MB, most stated that students ask them for advice from time to time, regardless of the students' backgrounds. Five of the 11 teachers reported that they have noticed increased demand inducement in the form of students with MB asking teachers with MB for advice more often than they ask teachers without MB. In turn, only two of the teachers with MB reported believing that students without MB prefer to ask for advice from teachers without migration background. It is noteworthy that, of the 26 teachers, 18 mentioned-regardless of whether or not they experienced demand inducement due to same migration backgrounds - that the teacher's personality also plays an important role as a catalyst for demand inducement.

Referring to the topic "identification with teacher," nine of 15 teachers with MB recalled situations that made them believe that their students identify with them. Interestingly, in all nine cases, the backgrounds of the students and teachers matched. Five of the six teachers with Turkish roots reported believing that some students with Turkish roots identified with them—similar beliefs were expressed by one teacher with Russian background and one with Polish background regarding students who shared their respective backgrounds. Additionally, the teachers with Egyptian and Macedonian roots both reported believing that students with a Muslim background identified with them. The 
importance of a common Muslim background is also apparent in the following quote of a teacher with Muslim background:

They [students with Turkish roots] want me to like them. I think this rather goes into the direction "liking them due to their personality" and not because of their performance in school since their performance does not improve significantly when they know [that I have a Turkish background], for them it is rather important that I like them and that we "fraternize." ${ }^{\text {" } 4}$ (Interviewee \#22)

For five of the 11 teachers without migration background, having a Muslim background was also perceived to facilitate identification with the teacher. All 11 have a teacher with a Muslim background among their colleagues. They were not asked specifically about their thoughts regarding Muslim backgrounds; yet, when asked questions that related to demand inducement, they all believed that they had observed how students identify with their teachers particularly when both have a Muslim background. For instance, Interviewee \#17 (no migration background), said: "I do believe that, if someone is Muslim and maybe also wears a headscarf, that it is an incredible possibility for the students who come from the same cultural areas to identify with those teachers." ${ }^{25}$

Of the 15 teachers with migration background, eight reported that students had asked them questions about their "home countries" from time to time. Specifically, four of

\footnotetext{
${ }^{24}$ German original: „Die versuchen, dass ich Gefallen empfinde. Ich glaube, das ist aber eher ein Gefallen in Richtung der Persönlichkeit und weniger der schulischen Leistungen, weil sich die schulischen Leistungen nicht signifikant verbessern, wenn sie das wissen, sondern denen ist eher wichtig, dass ich sie mag und dass man sich da so ein bisschen verbrüdert."

${ }^{25}$ German original: „Also ich denke schon, dass wenn jetzt jemand Moslem ist, vielleicht auch Kopftuch trägt, dass es für die Schüler die eben aus dem Kulturraum kommen, eine wahnsinnige Möglichkeit ist, sich zu identifizieren."
} 
the six teachers with Turkish roots had experienced this. The interested students were mostly those who also had a Turkish background. They wanted to know the teacher's opinion on recent political developments in Turkey. Students of all backgrounds often engaged in the conversations; however, students with the same background (as the teacher) usually sparked interest in the topic.

Regarding this aspect of demand inducement, matching background seems to play a major role. However, the teachers that did not have Turkish backgrounds mentioned that students asked questions about the teacher's origins because students are interested in the teacher's — or the teacher's parents' - experiences living in a different country. In those cases, all students showed interest, not only those with migration backgrounds. For example, the teacher with a Czech background, Interviewee \#18 (born in Germany; only one parent born abroad), said that students sometimes ask questions about Czech Republic, regardless of where they are from. The same is true for the two Spanish interviewees - the students are interested in those teachers' home countries, irrespective of their backgrounds.

\subsubsection{Coproduction Inducement}

Lim (2006) explained coproduction inducement the following way:

Minority bureaucrats can better stimulate clients from their social group to make the effort or behavioral changes that some programs need in order to improve outputs and especially subsequent outcomes for clients. In more durable relationships, such as between teachers and students, clients may even behave in this way to seek the approval of bureaucrats whom they like or identify with. (p. 
The questions in the interview schedule were: Do the students make an effort to satisfy you with their performance? Do you think that you motivate them to work harder through your presence? Do you think that you are a role model for the students? Are those proportionately more students with migration background?

The themes relating to coproduction inducement were "appease teacher," "role model," and "motivation". Motivation and perceiving the teacher as role model can overlap, and they can be catalysts for the effort to appease the teacher.

Of the 15 teachers with migration background, eight perceived some form of coproduction inducement to have occurred. Only four of those eight stated that those were more students with migration background. Opinions and experiences were antithetical which is evidenced in the responses of two teachers with Turkish roots — when discussing motivation: "This issue with getting motivated rather has to do with [overcoming] one's baser instincts $[\ldots]$ it doesn't make a difference who is standing in front" ${ }^{\prime 26}$ (Interviewee \#5); "I believe that it motivates them when I am in front. I have a similar background. And then they see that, notwithstanding, one can, let's say, climb up the ladder. And that, I think, is nice. That they see that a blackhead can make it"27 (Interviewee \#21). Both talk about motivation, but with different perceptions. The latter describes how being a role model to the students can serve as motivation, whereas the former describes motivation in general.

\footnotetext{
${ }^{26}$ German original: „Diese Sache mit der Motivation hat eher was mit dem inneren Schweinehund zu tun [...\} das macht keinen Unterschied, wer da vorne steht.“

${ }^{27}$ German original: "Ich glaube dass es jemanden motiviert wer da vorne ist. Ich habe ja einen relativ gleichen Hintergrund. Und dann sehen die auch mal, dass trotzdem jemand, sagen wir mal, hervorkommen kann, der auch mal etwas erreicht hat. Und das ist, glaube ich, ganz nett. Dass die dann halt auch mal sehen, dass ein Schwarzkopf das schaffen kann.“
} 
However, when specifically asked questions related to the theme role model, 10 of the 15 teachers with migration background stated that they perceive themselves to be role models to the students. Interviewee \#9 (with Turkish parents) said: "Two Turkish girls once asked me at what point I had decided to become a school teacher. During the conversation with them, I suddenly became aware of my role as a role model for them. One is actually studying primary school teaching now." 28 Two of the teachers without migration background stated that they had similar conversations with students without migration background who were interested in the teaching profession.

Regarding the theme "appease teacher", none of the interviewees reported believing that students with migration backgrounds try to satisfy them by working harder than students without migration background.

Finally, most of the 26 teachers - aside from a few who agreed on the role model function - said that some students can be motivated or motivate themselves easily and they work harder as a result. Thus, they believe motivation does not typically depend on the students' or their teachers' backgrounds.

\subsubsection{Advocacy}

According to Lim (2006), "advocacy may be the cessation of bias or discrimination against the represented group (i.e., restoration of the spirit of impartiality or neutrality in making decisions and applying rules) or something more than that (i.e., reverse discrimination in breach of impartiality and rules for the purpose of helping the

\footnotetext{
${ }^{28}$ German original: „Zwei türkische Mädchen haben mich mal gefragt, wann ich mich entschieden habe, Lehrerin zu werden. Während der Unterhaltung war ich mir auf einmal meiner Vorbildfunktion so richtig bewusst. Eine von ihnen studiert jetzt Grundschullehramt.“
} 
represented group)" (p. 195). The questions asked in the interview to address advocacy were: Did you ever stand up for a certain student with migration background? Do you make decisions that particularly benefit those students?

Most findings on advocacy were not based on the answers to the direct questions, but advocacy became rather visible in the stories the teachers told over the course of the interviews. I assumed that advocacy might be difficult to detect, as teachers must be impartial and not treat students differently based on their or their parents' origins, their social class, or other demographic features. When asked directly whether they sometimes advocate for specific students, most teachers responded with "I usually treat everybody the same," which was the expected answer. However, over the course of the interviews, nearly all 26 teachers shared a story in which they helped a specific student because they felt that he or she was treated unfairly or simply needed more support than others. More often, those students had migration background.

Advocacy can be understood and applied in more ways than outlined by Lim (2006). He rejected advocacy that constitutes reverse discrimination and only regarded it as justifiable if it serves to restore impartiality. However, several teachers reported acts of advocacy that can be regarded as reverse discrimination, yet they seemed appropriate and fair. For instance, Interviewee \#6, with Turkish parents, discussed a class field trip. The parents of several Turkish girls approached him and wanted him to closely monitor their daughters. He agreed, as he knew that without that assurance, the girls would have not been allowed to join their classmates on the trip.

Interviewee \#22 described a situation in which a Turkish student needed to complete an oral test after failing the final written test: the student was afraid of failing and 
was very intimidated and scared that the other teachers would make him fail. Interviewee \#22 reassured the student, telling him: "Everything is ok, you will be alright, nobody will treat you unfairly," thereby using their common background to calm the student down.

One teacher without migration background, from former East Germany, said that she once defended a Polish boy who was mobbed by his Russian speaking classmates. She reprimanded them in Russian ${ }^{29}$, and they were surprised and intimidated and stopped mobbing the Polish boy.

These examples show that advocacy — when used to defend or support those who need it - is far from unfair. It is fair and justified to help somebody in need of help, particularly considering that in the school context, the clients are children and adolescents who are, due to their young age, often more vulnerable.

The interviewees all stated that migration background itself does not influence their decisions to defend or support a student. They would defend or support anybody who needs it. However, as Interviewee \#19 (no migration background) stated: "Students with migration background need help more often than those without, so I would say that I do help those with migration background more often than those without." ${ }^{30}$ About $50 \%$ of the interviewees provided similar responses when asked if they help students with migration background more than others.

\footnotetext{
${ }^{29}$ Students in the former German Democratic Republic had to learn Russian as first foreign language.

${ }^{30}$ German original: "Schüler mit Migrationshintergrun brauchen öfter Hilfe als die ohne, von daher würde ich schon sagen, dass ich denen mit Migrationshintergrund auch öfter helfe als denen ohne."
} 


\subsubsection{Shared Values and Beliefs}

Lim (2006) described the role that shared values and beliefs can play in the following way: "Thus, when minority bureaucrats act in accordance with their own Representative Bureaucracy values and beliefs (we all do unless prevented), they also serve - whether they intend or know it - the interests of their social group" (p. 195). The questions in the interviews were direct: Do you think that you and your students have the same viewpoints on things? Do you share similar values?

The overall tone of the answers was: not really, at least not in the eyes of the students However, rather than migration backgrounds, the teacher-student role allocation played a larger role for the teachers' answers. A teacher is an authority — an adult who, in addition to teaching, contributes to raising the students, as they spend about half of their time in school every day. For the students, the teachers are first and foremost an authoritarian figure. Also, the age difference between teachers and students hindered teachers' ability to see clear signs of shared values and beliefs.

However, most of the teachers with a Muslim background (the teachers with Turkish, Macedonian, and Egyptian roots) stated that "there might be a certain value congruence" between students with similar backgrounds and them (Interviewee \#9). When elaborating on the topic, teachers provided examples that related to empathic understanding (discussed in more detail below), such as defending or supporting a student against comments or acts of a non-minority teacher, due to empathic understanding. Another interesting point was the perceived shared values by some students who had grown up in very traditional families and had patriarchal attitudes. Two of the teachers with Turkish roots reported that students behaved in ways or made comments that revealed their 
patriarchal attitudes toward women. Those students were apparently hoping that the teachers would share their attitude, which was not the case and was clearly communicated to the students by the teachers.

One of those teachers, Interviewee \#21, added that some of his students with Turkish roots are very interested in his private life: he is a man with Turkish background and he lives with a German woman - they are not married. He is open about the topic, which is likely of great symbolic value to the students. These students are not familiar with lifestyles that differ from the traditional lifestyles to which they are accustomed; thus, they may perceive certain lifestyles (e.g., cohabiting with a romantic partner while not married) of some people in Germany as unusual or even problematic. The example of someone (a teacher), who shares the student's migration background and the language spoken at home, and simultaneously lives this "German" lifestyle, may help students connect their cultural habits to those of the country they live in.

Referring to the role of women, a female teacher without migration background who was working full-time while raising two children said:

"The German female students actually like that and strive for it. They also have these values, since they know it from home [that the mother works]. But those with a migration background definitely do not. They tolerate me because I am their teacher. Because I help them if something comes up. For nothing else." (Interviewee \#23) ${ }^{31}$

\footnotetext{
${ }^{31}$ German original: „Deutsche Schülerinnen finden das eigentlich ganz gut und streben danach. Und haben auch diese Werte auch, weil sie es von zu Hause kennen. Aber die mit Migrationshintergrund auf keinen Fall. Die tolerieren mich, weil ich deren Lehrerin bin. Weil ich ihnen helfe, wenn was lost ist. Sonst nicht.“
} 
Additionally, another female teacher without Turkish migration background reported a situation in which a male student with migration background refused to cooperate because she was a woman. Similarly, two teachers with Turkish background stated that female colleagues sometimes ask them for advice for situations in which male students refuse to listen to a woman and also communicate this attitude. Here, teachers with migration background, particularly with a similar background, can be of great value as "bridgebuilders."

In summary, shared values and beliefs between students and teachers play a less important role than empathic understanding. However, these two themes are inextricably linked, as detailed in the next section.

\subsubsection{Empathic Understanding}

"Compared to other bureaucrats, minority bureaucrats better understand the values and beliefs of their minority group, even if they do not or no longer share them" (Lim, 2006, p. 196). The questions in the interview were: Do you understand the problems of your students? Better than teachers without migration background?

Nearly all 26 interviewees responded "yes" to the questions above. For the teachers with migration background, this response indicated that the teachers believe they understand students with migration background better than their colleagues without migration history. The teachers without migration background (with the exception of two) were aware of the additional value that teachers with migration background have in this regard to the students as well as to the school. 
Nevertheless, most of the 26 interviewees also agreed that a teacher's personality and attitude play a major role in empathic understanding of students. Some teachers are interested in their students' feelings and well-being, whereas others simply teach lessons without dedicating extensive effort to understanding their students' problems. Although most interviewees seemed to belong to the former group - genuinely caring about their students - they agree that teachers with migration background are beneficial in that they may better understand the problems of students that result from different cultural backgrounds.

Regarding the nature of shared migration backgrounds, mutual understanding seems to be more pronounced for students and teachers with Muslim backgrounds. Nevertheless, the interviewees with migration backgrounds (e.g., Ukrainian or Czech backgrounds) who do not teach students with the same national or religious background were convinced that — due to how they were raised, within or between two cultures — they were better able to understand the situations of students with migration background and the difficulties they may face (e.g., not knowing where one belongs). The quotes serve as examples:

Interviewee \#2, with Spanish background, stated:

I am their contact person, there is a closeness and they are very friendly and very... they adore you because they think "You understand me. You know exactly, you have experienced all this." And that's why there is a real intimacy. ${ }^{32}$

\footnotetext{
${ }^{32}$ German original: „Ich bin deren Anpsrechpartner, es gibt eine Nähe, und die sind ganz freundlich und ganz....Die himmeln dich an, weil die denken „du verstehst mich. Du weisst ganz genau, du hast das alles erlebt" Und deswegen ist da eine echte Vertrautheit."
} 
Interviewee \#5, with Turkish background, said: "I believe that the students simply feel: hey, so this teacher that's standing there in front, carries a story, has her package and this package, I can compare it better with my own package." ${ }^{33}$

Interviewee \#21, also with Turkish background-when discussing Muslim students—stated:

I assume that I better understand. That I can put myself into their position, since I can also extract the problems or the things behind it better. One student once asked me: "Why are you giving me a low grade? You know what's going to happen at home." ${ }^{34}$

The teacher with Czech background, Interviewee \#18, said:

I think that it is easier for me, to understand. 'Where do I belong, am I a member of the majority of this society? Or rather at the edge?' Those are at least questions that I have thought about before rather than somebody who never has to ask himself those questions because he always was a part of the majority. ${ }^{35}$

In summary, sharing similar experiences, especially when the experiences imply shared experiences of hardship (e.g., discrimination and the confusion about which culture

\footnotetext{
${ }^{33}$ German original: „Ich glaube, dass es die Schüler einfach spüren, "hups, also die Lehrerin, die da vorne steht, trägt eine Geschichte auf, also hat ihr Päckchen und dieses Päckchen kann ich irgendwie so ein bisschen mehr vergleichen mit meinem Päckchen."

${ }^{34}$ German original: „Ich gehe davon aus, dass ich es besser verstehe. Mich hinein versetzen kann, weil ich da auch die, ja, Problematik oder die Dinge, die dahinterstehen, vielleicht besser herauskristallisieren kann. Der Schüler hat mich mal gefragt: Warum geben sie mir schlechte Noten? Sie wissen doch, was bei uns zu Hause passiert.“

35 German original: „Ich denke, das fällt mir schon manchmal leicht, das zu verstehen,. Wo gehöre ich hin, bin ich Mitglied (unv.), also der Mehrheit der Gesellschaft? Oder - stehe ich am Rand. Das sind zumindest Fragen, über die ich mir vielleicht so eher schon mal Gedanken gemacht habe, als jemand, der sich diese Fragen nie stellen musste. Weil er einfach immer Teil der größeren Mehrheit war.“
} 
one belongs to), can lead to better understanding of each other. This, in turn, is likely to lead to increased trust.

The term trust deserves particular attention. Over the course of the interviews, participants used the term several times, mostly in connection with topics related to empathic understanding, demand inducement, and coproduction inducement. A students' willingness to trust their teacher more easily, due to common demographic characteristics, may lead to demand and/or coproduction inducement. In this case, the teacher does not need to act to build trust. The trust is built on the student's assumption of empathic understanding. On the other hand, as mentioned above, "real" empathic understanding (i.e., including a certain action of the bureaucrat that indicates he is understanding), may lead to trust. Regardless of whether or not a teacher is empathically understanding or merely perceived to be empathically understanding, trust may increase and may lead to other mechanisms, such as coproduction inducement.

\subsubsection{Peer Influence: Prior Restraint, Check/Disapproval, and Resocialization}

The three indirect sources (i.e., prior restraint, check/disapproval, and resocialization; summarized as peer influence) are particularly important to the qualitative component of this study because they were not examined in the quantitative analysis. They relate to the influence of minority bureaucrats on majority bureaucrats. Lim (2006) identified three such sources: (1) check/ disapproval of a majority bureaucrat's behavior by a minority bureaucrat, (2) prior restraint felt by bureaucrats acting on their bias "for fear of being disapproved of, exposed or otherwise checked by minority bureaucrats" (p. 196), 
and (3) resocialization, involving a change in values and beliefs of majority bureaucrats through the presence of minority bureaucrats.

The questions included in the interviews were: Do you think that you influence other teachers, for example their behavior? Do you think that your presence has made other teachers more sensitive towards people with an ethnic/ religious/ cultural background different from theirs? Has your presence ever stopped a teacher without migration background acting biased? Are there any tensions between teachers with and without migration background?

The responses to these questions were mixed. More than half of the teachers with migration background (MB) - and approximately half of the teachers without $\mathrm{MB}$ reported that they had not perceived any influences from one teacher to the other.

The other half of the interviewees confirmed one or several of the three peer influence mechanisms to have occurred in their school, as the following quotes show:

In conversations with colleagues when they are quick to judge: "He is weak. He's not able to do it." Then I give an insight on what might be going on inside the child in that moment when one considers the cultural background. And this way I could often help and change decisions [made by other teachers]. ${ }^{36}$ (Interviewee \#10)

The interviewee apparently stopped teachers without migration background (MB) from acting on their bias. In this case, the teacher was actively talking to the other teachers, so the change in the teachers' behavior was not provoked merely by the presence of the

\footnotetext{
${ }^{36}$ German original: „In Gesprächen mit Kollegen, wenn sie ganz schnell urteilen: "Der ist schwach. Der kann etwas nicht." Dann gebe ich so die Einblicke, wie es in dem Kind in dem Moment vorgehen kann, wenn man so den kulturellen Hintergrund betrachtet. Und so konnte ich schon oft helfen, und die Entscheidungen ändern."
} 
teacher with $\mathrm{MB}$, but also through actions. The situation above is a fitting example of the indirect source check - and possibly of resocialization (in the future). The interviewee intervened by providing insight into the student's situation, which altered the mindset of the teacher without MB; this intervention was not achieved by simply telling teachers to stop acting on their bias. By providing information on the underlying issues, the teacher's approach was likely more effective than if she merely stopped others from acting on their bias. In the long run, providing this kind of information is likely to lead to resocialization of the teachers without MB.

When asked if she thinks that her presence in the school has changed the attitudes of the other teachers toward people with MB, Interviewee \#12 responded: "Yes, I think so. They have less fears to open up, or, accepting a stranger into the system." ${ }^{37}$ This points to an initial resocialization of teachers without MB. Full resocialization, following Lim (2006), would entail that teachers adopt some of the values and beliefs of the students with MB. However, adopting a comprehensive and empathic understanding of the students' viewpoints is assumed to constitute resocialization.

Interviewee \#5, with Turkish background, stated:

It is always positive if people have to reflect a bit more. Fine, now the colleague is sitting here, now I'm going to watch out, that's a least something. If I don't sit there, they can talk freely, that it's the fault of the childhood home and when I sit there and think, "what the heck? The childhood home?" That doesn't have anything to

\footnotetext{
37 German original: „Glauben Sie, dass Ihre Anwesenheit in der Schule die Einstellung von anderen Lehrern gegenüber von Menschen mit Migrationshintergrund verändert hat schon?“ „Ja, ich denke schon. Man hat weniger Ängste, ja, sich zu öffnen, oder fremde Frau mit aufzunehmen ins System.“
} 
do with it. Then they have to think a bit more how to formulate things and that's at least a further step towards awareness. ${ }^{38}$

This quote shows how teachers without MB apparently felt restraint due to the presence of the teacher with MB. More frequent occurrences of this may also lead to resocialization.

The three quotes show how the three indirect sources check, resocialization, and prior restraint can occur. Particularly in the school context, with its intense and powerdiscrepant relationships between teachers and students (compared to other bureaucracies), it is important to provide for a fair, peaceful, and safe environment. In the three examples, the teachers influenced their colleagues, which in turn changed their behavior.

The following quote, which is also an example of the source check, illustrates the dynamics of the situation and provides deep insight into the teacher's perspective and position:

Teachers demand a discussion on values. I find that the intercultural competence of my colleagues is lacking in such a conversation, which, as I perceive it, always becomes very charged with emotions. That those occidental values-it is terrible that one has to reduce everything to religion, but that's where it comes from, also our values - that they are thrown out into the room and this multiperspectivity, why a student behaves this way and why he or she has problems to take part in the swimming lessons or whatever - that understanding is totally lacking, that there

\footnotetext{
${ }^{38}$ German original: „Es ist immer positiv, wenn Leute irgendwie ein bisschen mehr reflektieren müssen. Gut, jetzt sitzt hier die Kollegin da, jetzt passe ich mal auf, das ist doch schon mal was. Wenn ich nicht da sitze, können sie ganz frei erzählen und sagen, dass Elternhaus ist Schuld und wenn ich da sitze und ich denke dann, ja geht es noch? Wie das Elternhaus? Das hat doch damit nichts zu tun. Dann müssen sie halt, ja mehr überlegen. Dies in Worte fassen und das ist doch schon mal, zumindest ein weiterer Schritt in Richtung Bewusstsein.“
} 
might be a reason for this behavior. The behavior is perceived negatively right away, as if the student wants to wish me, the teacher, ill. That catches my eye and then I intervene, also when I am not asked to. And then they get a bit worked up artificially and I say: "But that's how it is anyway." And I say "You don't have to accept everything, but you should at least consider where it comes from.” And I do that loud and clearly, well, not swearing, but I do get actively involved into the discussion. ${ }^{39}$ (Interviewee \#22)

The teacher quoted above is an outlier in the group of interviewees and the group of people with a Turkish background in Germany (a fact that he is aware of, which he included in his response). He was born in Germany to one Turkish and one German parent. He has light hair and a German last name and if he does not reveal his $\mathrm{MB}$, there is no indication that he has one. This puts him into a special position between two groups, between the "we" and "the other." According to the definition, he clearly belongs to the group of people with $\mathrm{MB}$, but his physical features have mostly prevented him from perceiving the world in the same way that most people with Turkish roots in Germany dohe has mostly bypassed experiences of racism and discrimination. He stated that he usually

\footnotetext{
${ }^{39}$ German original: „Oder, dass dann gefordert wird, dass es so Kontroversen über Werte gibt. Also, mir fehlt dann ganz oft in so einem Gespräch, was dann, wie ich finde, auch immer sehr schnell emotionsaufgeladen ist, so die interkulturelle Kompetenz der Kollegen. Dass erst mal so diese abendländischen Werte - es ist furchtbar, dass man das alles auf Religion reduzieren muss, aber da kommte es ja nun mal her, also auch unsere Werte - dass die dann erst mal als gesetzt in den Raum gestellt werden und diese Multiperspektivität, warum ein Schüler sich jetzt so verhält und Probleme damit hat, am Schwimmunterricht teilzunehmen oder was auch immer - dass da so das Verständnis fehlt, dass das möglicherweise ein Grund hat.. Das wird erst mal negativ angenommen, dass der Schüler etwas böses will oder mir als Lehrer etwas böses will, das fällt mir dann schon auf und da interveniere ich dann auch, auch ungefragt. Das mache ich dann schon. Und dann wird sich darüber ein bisschen künstlich echauffiert und ich sage: "Ja, so ist es ja dann aber trotzdem nun einmal." Ich sage dann aber auch, man muss das nicht alles akzeptieren, aber man muss das alles mal beachten, wo es herkommt. Das mache ich aber dann auch offensiv und auch laut, also nicht pöbelnd, sondern ich schalte mich dann einfach in das Gespräch ein."
} 
does not volunteer his background information. He does not hide or reveal it if someone asks, but he "does not paddle it either" (Interviewee \#22). The reason for this is, first, the dislike of being categorized due to his MB or any other demographic features. Second, he fears discrimination. Nevertheless, his students know about his background and the quote above demonstrates how different mechanisms can be combined: he actively disapproved of his colleagues' behavior (and there might be resocialization at work, too), he is empathically understanding of the students' way of thinking and acting (even if he might not share the same values), and he actively defends and supports them. He seems to be in a particularly important position as a "bridgebuilder." And the fact that—for his colleagues without $\mathrm{MB}$ - he is not clearly recognizable as "the other," makes his role even more special; they may be more inclined to listen to somebody that they first perceive as belonging to their own group.

Of the teachers without MB, five perceived that their colleagues with MB enriched the teaching workforce at their schools. Insight into other cultures, exchanges of ideas and viewpoints, and a symbolic openness of the workforce were the three main benefits that were mentioned. Being asked specifically about potential changes in their behavior due to other teachers' influence — or vice versa — four of the teachers without MB stated that they might have become more open toward different cultures or ways of living due to their time spent with colleagues with MB. Also, two had asked their colleagues for help when they were unsure about how to handle a certain student; after advice from their colleagues, they developed a different strategy for the problem. One example involved a male student with MB who refused to cooperate with a female teacher. After changing her strategy, the situation slightly improved. 
Finally, the teachers were asked about potential tensions among their colleagues. While nearly all 26 teachers stated that they are not aware of tensions in their schools that are due to teacher migration backgrounds, 5 of the 15 teachers with MB reported their experiences with discrimination during their training. Upon graduation from university, applicants for teaching positions at public schools must work for two years in a school under the supervision of institutions that are supervised by the state. They have a busy and strenuous schedule, teaching a certain number of hours in school while also spending several hours per week in the institution for training purposes. The 5 interviewed teachers had faced discrimination in the form of discouragement from supervisors and trainers. They all reported that trainers and supervisors would discourage them with statements such as "You're never going to pass the final exam"; they had the overall perception that trainers and supervisors did not believe in their success, based either on their foreign accents or simply based on their different appearance (i.e., dark hair and eyes). As a comparison, none of the teachers without $\mathrm{MB}$ reported such discouraging comments during their training.

\subsubsection{Representative Role Perception and Perceived Role Expectations}

Following the interview questions addressing the indirect and direct sources, the participants were also asked about their perceptions regarding their representative role, including how they perceive representative role expectations from the school, parents, and the community.

Interestingly, 7 of the 15 teachers with MB answered with a firm "no" to the question: "Do you see yourself as a representative of your ethnic, religious or cultural group? " For instance, Interviewee \#5 said: 
I've never been a representative or anything, and I don't want to be any and I can't

be. I'm only what people see in me and sometimes they see a Turkish woman. I

want to have the right and possibility to change. ${ }^{40}$

When asked why they do not want to be representatives, participants seemingly indicated that they refuse to be categorized and put into boxes. The responses of some of those teachers, however, confirmed demand and coproduction inducement to be at workpossibly advocacy. Three realized during the interview-after stating that they do not regard themselves as representatives - that they do, occasionally, adopt a representative function. This indicates that the act of representation can occur subconsciously.

Six of the 15 teachers with MB said that they are representatives and they are aware of their role. Two of them admitted that they wished for their representative function to be more recognized by the principal, colleagues, and the government. Interviewee \#21 said that the school had once told him not to speak Turkish in class. He had used a few short phrases to make students be quiet and sit down and other students had complained about it.

I wish that this multiplicator-role that I can adopt would be more in the focus [of the school]. I believe that this one benefit that I really have is the understanding of these students [with Turkish roots]. The language and the cultural background. ${ }^{41}$ (Interviewee \#21)

\footnotetext{
${ }^{40}$ German originmal: „Ich bin nie eine Repräsentantin von irgendwas gewesen, will es auch nicht sein und kann es auch nicht sein. Ich bin auch nur das, was die Leute in mir sehen. Und manchmal sehen sie in mir die Türkin. Ich möchte das Recht haben, mich zu verändern.“

${ }^{41}$ German original: „Ich wünsche, dass diese Multiplikatorenrolle, die ich eigentlich einnehmen kann, stärker fokussiert wird. Ich glaube, dass diesen einen Mehrwert, den ich auf jeden Fall habe, ist quasi das Verständnis für diese Schüler. Dieses Sprachliche und diesen kulturellen Hintergrund.“
} 
Of the 11 teachers without MB, nine said that they believe that teacher(s) with MB are representatives. In regard to a colleague with Russian background, Interviewee \#19 said: "She doesn't necessarily represent Russian students, but she represents diversity. She has a light accent and I think that students who also have accents can identify with her more easily." ${ }_{42}$ The perceptions of the teachers without MB are an additional indicator that the representative role assumption can often be subconscious, or even a process that was not endorsed by the teacher.

Referring to the parents' and the community's expectations toward the teacher assuming a representative role, five of the teachers with MB (all Muslim background) said that they sometimes perceive certain expectations. Interviewee \#1 provided the following example:

They see me and they think, I'm one of them, I'm also a "Black head"' [referring to his dark hair and dark eyes]. I live close to the school, I meet parents on the streets, they see me and my family, see that we look different, too. They trust me more because I look more like them than like a German. In the first place, it is all about the looks. ${ }^{43}$

Interviewee \#26 (Polish roots) and Interviewee \#5 (Turkish roots) described experiences in which parents tried to "win them over." "Some parents try to benefit from

\footnotetext{
${ }^{42}$ German original: „Sie repräsentiert nicht unbedingt russiche Schüler, sondern eher eine gewisse Vielfalt. Sie hat einen leichten Akzent und ich denke, dass Schüler, die zB auch einen Akzent haben, sich viel eher mit ihr identifizieren können.“

${ }^{43}$ German original: „Die sehen mich und denken, ich bin einer von denen, ich bin auch so ein Schwarzkopf. Ich lebe hier in der Nähe, ich treffe Eltern auf der Straße, sie sehen mich mit meiner Familie, sehen, dass wir auch anders aussehen. Sie vertrauen mir mehr, weil ich eher wie sie als wie ein Deutscher aussehe. Letzendlich geht es nur ums Aussehen."
} 
me being the teacher of their children. For instance, they once asked me for better grades for their children while at the same time emphasizing our common Polish identity"44 (Interviewee \#26).

One of the Spanish teachers, Interviewee \#2, said that by virtue of being Spanish, she is a "first class foreigner" - at least this is how she feels she is treated by German students and parents - as opposed to other colleagues with migration backgrounds from different countries. She teaches German for foreigners, a subject taught more and more often due to the increase of immigrants, and is thus in contact with many students with MB.

I am like a mother to them. They often seem to be a bit lost and they desperately search for a trustable person in their lives outside of their homes. My colleague, a German, who teaches the other "German for foreigners" class, has the same perception of being like a mother figure for some. This probably does not have anything to do with my Spanish background, but rather with the character and also the characteristics of this special course. $" 45$ (Interviewee \#2)

One of the Turkish teachers told a similar story. She also used the term "mother figure" for her role in school, but says that she believes this role to be due to her behavior more than to her migration background.

\footnotetext{
${ }^{44}$ German original: „Manche Eltern versuchen es auszunutzen, dass ich hre Kinder unterrichte. Die haben mich zum Beispeil mal gebeten, ihrem Kind eine bessere Note zu geben und immer schön betont, dass wir ja alle aus Polen kommen.“

${ }^{45}$ „Ich bin wie eine Mutter für sie. Sie wirken oft so verloren und sie suchen verzweifelt nach jemandem, dem sie vertrauen können außerhalb ihres Zuhauses. Meine Kollegin, eine Deutsche, unterrichtet die andere DaF Klasse und sie hat denselben Eindruck, eine Art Mutterrolle zu übernehmen für manche. Das hat wahrscheinlich nichts mit meinem spanischen Hintergrund zu tun, sondern eher mit dem Charakter und auch mit dem Kurs.“
} 
In summary, about half of the 15 teachers with an $\mathrm{MB}$ do not perceive themselves to be representatives, mainly because they do not want to be reduced to their migration background. Six teachers are aware of their representative role- two of these teachers aspire to make more use of this role. Most teachers without MB stated that their colleagues with MB are representatives of the students with MB. Finally, a teacher's character seems to play a role that is—at minimum —as important as migration background.

\subsubsection{Role of Parents}

The theme "parents" was added to the interview schedule after the first four interviews because it had played a major role in all four. In most of the interviews, participants introduced the topic before they were asked about it. The content of the conversations related to parents can be assigned to two major themes: Trust and distrust. Most teachers with migration background (MB), particularly all with Muslim backgrounds, reported that an increased trust by parents who also have a migration background is apparent. If teachers were not sure whether parents trust them more, they at least perceived a certain opening process of the parents when they realized that the teacher also belongs to the group of "the others". According to two teachers, migration backgrounds do not necessarily have to match in order to increase parents' trust. "I would say that the parents trust me more, no matter where they are from, as long as it's not Germany"46 (Interviewee \#6). However, based on all interviewees' responses to this question, more trust was perceived by teachers with a Muslim background from parents with Muslim backgrounds.

\footnotetext{
${ }^{46}$ German original: „Ich würde sagen, dass die Eltern mir mehr vertrauen, egal wo sie herkommen, solange sie nicht aus Deutschland sind.“
} 
Those same teachers (with MB)—who believe that parents with MB trust them more than they trust teachers without MB-had also experienced distrust (e.g., overt discrimination) from parents without MB. Three teachers of German language arts, two with Turkish and one with Macedonian roots, recalled that parents openly complained about them-expressing disapproval toward them in regard to teaching their children. It is noteworthy that all three teachers were born in Germany and mastered the language, like every other German. In those three cases, the school principals supported the teachers and the parents finally accepted them as teachers. However, the fact that three of the 15 teachers with MB had been victims of overt racism based on prejudices, and six more teachers had perceived a certain distrust from parents due to their migration background, indicates a need for collective engagement to overcome prejudices.

The relationships of the teachers without MB with students' parents were less divided. Several teachers reported that they had encountered problems talking to minority background students' parents due to language barriers. Two of those asked a colleague to help them as interpreter. Trust and distrust in regard to the parents were not perceived in a meaningful way by the teachers without MB. Some suspected that parents with MB might trust them less than those without MB, but overall, the role of the parents was a minor point of discussion during interviews with teachers without MB.

\subsubsection{Language and Other Added Values of Teachers with Migration Background}

Sharing a common language (aside from German) with students and parents played a role in several of the interviews. The teachers reported a range of different experiences related to language with students and parents. While one teacher with Turkish roots was 
instructed not to use the Turkish language in class, not even to command students to "sit down" or "be quiet," another teacher with a Turkish background who uses such techniques reported no problems and no complaints. It is noteworthy that the Turkish teacher with one German parent and German "features" has not been instructed to stop this behavior.

In general, speaking the same language as the students' parents has been useful to nearly all teachers with $\mathrm{MB}$, including those who stated that they were not representatives of their group. Using the same language and, thus, helping parents to be part of the German school system, however, most likely makes those teachers representatives in the eyes of the parents - even if they are not aware of it or reject the idea of becoming a representative. Six of the 11 teachers without MB also reported the advantage of having teachers in their workforce who speak, for example, Turkish or Russian.

Another interesting aspect was the social status of languages. Several teachers, with and without MB, discussed the different levels of prestige of languages. Similar to the statement of the Spanish teacher of being a first-class foreigner, languages - and likely the corresponding ethnicities and nationalities - seem to be assigned different statuses. Interviewee \#3 stated: "Nobody would have a problem if students and teachers spoke English, Spanish, or, say, Norwegian. But if their native language happens to be Turkish, Arab, Farsi, or Russian, then they better don't engage in longer conversations in here." ${ }^{\prime 4}$ These statements are an additional indication that discrimination is present in this context.

The other main advantage that teachers with MB possess more than teachers without $\mathrm{MB}$ is-according to several interviewees with and without $\mathrm{MB}$ - higher

\footnotetext{
${ }^{47}$ German original: „Keiner würde ein Problem damit haben wenn Lehrer und Schüler sich auf English, Spanisch oder auch Norwegisch unterhalten. Aber wenn ihre Muttersprache zufällig Türksich, Arabisch, Farsi oder Russich sit, dann sollten sie sich hier drin lieber nicht allzu lange unterhalten.“
} 
intercultural competence. This refers to understanding students and their problems better (which would be the direct source empathic understanding), and involves intuitive understanding of issues related to the difference in cultures in general. An example of this is evidenced in the response from Interviewee \#22 (presented in Chapter 4.3.1.6), who explained that he intervenes when teachers without MB stress the importance of adhering to occidental values, thereby expressing their dislike for values that are not occidental. Teachers with MB function as bridgebuilders between differences in culture and habits.

\subsubsection{Assessing the Term "Migration Background"}

The last theme explored in the qualitative analysis is the term "migration background". The official meaning is defined by the Government. Similarly, the present study has defined the term to include everybody who was born outside of Germany or who has at least one parent born outside of Germany. Drawing from the experiences and stories

of the interviewees, however — in the real world — the term migration background is mostly reduced to those who do not have traditionally German appearance. More than half of the interviewees discussed the meaning of the term during their interview, and most introduced the term into the discussion. Interviewee \#26 (Polish background) stated:

People who live in Germany but were born in Britain are usually not regarded as people with migration background. They're expats. However, somebody who has Turkish grandparents who moved to Germany when they were 30 and who has darker hair and eyes than the average German is automatically seen as a foreigner. ${ }^{48}$

\footnotetext{
${ }^{48}$ German original: „Leute, die in Deustchland wohnen, aber in England geboren wurden, werden für gewöhnlich nicht als Menschen mit Migrationshintergrund bezeichnet. Das sind dann Expats. Aber jemand,
} 
The other teachers shared this view; according to them, the use of the term migration background seems to be connected to differences in appearance and the "otherness" connected to these differences - and less connected to immigration from a foreign country or having parents who were born outside of Germany.

Questions that arose during the first interviews, which were expected to be significant in the present study, concerned the impact of matching backgrounds. Do teachers and students need to have the same migration background for representation and / or any of the mechanisms to occur? What does it mean to have the same background? The same nationality? The same national roots? The same hair color or the same native language? The results of the interviews indicate that most of the mechanisms work more intensely when both teachers and students have a Muslim background. All teachers with Muslim backgrounds perceived many parents with Muslim backgrounds and their children to automatically trust them more or at least be more open toward them than toward other teachers. Discrimination, a very present phenomenon in Germany, is particularly directed toward people with Muslim backgrounds—as evidenced in the interviews. Muslims find themselves more often to be a target of "othering." Islam becomes an important marker of being different. As Interviewee \#22 suggested, it is all reduced to religion, as this is where many values originate. Thus, it is particularly important for Muslim students and parents to be represented by teachers who have a crucial function not only for the students but for society as a whole.

der türksiche Großeltern hat, die mit 30 nach Deutschland kamen und der ein bisschen dunklere Haare und Augen als der Durschnittsdeutsche hat, der wird automatisch als Ausländer betrachtet.“ 
Teachers with different backgrounds reported that migration backgrounds did not necessarily need to match; however, they also perceived less of the direct and indirect sources in general. Interviewee \#10, from Ukraine, said that, in her experience, national or ethnic backgrounds did not need to match for her to be a representative of her students with migration background. She stated that students approach her with questions regarding school as well as with questions of private nature-this includes all students (with and without migration background). Again, interviewees emphasized teacher personality as a reason for students to open-up or become reticent.

Below, I summarize the most important study findings.

\subsubsection{Summary and Discussion of Qualitative Findings}

The qualitative component of this study aimed to address Research Question 2: "How does a bureaucrat become representative?" The qualitative analysis provides deep insight into viewpoints, perceptions, feelings, and fears of the interviewees. Thus, the main focus was direct and indirect sources, which were also partially addressed using quantitative analyses in this study. They served as main themes in the interviews, and subthemes and additional themes that emerged during the interviews were added during the coding process.

All indirect and direct sources that were addressed in the interviews were perceived to have played a role in the teachers' lives. Overall, teachers with migration background (MB) experienced more sources than teachers without MB. During the discussion of the indirect and direct sources, the themes that played major roles were trust and distrust, role of parents, identification with the teacher, role model, access, language, intercultural 
competence, personality of teacher, physical appearance, meaning of the term migration background, and Muslim background. To structure the findings comprehensively, the themes are assigned to the different stages in the process of a teacher becoming a representative. Figure 9 summarizes the different themes and allocates them to the sources. 
Figure 9: Themes of the interviews

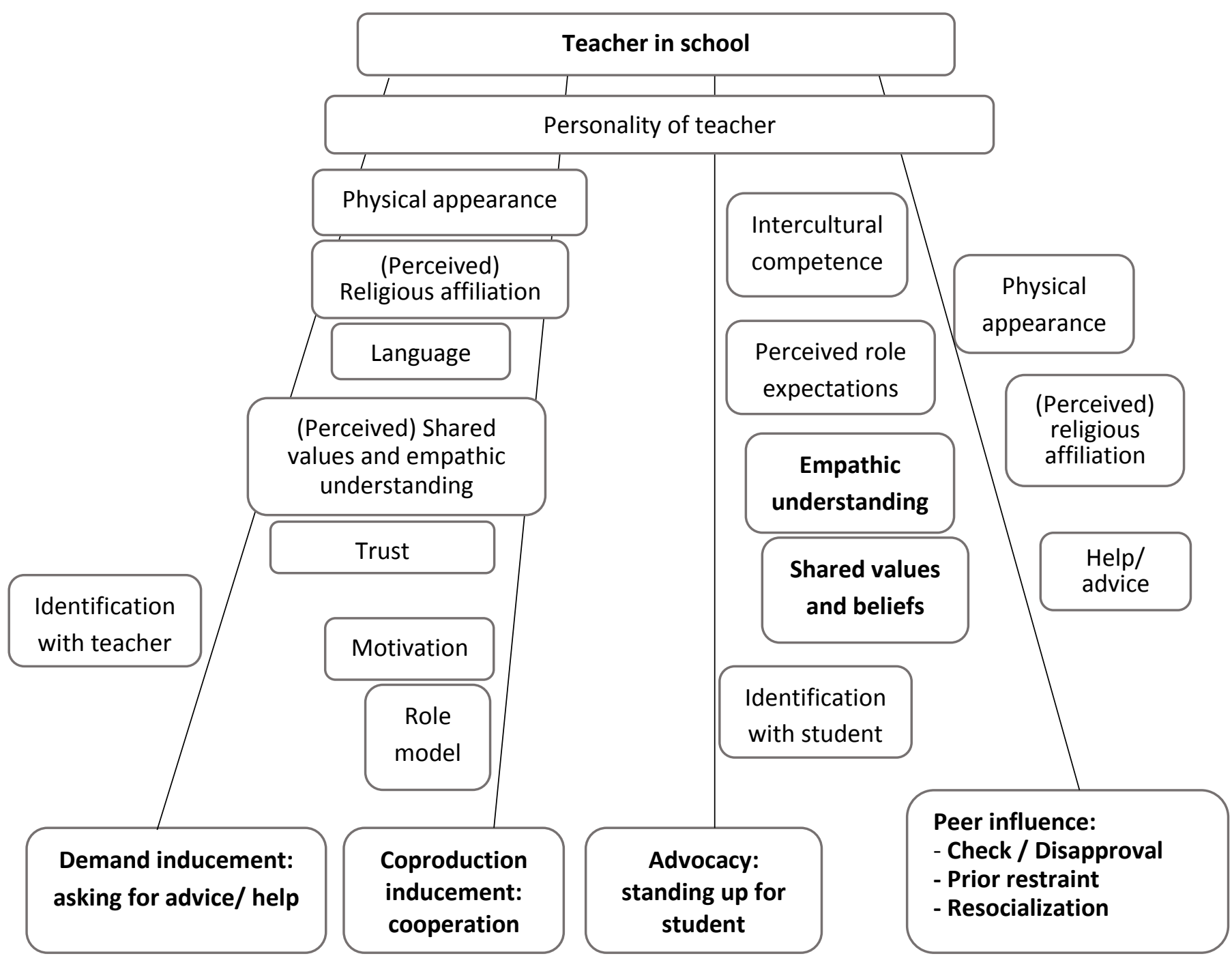


The top box of the figure represents the teacher's presence in a school. The second box from the top involves the personality of the teacher (e.g., being sensitive, helpful, motherly, understanding, involved, empathetic, or rather less involved, distanced, focused on teaching rather than interrelations). Personality of teacher and level of engagement appear to be unrelated to migration background or absence thereof; yet, they exert a strong influence on the relation between students and teachers as well as between different teachers. The interviewees agreed that personality plays—at minimum —as large a role as other attributes. This should be kept in mind when interpreting the findings.

The two boxes in the lower-left portion of Figure 9 are demand inducement and coproduction inducement. On the left half of the figure-along the two left lines that connect teacher in school and demand and coproduction inducement—-the boxes displayed pertain to attributes of the teacher and the resulting process that leads to demand or coproduction inducement. First, for teachers' migration background, the teachers agreed that physical appearance of the teacher is the determining factor for migration background - rather than whether or not the teacher or one of his parents were born abroad. As one teacher said, people from England are rarely regarded as "a person with migration background," whereas someone whose grandparents immigrated from Turkey is still regarded as a foreigner. Dark hair and dark eyes are attributes that constitute the migration background for most people.

Second, the (perceived) religious affiliation of the teacher plays an important role for demand or coproduction inducement to occur. Throughout the interviews, it was obvious that a common Muslim background was a catalyst for both sources to develop. Students' interest in the opinion of teachers was increased due to both student and teacher 
having Turkish backgrounds; teachers' advice regarding family issues was solicited; teachers had the impression that they served as role model due to common Muslim backgrounds; and teachers without MB confirmed that perception.

Third, teacher fluency in — or at least understanding — the student's native language has the potential to increase demand or coproduction inducement. Despite the very restricted use of, for example, Turkish or Russian in the classroom, teachers reported that the use of the language has either helped students to understand something or made them listen to the teacher.

Those three attributes, physical appearance, religious affiliation, and language, lead to perceived shared values and empathic understanding and trust in the teacher on the side of the students. Thus, the teacher does not need to be actively involved, and empathic understanding or shared values and beliefs does not need to occur as described by Lim (2006). The entire process is based on the students' perception and resulting behavior. They feel that they share values and beliefs with the teacher or that the teacher, at least, understands them and their problems. Thus, they start trusting the teacher.

Increased trust or perceived shared values can then lead to a certain level of identification with the teacher, which in turn leads to demand inducement. However, identifying with teacher is not a precondition for demand inducement to occur.

Trust and perceived shared values and understanding can also motivate students. Furthermore, as many teachers confirmed, the students are likely to perceive their teachers as role models. Those two processes can potentially lead to cooperation with the teacher, which constitutes coproduction inducement. 
The interviewees perceived demand inducement to occur more often than coproduction inducement. Particularly motivation was perceived differently; while some teachers with MB perceived students with MB to be more motivated, others stated that the motivation of students was due to many factors - and shared migration backgrounds was a rather insignificant factor. Nevertheless, both demand and coproduction inducement were confirmed in the responses of most teachers.

Both demand and coproduction inducement were also perceived to occur involving students without MB. As personality was the main attribute, physical appearance, perceived religious affiliation, and language did not play a role. Perceived shared values and increased trust can also occur when students do not have a migration background, and when they identify with the teacher or are motivated by them and regard them as role models. In the perception of the teachers with $\mathrm{MB}$, however, the three attributes physical appearance, perceived religious affiliation, and language appeared to play an important role for demand and coproduction to develop.

On the right half of Figure 9, the two lines on the right connect the teacher to advocacy and peer influence. Regarding the personality of the teacher, as in the case of demand and coproduction inducement, it does play a major role and is not related to the migration background. For advocacy and peer influence to occur, the teacher-attribute that emerged from the interviews as being most important is intercultural competence. Intercultural competence is not unique to teachers with MB; it can also be acquired by people without MB. However, as one teacher stated in the interview, it is more often absent in the attitude and behavior of teachers without MB. Teachers with MB often have a certain 
level of intercultural competence-acquired through exposure to at least two cultures during childhood.

Also, the perceived role expectations of the teacher heavily influence the teacher to become an advocate or enable peer influence to occur. Some interviewees felt they were perceived as representatives of their groups, particularly when they had a Muslim background by Muslim parents of students. One teacher with Turkish roots, for instance, promised to closely monitor two Turkish girls during a class field trip-knowing the parents would not have them allowed to join the trip without the promise (from a teacher who shared their background).

Figure 9 also displays Lim's (2006) two direct sources (empathic understanding and shared values and beliefs), which can play an important role in the process of teachers becoming representatives. Here, those two sources are not only perceived to occur, but they do occur. Lim (2006) suggested that shared values and empathic understanding were sources for substantive effects by themselves. While this is also assumed in the present study (which is why they are presented in bold in Figure 9), according to the interviews, they also serve as sources that may lead to advocacy and / or peer influence, particularly in the school context. Teachers perceived shared values and beliefs to occur less often than empathic understanding, which is likely due to the power-discrepant relationship between teachers and students. The teacher is an authoritarian figure, and there is (in the eyes of the students) a large age difference between teachers and students; hence, most teachers did not perceive shared values and beliefs to play a major role.

Empathic understanding, in turn, is arguably the source of all indirect and direct sources that is most experienced by teachers with MB and confirmed by teachers without 
MB. Empathic understanding (i.e., understanding students and their problems) is often an easier-or even a subconscious-process for teachers with $\mathrm{MB}$ in interactions with students with MB. Again, a common Muslim background was a strong catalyst for this source to occur. Nevertheless, teachers with migration backgrounds other than Muslim also confirmed that empathic understanding occurs with students with migration backgrounds different from theirs. Although empathic understanding also depends on the personality of the teacher-and can thus also be occurring in mixed student-teacher constellationssharing similar experiences, especially when those experiences include hardship (e.g., discrimination and confusion about which culture one belongs to), can help people understand each other.

Finally, for advocacy to occur, the teacher might identify with the student, which then motivates the teacher to defend and support the student. Identification with the student is not a precondition for advocacy, though. Several interviewees defended or supported their students because they were being discriminated against by their classmates or colleagues. While most teachers initially stated that they treat every student the same, over the course of the interviews, it became clear that most do advocate for those students who need help. Disproportionately, those are students with MB. More teachers with MB (compared to those teachers without MB) shared stories of defending or supporting their students. However, the teacher's personality plays a crucial role for advocacy to occur. A teacher who is not engaged may not care about the students' well-being and thus may not advocate for them as much as a very engaged teacher, regardless of the migration background. 
Regarding the indirect sources summarized under peer influence in Figure 9, physical appearance and perceived religious affiliations of teachers play an important role for prior restraint. As with demand inducement and coproduction inducement, prior restraint does not involve any action of the bureaucrat. Teachers without MB refrain from acting on their bias because of the presence of a teacher with MB. Several of the interviewees with $\mathrm{MB}$ believe that this occurred at least once due to their presence. Check/disapproval, in turn, often involves empathic understanding and may also involve the teacher identifying with the student. Three of the interviewed teachers became actively involved when other teachers were acting on their bias. Again, teachers with Turkish background disapproved of colleagues discriminating against students with Turkish background. One recalled becoming "loud and clear" when intervening, whereas others intervened by trying to alter the thinking of colleagues by presenting their view on the topic. The latter seemed to be more successful. Finally, whether resocialization has occurred can only be assumed, as it involves a change of perspective and adaptation of different viewpoints on the part of the teacher. Some teachers perceived that resocialization might have occurred, but were not certain.

Among the teachers without MB, several emphasized the added value of having teachers with MB in their school. Reported positive effects of teachers with MB included: providing advice to teachers regarding difficulties that arise with students with different backgrounds, providing insight into other cultures, exchanging ideas and viewpoints, and being a symbol for diversity in the school system). No interviewee specified any disadvantages — which is expected, because even if they perceived any disadvantages, they might refrain from openly admitting it in face-to-face interviews. 
One important theme, which is not included in Figure 9, is the role of the parents. While representative bureaucracy concerns the relationship of bureaucrats and citizens, which in the case of the school setting translates to teachers and students, the attributes of teachers influence parents of students with MB at least as much as they influence students. Physical appearance, religious affiliation, and, in particular, language can—if they match the parents' attributes - provoke trust and perceived openness and access to the system, which the parents might not have had before. Several of the teachers with MB reported using the parents' native language in cases where the parents did not speak German. For the parents, a teacher with similar attributes is immensely valuable in terms of provoking a feeling of belonging.

Parents of students without MB, however, have demonstrated distrust toward teachers with $\mathrm{MB}$, including distrust in the form of overt discrimination. Again, this is true for teachers with physical appearance that differs from traditional German appearance rather than the teachers with migration background by definition. For interviewees that experienced discrimination, their school principals aligned themselves with them. However, the existence of deep engrained distrust, solely based on a person's physical appearance, indicates a need for collective engagement to eliminate prejudices.

In sum, the most important findings of this study are:

- Shared values and empathic understanding play a crucial role and are likely to lead to advocacy and/or peer influence

- Advocacy is fair and necessary if it serves to help those in need

- Peer influence has a high potential to make a positive change, teachers with MB have the potential to serve a bridgebuilders and fight discrimination and racism 
- Regarding the term migration background, outer appearance is more important than the actual country of origin, "looking different" makes people more foreign than being foreign. Muslims find themselves more often to be target of "othering"; Islam becomes an important marker of being different.

- Sharing a Muslim background is a catalyst for most mechanisms; Having an MB, albeit not matching, also deploys the mechanisms.

\subsection{Conclusion}

This chapter comprised the quantitative and the qualitative analyses of the study and the corresponding findings. The quantitative analysis aimed at answering Research Question 1: Which mechanisms make a passive representative bureaucracy have substantive effects on the people it serves? The four hypotheses that involved the role of the four mechanisms - demand inducement, coproduction inducement, advocacy, and values and empathy — were tested with the help of two MANOVAs and four sets multiple regression analyses testing mediation effects of the four mechanisms.

The MANOVAs revealed significant differences between two of the four student-teacher constellations (i.e., (1) Teacher and student both have MB; (2) Only teacher has MB; (3) Only student has MB; (4) Neither teacher nor student have MB) regarding their evaluation of demand inducement, coproduction inducement, classroom climate, and grades.

The findings of the mediation analyses revealed that seven of the 24 tested mediations (four mechanisms $\mathrm{x}$ three criterion variables $\mathrm{x}$ two predictor variables) found $\mathrm{a}$ significant indirect effect of the mechanism on the relationship between predictor and criterion variable. The effect sizes were relatively small. 
Demand inducement and coproduction inducement mediated all three substantive effects (grades, career expectations, and classroom climate). Furthermore, Values and empathy mediate the relationship between predictor and the classroom climate. Overall, the predictor "Both no MB" $(1=$ both teachers and students have no migration background, $0=$ otherwise) was more important for mediation to occur than the predictor "Both MB." This is likely due to the fact that in the quantitative analyses, migration backgrounds could not be matched by country, ethnicity, or other demographic characteristics.

While the b-path of the mediation analyses (i.e., the regression of the criterion variables on the mediators) were mostly significant for all four mechanisms, the a-path (i.e., the regression of the mediators on the predictors) were mostly insignificant. This indicates that the engagement of the teacher (direct sources advocacy and values and empathy) and the engagement of the student (indirect sources coproduction inducement and demand inducement) are mostly due to factors other than migration background.

The qualitative analysis addressed Research Question 2: How do bureaucrats become representatives? The analysis of 26 interviews with teachers with and without MB showed that all direct and indirect sources described by Lim (2006) occur in the school setting. Empathic understanding is the source that was perceived to occur most often and is likely to lead to advocacy and peer influence. Similar outer appearance, religious affiliation, and having the same native language is more important than having a migration background as defined by the government (i.e., being born abroad or having at least one parent that was born abroad).

Sharing a Muslim background is a strong factor for all eight sources to occur. Muslims find themselves more often to be a target of discrimination; Islam stands for 
"being different" in Germany. Teachers with MB can adopt an important bridgebuilder function that may help reduce discrimination, particularly when teachers have a Muslim background. For parents with $\mathrm{MB}$, the bridgebuilder function is particularly important. It can lead to integration of those who need it most-in this case, people with Muslim background - and help overcome racism. Furthermore, the presence of teachers with MB symbolizes access to the system (particularly for parents of students with MB who feel excluded or left behind), openness, and diversity. Reaching a critical mass of teachers with MB is important to create appreciation and overcome discrimination. Finally, while a teacher's personality and level of engagement have little to do with migration background, they are important for the mechanisms to occur.

The following chapter comprises the discussion and conclusions. It first discusses the qualitative and quantitative findings in relation to existing studies in the field, thereby synthesizing them. The chapter also describes implications of the present study for theory and practice, its limitations, and recommendations for further research. 


\section{DISCUSSION AND CONCLUSIONS}

\subsection{Introduction}

The concluding chapter of this dissertation has two main purposes: (1) discuss the findings of the study and (2) present the study's implications for theory and practice. The chapter first provides an overview of the study and discusses the main findings of the quantitative and qualitative analyses by synthesizing the results of the two applied methods. Subsequently, the implications of these findings for current theory are examined, followed by an assessment of the findings' implications for policy and practice. Finally, the limitations of the study and recommendations for future research are provided and the conclusion provides a final summary of the study.

\section{$5.2 \quad$ Overview of Study}

To examine the mechanisms of representative bureaucracy, the present study applied quantitative as well as qualitative methods. The reason for using two methods is twofold. First, the nature of the research questions is such that two different methods were needed to comprehensively investigate them. On one hand, Research Question 1, "Which mechanisms make a passive representative bureaucracy have substantive effects on the people it serves?", assesses how the mechanisms of representative bureaucracy affect the causal relationship between representative bureaucracy and its outcomes. Thus, regression analysis was the best approach to address this question. On the other hand, Research Question 2 involves perceptions and opinions of teachers that are based on personal experiences, cultural influences, and feelings. Hence, in-depth interviews were appropriate to obtain detailed information on perceptions that could not be obtained with the analytical 
survey. Second, by applying two methods that are very different in nature, a triangulation of the research findings could be achieved. Several of the uncertainties that remained after the quantitative analysis could be further addressed with the data obtained from the interviews.

\subsection{Discussion of Synthesized Research Findings}

To examine how the mechanisms influence the relationship between representative bureaucracy and substantive effects for the students, it was useful to first obtain insight into the students' evaluation of the four mechanisms and the three substantive effects. The four mechanisms include demand inducement, coproduction inducement, advocacy, and values and empathy. The substantive effects measure the impact that representative bureaucracy can have on the students in the form of change in grades, career expectations, and perception of the classroom climate. For this purpose, a significant difference between means between the different groups of students was tested. The students were categorized into 4 groups based on migration background (MB): (1) Students with MB who have a teacher with MB, (2) Students without MB who have a teacher with MB, (3) Students with MB who have a teacher without MB, and (4) Students without MB who have a teacher without MB.

The subsequent mediation analyses tested mediating effects of the four mechanisms on the relationship between representative bureaucracy and the three substantive effects. For the sets of multiple regressions that constituted the mediation analyses, representative bureaucracy was measured with two dummy variables: "Both MB" and "Both no MB." If both teacher and student had a migration background or both did not have a migration 
background, they were coded with 1 respectively. For all other constellations, they were coded with 0 . Finally, the qualitative analysis explored the different mechanisms that turn teachers into representatives with the help of 26 in-depth interviews.

The following paragraphs discuss the findings of all analyses in relation to the four hypotheses of Research Question 1. Additionally, findings from the qualitative analysis regarding peer influence and further significant results are discussed.

H1.1. Demand inducement plays a role in the relationship between passive representation and substantive effects on the population.

The MANOVA found a significant difference in means for the evaluation of demand inducement. It was higher when teacher and student had an MB in comparison to when only the student had an MB - indicating that students with MB are more likely to ask for advice and identify with their teachers when the teachers also have a MB.

Referring to the influence of demand inducement on the substantive effects, the regression (the b-path of the mediation) found that when demand inducement is higher, classroom climate improves slightly and career expectations and grades also increase slightly.

The mediation analysis, which used slightly different predictor variables, found positive indirect effects of demand inducement on the relationship between "Both no MB" and all three criterion variables. The group of students who do not have an MB and who have teachers without MB evaluate their grades, career expectations, and the classroom climate slightly higher than students with other background features-based on the influence 
of their background on demand inducement, which in turn influences the three criterion variables.

The unexpected result was that mediation occurred for the predictor "Both no MB." While the MANOVA only found one difference in means between students with MB who have a teacher with MB and students with MB who have a teacher without MB, the a-path of the mediation analysis was only significant for students without MB who have teachers without MB. Because the mediation analysis included several control variables (age, sex, education of parents, and fixed effects for the 13 school classes that participated in the student survey), the effect of being a student in a certain class likely contributed to the different results. Nevertheless, both teacher and student having an MB or both not having an MB appears to lead to higher outcomes than mixed teacher-student constellations.

The interviews revealed that most teachers with $\mathrm{MB}$ experienced demand inducement. In the school context, demand inducement occurs when a student perceives common identity with the teacher, which is most often provoked by similar physical appearance, the same native language, and/or the same religious affiliations. Atkins et al. (2014), when interviewing school teachers, also found "looking alike" to be an important attribute for students to connect with their teachers. In the present study, demand inducement was present when both teacher and student have a Muslim background. However, most teachers (with and without migration background) agreed that the personality of the teacher (i.e., being more vs. being less engaged) also plays an important role for demand inducement to occur. This is consistent with Bradbury and Kellough's (2008) findings. They concluded that sharing attitudes between administrators and citizens is more influential on the adoption of a minority representative role than race. Nevertheless, 
both interviewee groups - those with and without MB - also agreed that students with Muslim migration backgrounds appeared to identify with their teachers more easily when the teachers also have a Muslim background.

\section{H.1.2. Coproduction inducement plays a role in the relationship between passive} representation and substantive effects on the population

The MANOVA found that coproduction inducement was higher when both student and teacher did not have a MB compared to when only the teacher had a MB. This indicates that students are motivated and want to appease their teachers more when they match in terms of not having a migration background.

Coproduction inducement positively influences the three substantive effects. When testing for mediation, the indirect effect of coproduction inducement on the relationship between representative bureaucracy and the substantive effects is significant when using the predictor variable "Both MB." Thus, similar to the findings for demand inducement, the findings of the MANOVA and the mediation analysis both show significant differences - but for different predictors. According to the mediation analysis, the group of students who have a MB and who have teachers with $\mathrm{MB}$ evaluate their grades, career expectations, and the classroom climate slightly higher than students with other background features-based on the influence of their background on coproduction inducement, which in turn influences the three criterion variables. Again, the control variables may have captured effects in the mediation that were captured by the representative bureaucracy variables in the MANOVA. Furthermore, the predictors used in the MANOVA and the mediation analyses differ slightly. The significant indirect effect 
of coproduction inducement indicates that a common MB motivates the students and that they are likely to regard their teachers as role models.

The qualitative analysis also found evidence for coproduction inducement. Many of the interviewees perceived that teachers were role models for the students. The teacher attributes that cause coproduction inducement to occur are identical to those for demand inducement: physical appearance, religious affiliation, and language. These attributes may lead to perceived empathic understanding and increasing trust, as in the case of demand inducement. Finally, this may motivate the students to work harder.

Demand and coproduction inducement appear to be similar mechanisms in the context of this study. The difference is that demand inducement increases the cases of students asking for advice or help, possibly because they identify with the teacher, while coproduction inducement motivates students because they regard teachers as role models. Here, identification with the teacher is more personal and provokes the student to ask for personal advice. Coproduction inducement primarily concerns achievement and regard for the teacher as a role model who motivates the student to work hard. However, the two mechanisms can occur simultaneously and subsequently (as is the case with all other mechanisms, too).

Responses to the interview questions pertaining to motivation differed substantially. Not much evidence was found for students with MB being more motivated by their teachers with MB. Motivation among students has, according to the interviewees, many different catalysts (e.g., intrinsic, parents, friends, engaged teachers), making it difficult to assess how much is due to MB. Responses from the interviews suggest that students view teachers as role models. In one example, a female teacher with Turkish roots 
recalled how two female students with Turkish roots asked about her decision to become teacher and how children could be integrated into her current lifestyle. One of these students is currently pursuing a degree in primary school education.

Atkins et al. (2014) also found evidence for students viewing teachers as role models. In their study, this led to higher career expectations among students, which also occurred in the present study. As in the case of demand inducement, the role model notion was most often connected to students with Muslim backgrounds having teachers with Muslim backgrounds in the present study.

Another result from the interviews concerns a female teacher without MB, who reported being a role model—particularly for female students without migration backgrounds. She did not specifically motivate the students to work harder, but the students viewed her as a role model because she was working full time while raising two children by herself. Keiser et al. (2002) also speculated that representative bureaucracy had effects for women in the school setting through coproduction inducement. Their study was among the first to find evidence for representative bureaucracy in relation to gender.

Hypothesis 1.3.: Advocacy plays a role in the relationship between passive representation and substantive effects on the population.

The mechanism advocacy is often referred to as "active representation" - the active involvement of a bureaucrat. The MANOVA did not find evidence for a significant difference in means concerning advocacy. Referring to the influence of advocacy on the three substantive effects, the classroom climate is slightly better when advocacy increases. The mediation analysis did not find a significant indirect effect of advocacy on the 
relationship between representation and grades, career expectations, or the classroom climate.

These findings are not surprising. Advocacy was measured with the survey items "My teacher stands up for me" and "My teacher makes decision that benefit me." The interviewed teachers agreed that they do stand up for their students if they need supportregardless of their MB. The quantitative findings mirror the teachers' statements by not finding significant effects based on migration background. However, most teachers (with and without migration background) stated that, on average, the students with MB need more help than those without, which provokes them to advocate more for those with MB. However, this particular finding is not mirrored in the quantitative analysis, because standing up more often for those who need more help does not imply that teachers do not stand up for those who need less help. They may stand up less often for those needing less help, but only because there is less demand. Thus, there are not more instances of students without MB not receiving help than for students with MB.

In the existing literature, research that addresses advocacy in the school context is scarce. Because standing up for a student based on demographic factors can be regarded as being partial and unfair, it is very difficult to capture advocacy with surveys or interviews. Many studies on representative bureaucracy in schools point to positive outcomes for minority students, but the mechanisms behind it are most often assumed to be related to demand or coproduction inducement than to advocacy (Atkins et al, 2014; Meier \& Bohte, 2001; Meier et al., 1999). Further research on advocacy in the school context may help shed light on its benefits and drawbacks. In particular, the negative connotation due to potential partiality should be considered. 
Hypothesis 1.4. Values and empathy play a role in the relationship between passive representation and substantive effects on the population.

The MANOVA did not find a significant difference between the four studentteacher constellations for their perception of values and empathy. The influence of values and empathy on the three substantive effects is significant for classroom climate and career expectations, increasing both slightly when values and empathy increase. Referring to the mediation analysis, values and empathy has a positive mediating effect on one of the criterion variables; the group of students without $\mathrm{MB}$ and teachers without $\mathrm{MB}$ evaluate the classroom climate slightly higher than students with other background features—based on the influence of their background on values and empathy, which in turn influences classroom climate.

It is surprising that a mediating effect occurs only for the group in which student and teacher do not have migration backgrounds. The analysis of the interviews revealed that empathic understanding plays a crucial role for teachers to become representatives. However, a strong perception of empathic understanding was mainly reported by teachers with Muslim background in regard to students with Muslim background. Because the quantitative analysis of this study did not match migration backgrounds by country of origin or religious affiliation, a stronger effect only for teacher-student matches of Muslim background was not captured.

The analysis of the interviews showed that shared values and beliefs and empathic understanding each played dual-roles. On one hand, perceived empathic understanding and perceived shared values are conducive to demand and coproduction inducement. A student 
perceives that the teacher believes in the same things or understands the student's problems due to similar or same background, and, thus, the student asks the teacher for help or works harder. Whether or not the teacher actually feels this way does not affect the success of the two mechanisms - at least not initially. On the other hand, real shared values and beliefs and/or real empathic understanding can lead to advocacy and peer influence (which is addressed in the section below). The two "versions" of each mechanism can occur by themselves, but they can also occur consecutively. For example: a student sees a teacher, and observes that they share common physical attributes. The student assumes that the teacher is aware of how the student's family life differs from that of the average German student (e.g., father berates child for low grade in school). Upon obtaining a low grade, the student tells the teacher: "You know what happens when I come home with a bad grade." The teacher understands the meaning of "you know what happens"- even without having experienced it personally. The teacher is not obligated to give a better grade, but can offer to talk to the father. This way, perceived empathic understanding led to demand inducement, which led to empathic understanding, which in turn may lead to advocacy (the example stems from the interviews).

Perceived shared values and beliefs and perceived empathic understanding seem to be the catalysts for substantive effects in several existing studies on representative bureaucracy in schools. Atkins et al. (2014), for instance, found that students connect to teachers due to the attributes "looking alike" as well as "shared culture, experience, and language $[\ldots]$ even if this match is only perceived" (p. 509). Other studies in this field did not use qualitative methods and were, hence, not able to specifically determine which of the mechanisms helped to make representation impact students' outcomes. Keiser et al. 
(2002) assumed that regarding the teacher as role model, due to the same gender, may have led to better results for female students.

Overall, the importance of shared values and empathic understanding, particularly the latter, became obvious in the analysis of the interviews. Empathic understanding is the mechanism that occurred most often to the interviewees, mostly connected to having a migration background (MB). While teachers with backgrounds other than Muslim also felt that they can understand students with any MB better than other teachers can, a common opinion in the interviews was that teachers with Muslim roots understand students with Muslim background better — and that those students perceive teachers with the same background to understand them better.

The role of peer influence

The role of peer influence in the form of check/disapproval, prior restraint, and resocialization was explored with the help of the interviews. Overall, the findings indicate that although peer influence was not experienced by many of the interviewees, the potential for peer influence to have substantive effects is large, particularly over time.

The physical appearance and (perceived) religious affiliations of the teachers play an important role for prior restraint. Teachers without MB refrain from acting on their bias because of the presence of a teacher with MB. A few interviewees perceived that prior restraint has occurred at their schools. Check/disapproval, in turn, involves empathic understanding and active behavior on the part of the bureaucrat. Interviewees reported cases of teachers with Turkish background disapproving of colleagues discriminating against students with Turkish background. 
Finally, resocialization involves a change of values and viewpoints of the majority bureaucrat. Whether resocialization occurred was not clear for the teachers with MB; some believed that it might have occurred. Four of the teachers without MB reported that they might have become more aware and open minded, but none stated that they have adapted different values due to their colleagues. However, they did emphasize the added value of having teachers with MB in their school. This value includes: providing advice to teachers regarding difficulties that arise with students with different backgrounds, providing insight into other cultures, exchanging ideas and viewpoints, and being a symbol for openness of the school system.

Burke (1986) described disapproval of a perceived wrongful behavior as a bureaucrat's responsibility. In the representative bureaucracy literature, specific studies on the three sources belonging to peer influence are scarce. Meier and Nicholson-Crotty (2006) stated that peer influence is one of the four mechanisms that might have facilitated active representation in their study, but due to the type of data, they were not able to attribute their outcomes to peer influence. Studies specifically examining the influence of one minority bureaucrat on another would be of great value.

\section{Additional findings of the qualitative analysis}

Several additional findings that do not correspond to any mechanism were obtained through the analysis of the interviews. Those include the assessment of the term migration background, the function of teachers as bridgebuilders, the role of parents, and the potential of symbolic representation. These themes are addressed in the sections below. 


\subsection{Contributions to the Literature}

A representative bureaucracy is a powerful tool to provide for more equitable outcomes for all segments of society. However, the numerous studies on the topic have mainly examined the link between passive and active representation (i.e., the factors that turn passive representation into outcomes for the population). To date, few studies have examined the causal mechanisms. Yet, these mechanisms are critically important; investigating the process behind representation producing effects can yield knowledge that can then be applied purposefully to enhance outcomes more effectively. The present study's contribution to the literature consists of four main points.

First, this study adds to the knowledgebase of representative bureaucracy by examining several mechanisms of representative bureaucracy using a mixed-methods approach. The qualitative study showed that all of the investigated mechanisms occur in the school context. While research in this field has most often emphasized the importance of teachers becoming role models, the present study found the role model function to be only one of several steps and several possible ways in the process of a teacher becoming a representative. A mechanism that was identified to play a crucial role, and that has not been sufficiently addressed in the research literature, is empathic understanding and its two varieties: perceived and "real" emphatic understanding. The former acts as a catalyst for teacher becoming a role model or student identifying with teacher; the latter is a catalyst for advocacy and peer influence. Both processes were experienced by the interview participants and were perceived to be important for the students. Also, the mechanisms summarized as peer influence have the potential to have a major impact on the population; peer influence has not been researched before in the school context. 
Second, most studies of representation in the school context use student grades, their assignment to gifted classes, or similar measures of performance as outcome variables. With very few exceptions (e.g., Atkins et al., 2014), outcomes that could not be measured with a performance related variable were not considered. The present study used classroom climate as one outcome variable and found three of the four mechanisms to mediate the relationship between representative bureaucracy and classroom climate. Furthermore, the qualitative analysis indicates that the fifth mechanism, peer influence, also has the potential to improve the classroom climate. A positive classroom climate, which can lead to better academic performance (Bond et al., 2007), contributes to the wellbeing of the student (Atkins et al., 2014). The MANOVA of the present study found that students with and without migration background (MB) evaluated the classroom climate higher when their teacher had an MB. Diversity in the classroom appears to have a positive effect not only for students with MB. Hence, classroom climate or similar concepts should be used more frequently as outcome variable in studies of representative bureaucracy in the school context.

Third, this study emphasizes the importance of teachers' engagement. Some of the mechanisms (i.e., those that do not involve active behavior of the teacher) occur often when both teacher and student have a Muslim background. Nevertheless, for the mechanisms that involve an active teacher, this quantitative and the qualitative study found teacher personality and engagement to be more important than migration background. Most prior studies in this field have not differentiated between passive and active mechanisms; thus, focus has not been concentrated on determining the mechanisms in which minority status 
is more important, and determining the mechanisms in which teacher engagement is more important.

Fourth, the study examined the school context in Germany. Focusing on the influence of teachers with migration background, the findings suggest that different mechanisms can be conducive to students having better grades, higher career expectations, and a more positive perception of the classroom climate. Although this topic is extremely important, particularly in light of recent political events in Germany, few studies of a similar focus have been conducted. The next section assesses the implications of this study for German policy and practice.

\subsection{Implications for policy and practice}

The German government promotes the hiring of people with migration background as public school teachers. The government's assumption is that increasing the number of school teachers with MB is likely to enhance the performance of students-because teachers might serve as role models or students might identify with them due to shared migration background. Also, teachers with MB reflect cultural and ethnic diversity in the classroom and bring intercultural perspectives to the school and to teaching; these teachers reflect equal opportunity in terms of access to the teaching workforce (Bundeskongress, 2010, p. 19; Bundesregierung, 2012).

The present study serves as a first assessment of the effects that a teacher with MB can produce. The government has assumed that teachers with MB can produce the abovelisted benefits, and this study found that virtually all of them were confirmed. Thus, the government should not only continue to promote the hiring of teachers with MB on a rather 
abstract level by publishing general recommendations, but it should also become more actively and directly involved in the process. Regarding teachers with MB in the workforce, the three measures below can help provide additional benefits.

First, the numbers of teachers with MB are still low compared to the number of people in the population with MB (estimated 2\% compared to 21\%). The Federal government should further push to increase the number of teachers with MB by urging state governments (which are responsible for the educational sector) to become more active in the recruitment and hiring process. A useful measure for the state government and school authorities would be to consider each school's needs by providing them with more authority and responsibility. Given the current situation — an increasing number of students with MB from the countries affected by war in the Middle East-help in the form of additional teachers is needed urgently. Extensive bureaucratic processes impede action without delays. Currently, schools must wait months for school authorities to make hiringdecisions. Additionally, schools would benefit from greater hiring authority because they are better informed about which candidates would better complement their demographic composition. For instance, hiring a teacher who speaks Arabic in a school that has many refugees from Arabic-speaking countries is likely to be beneficial.

Second, training on intercultural competence for teachers, administrators, and management without MB is needed. The interview results revealed several occurrences of discrimination against students, teachers, and parents with MB by teachers without MB acting on their bias. A thorough, high quality, obligatory training that occurs regularly can help decrease acts of discrimination. Furthermore, in addition to decreasing discrimination, a very important function of such training is increasing the ability of teachers without MB 
to represent students with MB. The training, which would ideally be co-organized by teachers with and without MB, would provide exposure to diverse cultural habits; participating teachers without MB would likely adopt a more openminded view of the feelings, perceptions, and viewpoints of "the others."

Third, the on the job training that graduates must participate in to become licensed teachers must be closely monitored; the responsible administrators, trainers, and teachers must also be trained in intercultural competencies. Several of the teachers with MB reported discriminatory behavior against them during their training - solely due to their physical appearance and not connected to their performance. The job training team should include members with MB - to ensure a balanced team.

Finally, increasing the numbers of teachers with MB is, by itself, a worthwhile objective. In addition to the abovementioned positive outcomes, including more teachers with MB in the teacher workforce normalizes individuals with a MB. Thus, this has the potential to decrease racism and discrimination by making "the other" less foreign. Prior studies have found evidence for a critical mass effect in representative bureaucracy (e.g., Meier, 1993). In the present study, Muslims found themselves more often to be a target of “othering." Increasing the number of teachers with Muslim background in schools with Muslim students is likely to decrease "othering" and produce an environment with less tension.

\subsection{Limitations}

The study has three limitations. First, to measure representative bureaucracy, students and teachers were categorized based on whether they or their parents were born 
inside or outside of Germany. No categorization based on nationality or ethnicity was performed. On the surface, it may seem logical to categorize people according to their backgrounds and draw conclusions based on different nationalities; however, even people with the same national background who have spent the same amount of time in Germany may have significantly different experiences. Differences in perceptions, behaviors, and attitudes were, however, extensively discussed in the interviews and are part of the qualitative analysis.

A second limitation relates to generalizability. While the findings may be transferable to different schools, it would be difficult to transfer them to other types of organizations, as some mechanisms (e.g., coproduction inducement) might be particularly important in the educational (i.e., school) context because teachers often serve as role models. These mechanisms might be less effective in other contexts. This limitation, however, is due to the nature of the research topic rather than the choice of methodology in this study.

A third limitation concerns potential self-selection bias in the data collection, particularly the qualitative data collection. The teachers who were willing to participate tended to be particularly interested in the topic. Many are part of a network for teachers with migration background; all made the impression to be dedicated teachers who sacrifice a considerable amount of their free time to "be there" for their students in different ways. Even with their busy schedules, the teachers still set aside time to be interviewed for the study. This is, however, true for many interviews in scientific research: Those who agree to be interviewed are often those most interested in the research topic and eager to help. Thus, the insight gained from this study is based on individuals who were willing to 
participate in the study, which must be considered in the data analyses and the interpretation of my findings.

\subsection{Recommendations for Future Research}

The findings of this study point to a variety of themes that need and deserve further research. Three main dimensions could be identified.

First, as mentioned in previous chapters, the various mechanisms of representation and their underlying catalysts should be further assessed. While demand inducement and coproduction inducement have already been examined (e.g., Atkins et al., 2014, Gade \& Wilkins, 2013; Meier \& Nicholson-Crotty, 2006; Theobald \& Haider-Markel, 2008), advocacy and peer influence have not been examined sufficiently in the school context. In particular, the potential impact of peer influence deserves attention. Because teachers and students have long-term, power discrepant relationships, it is important to learn more about how peer influence can have an effect. Also, advocacy should be addressed in more detail.

Another detail that deserves more attention is the potential role of teachers without MB. As Grissom, Kern, and Rodriguez (2015) suggested, "Exploring how and under what conditions white educators can take up the mantle of equity for minority students in their classrooms and schools is indeed a worthwhile endeavor for educational research" (p. 190). The present study found strong evidence that the engagement of a teacher is at least as important as migration background for advocacy to occur; thus, the roles of teachers without MB should be assessed in the German context.

A second dimension in need of further study involves the outcome variables. Prior research has put a strong focus on choosing variables measuring a student's performance. 
The present study used classroom climate in addition to performance measures. Given the importance that the well-being of a student has, further investigating the influence of passive representation on variables aside from performance variables is recommended. Also, the symbolic effects of representation in the school context should be further investigated. Symbolic representation concerns what a representative can embody for the people being represented (Pitkin, 1967). Teachers with migration background symbolize access to the system, inclusion, and diversity and provide the system with legitimacy. This symbolism by itself has the potential to change outcomes (Theobald \& Haider-Markel, 2008). It serves to decrease prejudice and discrimination, make "the other" less different, and prepare society for a diverse future.

The third dimension in need of further study pertains to methodology. There is a lack of studies in this field that apply qualitative methods or mixed methods. Use of multiple approaches is appropriate and valuable for representative bureaucracy research in the school context. Qualitative studies have great potential to collect data information that cannot be collected otherwise. An in-depth case study of a number of selected schools involving interviews, focus groups, and observation would provide valuable insight that is needed to further address the mechanisms of representative bureaucracy. Teachers, students, administrators, principals, and parents should be involved - so that data can provide more comprehensive understanding of the topic. Also, a large scale quantitative study including the different mechanisms into one model would be useful. This would help to assess the mechanisms' influences on one another. 


\subsection{Conclusion}

This study examined the mechanisms of representative bureaucracy. Focusing on the German public school sector, the aim of this study was to understand through which mechanisms teachers with migration background have an impact on their students. Thus, I examined the following mechanisms: demand inducement, coproduction inducement, advocacy, shared values and empathic understanding, and three mechanisms summarized as peer influence.

The study found evidence for the occurrence of all eight mechanisms. The findings of the quantitative analysis point to a mediating effect of demand and coproduction inducement on the relationship between representation and the three outcome variables: grades, career expectations, and classroom climate. Furthermore, values and empathy mediated the relationship between representation and the classroom climate. Representation was measured as teachers and students having or not having a migration background. The subsequent qualitative analysis revealed the importance of empathic understanding and its two manifestations for other mechanisms to occur. I also found evidence for advocacy as a mechanism of representation and indications that point to the potential of peer influence. Furthermore, the matching of migration backgrounds - for teacher and student — was important for the mechanisms that do not involve active behavior by the bureaucrat. Specifically, teacher and student sharing a Muslim background was a catalyst for demand inducement, coproduction inducement, and check/disapproval to occur.

The findings of the study contribute to the literature in four ways. First, this study adds to the knowledge on the mechanisms of representative bureaucracy by examining 
several mechanisms, which were suggested by the research literature, in one study with the help of mixed methods. Second, the study provides evidence supporting the use of additional outcome variables to measure the effects of representative bureaucracy in the school context. A sole focus on the performance related variables excludes the potential outcomes of symbolic representation from being researched. Third, the study emphasizes the importance of teachers' engagement by finding that a teacher's personality and engagement more important than the migration background for those mechanisms that involve active teacher behavior. Fourth, the study context was Germany, a country of increasing diversity, which is in need of research that investigates the effects of diversity.

The German government promotes the hiring of people with migration background as public school teachers. It assumes that increasing the number of school teachers with migration background will: enhance the academic performance of students, reflect cultural and ethnic diversity in the classrooms, bring intercultural perspectives to schools, and reflect access and equal opportunity.

The implications of the study for policy and practice are threefold. First, each school's needs should be considered by providing them with more authority and responsibility in the hiring process. Currently, extensive paperwork impedes fast action, which is desperately needed to provide sufficient numbers of teachers to schools—without delays. Second, trainings of intercultural competence for teachers, administrators, and management without migration background are urgently needed. Third, the on the job training that graduates must participate in to become licensed teachers must be closely monitored; administrators, trainers, and teachers must also be trained in intercultural competencies. 
Finally, assessing the role of teachers with migration background is important in today's Germany to reduce prejudice and help normalize diversity. Paying continuous attention to the topic by examining its potential impact and outcomes — and by addressing it publicly in the media-will help raise awareness of its vital importance. 


\section{REFERENCES}

Andrews, R., Boyne, G., Meier, K. J., O’Toole, L. J., \& Walker, R. (2005). Representative bureaucracy, organizational strategy, and public service performance: An empirical analysis of English local government. Journal of Public Administration Research and Theory, 15(4), 489-504.

Arksey, H., \& Knight, P. (1999). Interviewing for Social Scientists. London: Sage.

Atkins, D. N., Fertig, A. R., \& Wilkins, V. M. (2014). Connectedness and Expectations: How minority teachers can improve educational outcomes for minority students. Public Management Review, 16(4), 503-526.

Atkins, D. N., \& Wilkins, V. M. (2013) Going Beyond Reading, Writing, and Arithmetic: The Effects of Teacher Representation on Teen Pregnancy Rates. Journal of Public Administration Research and Theory, 23(4), 771-790.

Bade, K., \& Oltmer, J. (2004). Normalfall Migration. ZeitBilder 15. Bonn. 127-132.

BAMF-Federal Office for Migration and Refugees. (2011a). Federal office. Retrieved from http://www.bamf.de/EN/DasBAMF/Chronik/Bundesamt/bundesamtnode.html

BAMF-Federal Office for Migration and Refugees. (2011b). Integrationskurs. Retrieved from

http://www.bamf.de/DE/DasBAMF/Aufgaben/Integrationskurs/integrationskurs.h tml

BAMF-Federal Office for Migration and Refugees. (2013). Bericht zur Integrationskursgeschäftsstatistik für das Jahr 2012. Retrieved from http://www.bamf.de/SharedDocs/Anlagen/DE/Downloads/Infothek/Integrationsku rse/Kurstraeger/Statistiken/2012quartal4_integrationskursgeschaeftsstatistik_bund.pdf?_blob= publicationFile

Baron, R. M., \& Kenny, D. A. (1986). The moderator-mediator variable distinction in social psychological research: Conceptual, strategic and statistical considerations. Journal of Personality and Social Psychology, 51, 1173-1182.

Bevir, M., \& Rhodes, R. A. W. (2002). Interpretive theory. In D. Marsh \& G. Stoker (Eds.), Theory and methods in political science (pp. 131-152). London: Palgrave.

Birch, A. H. (1971). Representation. New York: Praeger.

Blanz, M. (2015). Forschungsmethoden und Statistik für die Soziale Arbeit: Grundlagen und Anwendungen. Stuttgart: Kohlhammer. 
Bond, L., Butler, H., Thomas, L., Carlin, J., Glover, S., Bowes, G., \& Patton, G. (2007). Social and School Connectedness in Early Secondary School as Predictors of Late Teenage Substance Use, Mental Health, and Academic Outcomes. Journal of Adolescent Health, 40(4), 357-359.

Blum, R. (2005). School Connectedness: Improving the Lives of Students. Baltimore, MD: Johns Hopkins University School of Public Health Report.

Bradbury, M. D., \& Kellough, E. J. (2008). Representative bureaucracy: Exploring the potential for active representation in local government. Journal of Public Administration Research and Theory, 18(4), 697-714.

Bundeskongress Lehrkräfte mit Migrationshintergrund. (2010). Potenziale gewinnen. Ausbildung begleiten. Personalentwicklung gestalten. Kongressdokumentation. Retrieved from http://www.bamf.de/SharedDocs/Anlagen/DE/Downloads/ Infothek/Integrationsprogramm/doku-tagung-lehrer.pdf?_blob=publicationFile

Bundesregierung. (2012). National Action Plan on Integration. Retrieved from http://www.bundesregierung.de/Content/DE/_Anlagen/IB/2012-01-31-napkurzfassung-presse-englisch.pdf?_blob=publicationFile

Burke, J. P. (1986). Bureaucratic Responsibility. Baltimore: Johns Hopkins University Press.

Clark, J., Kim., B., Poulton, R., \& Milne, B. (2006). The Role of Low Expectations in Health and Education Investment and Hazardous Consumption. Canadian Journal of Economics/ Revue Canadienne d'Economique, 39(4), 1151-1172.

Close, B. R., Mason, P., Wilkins, V. M., \& Williams, B. N. (2011, June). Searching Less and Finding More: How Bureaucratic Representation Leads to Efficient Policing. Paper presented at the 10th Public Management Research Conference.

Cole, B.P. (1986). The Black Educator: An Endangered Species. Journal of Negro Education 55, 326-334.

Denhardt, R. B., \& Denhardt, J. V. (2000). The New Public Service: Serving Rather than Steering. Public Administration Review, 60(6), 549-559.

Dolan, J. A., \& Rosenbloom, D. H. (Eds.). (2003). Representative Bureaucracy. Classic Readings and Continuing Controversies. New York: M. E. Sharpe.

Dometrius, N. C., \& L. Sigelman. (1984). Assessing progress toward affirmative action goals in state and local government: A new benchmark. Public Administration Review, 44, 241-246. 
Drechsler, W. (2009). Towards a Neo-Weberian European Union? Lisbon Agenda and Public Administration. Halduskultuur, 10, 6-21.

Fassmann, H., Münz, R., \& Seifert, W. (1999). Was wurde aus den Gastarbeitern? Türken und (Ex-)Jugoslawen in Deutschland und Österreich. Demographische Informationen. pp. 57-70.

Friedrich, C. J. (1940). Public Policy and the Nature of Administrative Responsibility. Public Policy, 1, 3-24.

Fry, B. R., \& Raadschelders, J. C. M. (2008). Mastering public administration: from Max Weber to Dwight Waldo. Washington, D.C.: CQ Press.

Gade, D. M., \& Wilkins, V. M. (2013). Where Did You Serve? Veteran Identity, Representative Bureaucracy, and Vocational Rehabilitation. Journal of Public Administration Research and Theory, 23(2), 267-288.

Gibran, J. (2007). Representative Bureaucracy and Active Representation: A Search for Missing Links (Doctoral Dissertation). Tennessee State University, Nashville, TN.

Gray, D. E. (2009). Doing Research in the Real World. London: Sage.

Grissom, J. A., Kern, E. C., \& Rodriguez, L. A. (2015). The "Representative Bureaucracy" in Education: Educator Workforce Diversity, Policy Outputs, and Outcomes for Disadvantaged Students. Educational Researcher, 44(3), 185-192.

Guba, E. G., \& Lincoln, Y. S. (1994). Competing paradigms in qualitative research. In N. K. Denzin \& Y. S. Lincoln (Eds.), Handbook of qualitative research (pp. 105-117). Thousand Oaks, CA: Sage.

Hayes, A. F. (2009). Beyond Baron and Kenny: Statistical Mediation Analysis in the New Millennium. Communication Monographs, 76(4), 408-420.

Hayes, A. F. (2013). Introduction to Mediation, Moderation, and Conditional Process Analysis: A Regression-Based Approach. New York City, NY: Guilford Press.

Herbert, U. (2001). Geschichte der Ausländerpolitik in Deutschland: Saisonarbeiter, Zwangsarbeiter, Gastarbeiter, Flüchtlinge. Schriftenreihe der Bundeszentrale für Politische Bildung, Band 410. Munich, Germany: C.K. Beck

Hindera, J. J. (1993). Representative Bureaucracy: Further Evidence of Active Representation in the EEOC District Offices. Journal of Public Administration Research and Theory, 3(4), 415-429. 
Howell, D. C. (2009). Statistical Methods for Psychology. Florence, KY: Cengage Learning.

Huberty, C. J., \& Petoskey, M. D. (2000). Multivariate Analysis of Variance and Covariance. In H. Tinsley \& S. Brown (Eds.), Handbook of Applied Multivariate Statistics and Mathematical Modeling (pp. 182-208). New York City, NY: Academic Press.

Jick, T. D. (1979). Mixing Qualitative and Quantitative Methods: Triangulation in Action. Administrative Science Quarterly, 24(4), 602-611.

Johnson, L. B. (1965) "Commencement Address at Howard University: 'To Fulfill These Rights," June 4, 1965, in Public Papers of the Presidents of the United States: Lyndon B. Johnson, 2, 635-640. Washington, D.C.: Government Printing Office.

Joppke, C. (1996). Multiculturalism and immigration: A comparison of the United States, Germany, and Great Britain. Theory and Society, 25, 449-500.

Keiser, L. R., Wilkins, V. M., Meier, K. J., \& Holland, C. A. (2002). Lipstick and Logarithms: Gender, Institutional Context, and Representative Bureaucracy. American Political Science Review, 96(3), 553-564.

Kelly, R. M. (1998). An inclusive democratic polity, representative bureaucracies and the new public management. Public Administration Review, 58, 201-208.

Kennedy, B.A. (2013). Sorting Through: The Role of Representation in Bureaucracy. Journal of Public Administration Research and Theory 23(4), 791-816.

Kennedy, B. (2014). Unraveling Representative Bureaucracy: A Systematic Analysis of the Literature. Administration and Society, 46(4), 395-421.

Kernaghan, K. (1991). The Evolution of Representative Bureaucracy in Canada. In V. Wright (Ed.), The Representativity of Public Administration (pp. 127-144). Brussels, Belgium: International Institute of Administrative Sciences.

Kim, P. S. (1994). Theoretical Overview of Representative Bureaucracy: Synthesis. International Review of Administrative Sciences, 60, 385-397.

Kingsley, J. D. (1944). Representative Bureaucracy. Yellow Springs, Ohio: Antioch Press.

Kranz, H. (1974). Are Merit and Equity Compatible? Public Administration Review, 34(5), 434-440

Kranz, H. (1976). The participatory bureaucracy. Washington, D.C.: D.C. Heath and Company. 
Krislov, S. (1974). Representative Bureaucracy. Englewood cliffs, New Jersey: PrenticeHall.

Kübler, D., Kobelt, E., \& Andrey, S. (2012). Towards a Representative Bureaucracy: Promoting Linguistic Representation and Diversity in the Swiss and Canadian Federal Public Services. World Political Science Review, 8(1), 272-296.

Larson, A. D. (1973). Representative Bureaucracy and Administrative Responsibility: A Reassessment. Midwest Review of Public Administration, 7(1), 79-89.

Levitan, D. M. (1946). The Responsibility of Administrative Officials in a Democratic Society. Political Science Quarterly, 61, 562-598.

Lewis, G. B., \& Ng, E. S. (2013). Sexual orientation, work values, pay, and preference for public and nonprofit employment: Evidence from Canadian postsecondary students. Canadian Public Administration, 56(4), 542-564.

Lim, H.-H. (2006). Representative Bureaucracy: Rethinking Substantive Effects and Active Representation. Public Administration Review, 66(2), 193-204.

Lipsky, M. (1980). Street-Level Bureaucracy: Dilemmas of the Individual in Public Services. New York, NY: Russell Sage.

Long, N. (1952). Bureaucracy and Constitutionalism. American Political Science Review $47,808-818$.

Lowi T. J. (1985). The state in politics: The relation between policy and administration. In R. G. Noll (Ed.), Regulatory policy and the social sciences (pp. 67-97). Berkeley: University of California Press.

MacKinnon, D. P., Warsi, G., \& Dwyer, J. H. (1995). A simulation study of mediated effect measures. Multivariate Behavioral Research, 30, 41-62.

MacKinnon, D. P. (2008). Introduction to Statistical Mediation Analysis. New York City, NY: Taylor and Francis Group.

Mayer, H. O. (2012). Interview und schriftliche Befragung. Grundlagen und Methoden empirischer Sozialforschung (6th ed.). München: Oldenbourg.

McDade, T. W., Chyu, L., Duncan, G. J., Hoyt, L. T., Doane, L. D., \& Adam, E. K. (2011). Adolescents' Expectations for the Future Predict Health Behaviors in Early Adulthood. Social Science \& Medicine, 73, 391-398. 
McNabb, D. E. (2013). Research Methods in Public Administration and Nonprofit Management ( $3^{\text {rd }}$ ed). New York, NY: Routledge.

Meier, K. J. (1993). Representative bureaucracy: A theoretical and empirical exposition. Research in Public Administration, 2, 1-35.

Meier, K. J., \& Bohte, J. (2001). Structure and Discretion: The Missing Links in Representative Bureaucracy. Journal of Public Administration Research and Theory, 11(4), 455-470.

Meier, K. J., \& England, R. E. (1984). Black Representation and Educational Policy: Are They Related? The American Political Science Review, 78(2), 392-403.

Meier, K. J., \& Nicholson-Crotty, J. (2006). Gender, Representative Bureaucracy and Law Enforcement: The Case of Sexual Assault. Public Administration Review 66(6), 850-860.

Meier, K. J., \& Nigro, L. G. (1976). Representative bureaucracy and policy preferences: A study in the attitudes of federal executives. American Society for Public Administration, 36(4), 458-469.

Meier, K. J., \& Stewart, J., Jr. (1992). The impact of representative bureaucracies: Educational systems and public policies. American Review of Public Administration, 22(3), 157-171.

Meier, K. J., Wrinkle, R. D., \& Polinard, J. L. (1999). Representative bureaucracy and distributional equity: Addressing the hard question. Journal of Politics, 61(4), 1025-1039.

Meyers, L.S., Gamst, G., \& Guarino, A. J. (2006). Applied multivariate research: Design and interpretation. Thousand Oaks, CA: Sage.

Mosher, F. C. (1968). Democracy and the Public Service. New York: Oxford University Press.

Olsen, W K. (2004). Triangulation in Social Research: Qualitative and Quantitative Methods Can Really Be Mixed. In M. Holborn \& M. Haralambos (Eds.), Developments in Sociology Ormskirk, UK: Causeway Press.

Pedersen, M. J. (2013, January). 'Working, Shirking, Sabotage' and Public Performance: When Public Employees Slack their Focus and Effort at Work.' Paper presented at the annual meeting of the Southern Political Science Association, Orlando, FL.

Pitkin, H. (1967). The concept of representation. Berkeley, CA: Univ. of California Press. 
Pitts, D. (2005). Diversity, representation and performance: Evidence about race and ethnicity in public organizations. Journal of Public Administration Research and Theory, 15, 615-631.

Pollitt, C., \& Bouckaert, G. (2004). Public Management Reform. A Comparative Analysis. 2nd ed. Oxford: Oxford University Press.

Preacher, K. J., \& Hayes, A. F. (2004). SPSS and SAS procedures for estimating indirect effects in simple mediation models. Behavior Research Methods, Instruments, \& Computers, 36(4), 717-731.

Reichhardt, C. S., \& Rallis, S. F. (1994). Qualitative and quantitative inquiries are not incompatible: A call for a new partnership. In C. S. Reichhardt \& S. F. Rallis (Eds.), The qualitative-quantitative debate: New perspectives (pp. 85-91). San Francisco, CA: Jossey Bass.

Riccucci, N. M., \& Saidel, J. R. (1997). The Representativeness of State-Level Bureaucratic Leaders: A Missing Piece of the Representative Bureaucracy Puzzle. Public Administration Review, 57(5), 423-430.

Robson, C. (2002). Real World Research. A Resource for Social Scientists and Practitioner-Researchers ( $2^{\text {nd }}$ Ed.). Malden: Blackwell.

Saidel, J. R., \& Loscocco, K. (2005). Agency leaders, gendered institutions, and representative bureaucracy. Public Administration Review, 65(2), 158-170.

Scott, P. G. (1997). Assessing Determinants of Bureaucratic Discretion: An Experiment in Street-Level Decision Making. Journal of Public Administration Research and Theory, 7(1), 35-57.

Selden, S. C. (1997). Representative bureaucracy: Examining the linkage between passive and active representation in the Farmers Home Administration. American Review of Public Administration, 27(1), 22-42.

Selden, S. C. (2006). A Solution in Search of a Problem? Discrimination, Affirmative Action, and the New Public Service. Public Administration Review, 66(6), 911-923.

Selden, S. C., Brewer, G. A., \& Brudney, J. L. (1999). Reconciling Competing Values in Public Administration: Understanding the Administrative Role Concept." Administration and Society, 31(2), 171-204.

Selden, S. C., Brudney, J. L., \& Kellough, J. E. (1998). Bureaucracy as a representative institution: Toward a reconciliation of bureaucratic government and democratic theory. American Journal of Political Science 42(3), 717-744. 
Slack, J. (2001). Zero-sum politics, the Herbert thesis and the Ryan White Care Act: Lessons learned from the local side of AIDS. Journal of Health and Human Services Administration, 24, 80-103.

Sowa, J. E., \& Selden, S. C. (2003). Administrative discretion and active representation: An expansion of the theory of representative bureaucracy. Public Administration Review, 63(6), 700-710.

Spiegel. (2010, Oct. 16). Integration: Merkel erklärt Multikulti für gescheitert. Retrieved from http://www.spiegel.de/politik/deutschland/integration-merkel-erklaertmultikulti-fuer-gescheitert-a-723532.html

Statistisches Bundesamt (2005). Bevölkerung und Erwerbstätigkeit Bevölkerung mit Migrationshintergrund. Ergebnisse des Mikrozensus 2005. Fachserie 1 Reihe 2.2. Retrieved from https://www.destatis.de/DE/Publikationen/Thematisch/ Bevoelkerung/MigrationIntegration/Migrationshintergrund2010220057004.pdf? blob=publicationFile

Statistisches Bundesamt. (2016). Bevölkerung und Erwerbstätigkeit. Bevölkerung mit Migrationshintergrund. Ergebnisse des Mikrozensus 2015. Fachserie 1 Reihe 2.2. Retrieved from https://www.destatis.de/DE/Publikationen/Thematisch/ Bevoelkerung/MigrationIntegration/Migrationshintergrund2010220157004.pdf? _blob=publicationFile

Statistisches Bundesamt. (2016, September 16). Bevölkerung mit Migrationshintergrund auf Rekordniveau. 327/16. Retrieved from https://www.destatis.de/DE/ PresseService/Presse/Pressemitteilungen/2016/09/PD16_327_122pdf.pdf?_blob =publicationFile

Storz, H., \& Wilmes, B. (2007). Die Reform des Staatsangehörigkeitsrechts und das neue Einbürgerungsrecht. Bundeszentrale für politische Bildung. Retrieved from http://www.bpb.de/gesellschaft/migration/dossiermigration/56483/einbuergerung? $\mathrm{p}=$ all

Theobald, N., \& Haider-Markel, D. (2008). Race, bureaucracy, and symbolic representation: Interactions between citizens and police. Journal of Public Administration Research and Theory, 19(2), 409-426.

Thompson, F. J. (1976). Minority Groups in Public Bureaucracies: Are Passive and Active Representation Linked? Administration and Society, 8(2), 201-226.

Thielemann, G. S., \& Stewart, J., Jr. (1996). A Demand-Side Perspective on the Importance of Representative Bureaucracy: AIDS, Ethnicity, Gender, and Sexual Orientation. Public Administration Review, 56(2), 168-173. 
Tower, L. E., Bowen, E., \& Alkadry, M. (2011). A Snapshot of Organizational Climate: Perceptions of Extension Faculty. Journal of Extension, 49(5).

Trenkamp, O. (2014, June 25). Die meisten Hip-Hopper haben Abitur. Spiegel Online. Retrieved from http://www.spiegel.de/lebenundlernen/job/lehrer-mitmigrationshintergrund-sind-in-deutschen-schulen-selten-a-974726.html

Turgeon, L., \& Gagnon, A. G. (2013). The Politics of Representative Bureaucracy in Multilingual States: A Comparison of Belgium, Canada, and Switzerland. Regional and Federal Studies, 23(4), 407-425.

Van Riper, P. (1958). History of the United States Civil Service. New York: Harper and Row.

Waldo, D. (1948). The Administrative State. A Study of the Political Theory of American Public Administration. New York: Ronald Press.

Waldo, D. (1980). The enterprise of public administration: a summary view. Novato, CA: Chandler \& Sharp Publishers, Incorporated.

Weber, M. (1922). Grundriß der Sozialökonomik 3: Wirtschaft und Gesellschaft. Tübingen: Mohr Siebeck.

Weber, M. (1947). Bureaucracy. In H. H. Gerth \& C. W. Mills (Eds.), From Max Weber: Essays in Sociology (pp. 196-244). London: Kegan Paul.

Wilkins, V. M., \& Keiser, L. R. (2004). Linking Passive and Active Representation by Gender: The Case of Child Support Agencies. Journal of Public Administration Research and Theory, 16, 87-102.

Zhao, X., Lynch, J. G., \& Chen, Q. (2010). Reconsidering Baron and Kenny: Myths and Truths about Mediation Analysis. Journal of Consumer Research, 37(2), 197-206. 


\section{APPENDIX}

Appendix A: Student questionnaire in German

Appendix B: Interview schedule in German

Appendix C: Information letter for schools in German

Appendix D: List of variables

Appendix E: List of interview participants 
Appendix A: Student questionnaire in German

\section{Student Survey}

1. Ich bin

o weiblich

o männlich

2. Ich bin

0 $15 \quad 016 \quad 017$

o 18

o 19 oder älter

3. Ich bin geboren

$\mathrm{o}$ in Deutschland o im Ausland, in , und ich lebe seit Jahren in Deutschland

4. Meine Mutter ist geboren o in Deutschland o im Ausland, in

5. Mein Vater ist geboren o in Deutschland o im Ausland, in

6. Meine Mutter hat o einen Universitätsabschluss o einen Schulabschluss o keinen Schulabschluss

7. Mein Vater hat: o einen Universitätsabschluss o einen Schulabschluss o keinen Schulabschluss

8. Meine Note in diesem Fach ist:
o 1,0-1,4 (13-15 P.)
o 1,5-1,9 (12 P.)
o 2,0-2,4 (10-11 P.)
o 2,5-2,9 (9 P.)
o 3,0-3,4 (7-8 P.)
o 3.5 und höher (0-6 P.)

Die folgenden Fragen reichen von 1 (stimme gar nicht zu) bis 7 (stimme voll zu)

\begin{tabular}{|c|c|c|c|c|c|c|c|}
\hline & $\begin{array}{l}1 \\
\text { stimme } \\
\text { gar nicht } \\
\text { zu }\end{array}$ & 2 & 3 & 4 & 5 & 6 & $\begin{array}{l}7 \quad- \\
\text { stimme } \\
\text { voll zu }\end{array}$ \\
\hline \multicolumn{8}{|l|}{ 9. Ich fühle mich sicher in dieser Klasse } \\
\hline \multicolumn{8}{|l|}{ 10. In dieser Klasse halten wir zusammen } \\
\hline \multicolumn{8}{|c|}{ 11. Ich habe das Gefühl, zu dieser Klasse zu gehören } \\
\hline \multicolumn{8}{|l|}{ 12. Ich bin stolz, ein Teil dieser Klasse zu sein } \\
\hline \multicolumn{8}{|c|}{ 13. Diese Klasse ist ein guter Ort, um Freunde zu finden } \\
\hline \multicolumn{8}{|c|}{ 14. Es ist wahrscheinlich, dass ich die Schule erfolgreich beende } \\
\hline \multicolumn{8}{|l|}{ 15. Es ist wahrscheinlich, dass ich zur Uni gehe } \\
\hline \multicolumn{8}{|c|}{ 16. Es ist wahrscheinlich, dass ich einen Job bekomme, der gut bezahlt wird } \\
\hline \multicolumn{8}{|c|}{ 17. Es ist wahrscheinlich, dass ich den Job bekomme, den ich will } \\
\hline \multicolumn{8}{|c|}{ 18. Manchmal frage ich meine(n) Lehrer(in) um (persönlichen) Rat } \\
\hline \multicolumn{8}{|c|}{ 19. Manchmal identifiziere ich mich mit meiner/meinem Lehrer(in) } \\
\hline \multicolumn{8}{|c|}{ 20. Ich will, dass mein(e) Lehrer(in) mit meiner Leistung zufrieden ist } \\
\hline \multicolumn{8}{|c|}{ 21. Mein(e) Lehrer(in) motiviert mich, härter zu arbeiten } \\
\hline 22. Mein(e) Lehrer(in) ist ein Vorbild für mich & & & & & & & \\
\hline
\end{tabular}


23. Ich schaue zu meiner/m Lehrer(in) auf

24. Mein(e) Lehrer(in) setzt sich für mich ein

25. Mein(e) Lehrer(in) trifft Entscheidungen, die besonders mir helfen

26. Ich denke, dass mein(e) Lehrer(in) und ich ähnliche Dinge wichtig finden

27. Mein(e) Lehrer(in) versteht mich und meine Probleme 
Appendix B: Interview schedule in German

EINLEITUNG: Diese Studie beschäftigt sich ja mit Lehrkräften mit Zuwanderungsgeschichte und den Auswirkungen von mehr Lehrern mit Zuwanderungsgeschichte auf die Schüler und auch auf die Atmosphäre im Klassenraum. Gab es für Sie schon einmal eine Situation, in der Ihre Zuwanderungsgeschichte eine Rolle gespielt hat? Erzählen Sie mir davon.

1. Bitten Schüler Sie gewöhnlich um Rat die Schule betreffend oder auch persönlicher Natur? Glauben Sie, dass Ihre Zuwanderungsgeschichte hierbei eine Rolle spielt, z.B. wer Sie eher um Rat bittet und wer eher nicht?

2. Welchen Einfluss hat Ihre Zuwanderungsgeschichte auf die Motivation der Schüler, was denken Sie? Gibt es Situationen, in denen Sie merken, dass sich Schüler besonders anstrengen, um Sie zu beeindrucken? Oder besonders wenig anstrengen?

3. Glauben Sie, dass Sie ein Vorbild sind für Ihre Schüler? (Sind das proportional mehr Schüler, die ebenfalls eine Zuwanderungsgeschichte haben? Haben sie denselben Hintergrund?

4. Gab es schon einmal eine Situation, in der Sie sich besonders für Schüler mit Migrationshintergrund eingesetzt haben? Erzählen Sie mir davon.

5. Glauben Sie, dass Ihre Wertvorstellungen ähnlich sind wie die Ihrer Schüler? Inwiefern beeinflusst Ihre Zuwanderungsgeschichte Ihre Möglichkeit, die Sorgen und Probleme Ihrer Schüler zu verstehen? Auch im Vergleich zu Lehrern ohne Zuwanderungsgeschichte? Gibt es hier eine bestimmte Situation, an die Sie denken? (VERTRAUEN: Glauben Sie, dass manche Schüler Ihnen eher vertrauen als andere Schüler?) (Hypothese 4)

6. Sehen Sie sich als Vertreterin oder Repräsentantin Ihrer ethnischen, religiösen oder kulturellen Gruppe? War dies von Anfang an so, oder hat es sich mit der Zeit so ergeben/ entwickelt?

6.1. Haben Sie das Gefühl, dass Ihre Schule (Schulleitung) erwartet, und wünscht, dass Sie diese Rolle spielen und Ihre Gruppe vertreten?

6.2.Wie sehen Eltern und Schüler Sie? Glauben Sie, dass deren Wahrnehmung von Ihnen als Repräsentantin einer Gruppe mit Ihrer übereinstimmt?

6.3.Und wie sehen Ihre Kollegen Sie und Ihre Rolle als Repräsentantin?

6.4.Haben Sie ein Beispiel für mich? 
7. Glauben Sie, dass Sie andere Lehrer beeinflussen, beispielsweise deren Verhalten? Glauben Sie, dass Ihre Anwesenheit in der Schule die Einstellung anderer Lehrer gegenüber Menschen mit einem anderen ethnischen / religiösen / kulturellen Hintergrund in irgendeiner Weise verändert hat? Gibt es Spannungen zwischen Lehrern mit und ohne Migrationshintergrund?

8. Wie reagieren Eltern auf Sie als Lehrer mit Zuwanderungsgeschichte? Gab es Situationen, in denen Ihr Hintergrund eine Rolle gespielt hat? Wie reagieren Eltern von Schülern mit Zuwanderungsgeschichte darauf, dass Sie auch eine Zuwanderungsgeschichte haben? Haben Sie jemals Ihre Muttersprache /Zweitsprache genutzt, um die Verständigung mit Eltern (oder Schülern zu erleichtern? (VERTRAUEN: Welche Rolle spielt Ihre ZG, wenn es um Vertrauen in Sie seitens der Eltern von Schülern geht?

9. Migrationshintergrund: Welche Rolle spielt es, welchen Migrationshintergrund jemand hat? Spielt der Migrationshintergrund nur eine Rolle, wenn Lehrer und Schüler „den gleichen" haben, also z.B aus demselben Land stammen, dieselbe Sprache sprechen, derselben Religion angehören? 
Appendix C: Information letter for schools

Gretha Burchard · XXX XXXX XXXX

Herr / Frau

Straße

Ort

Sehr geehrte

mein Name ist Gretha Burchard, ich bin Doktorandin an der Florida International University in Miami und schreibe meine Doktorarbeit über Lehrkräfte mit Zuwanderungsgeschichte an deutschen Schulen.

Die Studie befasst sich mit mehr Vielfalt in der Lehrerschaft an deutschen Schulen. Deutschland wird ethnisch und kulturell immer vielfältiger und die Bundesregierung versucht nun, mehr Menschen mit Zuwanderungsgeschichte für die Arbeit im öffentlichen Sektor zu begeistern. Das Ziel dieser Studie ist es, herauszufinden, ob und inwiefern eine höhere Anzahl von Lehrern mit Migrationshintergrund an deutschen Schulen Auswirkungen auf die Leistungen und Berufswünsche der Schüler und auf die Atmosphäre im Klassenraum hat.

Der erste Teil der Datenerhebung besteht aus Interviews. Einige Lehrkräfte habe ich bereits interviewt, weitere Interviews sollen zudem in den nächsten Wochen durchgeführt werden. Ich würde mich freuen und bin Ihnen sehr dankbar, wenn ich auch Sie im Rahmen der Studie interviewen kann. Das Interview dauert ca 20 Minuten bis eine Stunde. Es kann z. B. in Ihrer Schule oder einem anderen Ort Ihrer Wahl stattfinden. Wenn Sie einverstanden sind, möchte ich es gern aufzeichnen. Ansonsten werde ich nur Notizen machen.

Die Fragen sollen die Brauchbarkeit des Fragebogens testen, der später als Teil dieser Studie durchgeführt wird. Sie enthalten u.a. demografische Fragen, z.B. Ihre Ausbildung und Ihren Geburtsort betreffend sowie Ausbildung und Geburtsort Ihrer Eltern. Außerdem gibt es Fragen zu Ihren Wahrnehmungen unterschiedlicher Details im Klassenraum.

Ihre Teilnahme ist selbstverständlich freiwillig. Sie können Ihr Einverständnis zu jeder Zeit vor, während und nach der Studie entziehen. Sie können auch lediglich die Beantwortung einzelner Fragen verweigern.

Ihre Antworten werden vertraulich behandelt und wenn die Ergebnisse dieser Studie öffentlich zugänglich gemacht werden, dann so, dass Antworten einzelner nicht zu den Teilnehmern 
zurückzuverfolgen sind. Falls Ton- oder Videoaufnahmen durchgeführt werden, sind sie nur für die an der Studie unmittelbar Beteiligten zugänglich und müssen nach Beendigung der Untersuchung ebenfalls gelöscht werden. Falls Bilddokumente veröffentlicht werden sollen, müssen die abgebildeten Personen bzw. deren Erziehungsberechtigte schriftlich einer Veröffentlichung des Bilddokumentes zustimmen. Diese Zustimmung ist langfristig aufzubewahren.

Ich freue mich auf eine Antwort, per Email an xxxx@gmail.com oder telefonisch unter 0151 XXXXXXX und verbleibe

mit freundlichen Grüßen

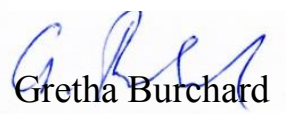


Appendix D: List of variables

\begin{tabular}{|c|c|}
\hline Demographics & \\
\hline MB_s & Migration background of student (y/n) \\
\hline MB_t & Migration background of teacher $(\mathrm{y} / \mathrm{n})$ \\
\hline MB_Const & $\begin{array}{l}\text { Constellation of migration backgrounds } \\
\text { (1) Teacher and student both have a migration background } \\
\text { (2) Teacher has a migration background, student does not } \\
\text { (3) Teacher does not have a migration background, student has migration } \\
\text { background } \\
\text { (4) Teacher and student both have no migration background. }\end{array}$ \\
\hline Both_MB & $\begin{array}{l}1=\text { Both, teacher and student have migration background } \\
0=\text { all other constellations }\end{array}$ \\
\hline Both_no_MB & $\begin{array}{l}1=\text { Both, teacher and student do not have migration background } \\
0=\text { all other constellations }\end{array}$ \\
\hline age & Age, ranges from 14 to 19 an older \\
\hline $\operatorname{sex}$ & Sex, $\mathrm{m} / \mathrm{f}$ \\
\hline Edu_m & $\begin{array}{l}\text { Education of mother; } 0=\text { no high school degree, } 1=\text { high school degree, } 2= \\
\text { university degree }\end{array}$ \\
\hline Edu_f & $\begin{array}{l}\text { Education of father; } 0=\text { no high school degree, } 1=\text { high school degree, } 2= \\
\text { university degree }\end{array}$ \\
\hline Class $1-$ Class 13 & 13 Dummy variables for the class fixed effects \\
\hline Substantive Effects & \\
\hline grade & Student's grade, 1 (worst) - 6 (best) \\
\hline $\begin{array}{ll}\text { CE } & \\
\text { - } & \text { fin_school } \\
- & \text { univer } \\
- & \text { well_paid } \\
- & \text { job_want }\end{array}$ & $\begin{array}{ll}\text { Career expectations } \\
\text { - } & \text { Finish school successfully } \\
- & \text { go to university } \\
- & \text { find well paid job } \\
- & \text { find job I want }\end{array}$ \\
\hline $\mathrm{CC}$ & Classroom climate index \\
\hline
\end{tabular}




\begin{tabular}{|c|c|}
\hline $\begin{array}{ll}- & \text { safe } \\
- & \text { unity } \\
- & \text { belong } \\
- & \text { proud } \\
\text { - } & \text { friends }\end{array}$ & $\begin{array}{ll}- & \text { Safe in class } \\
\text { - } & \text { Feeling of unity in class } \\
\text { - } & \text { Feeling of belongingness } \\
\text { - } & \text { Proud to be in class } \\
\text { - } & \text { Easy to find friends in class }\end{array}$ \\
\hline \multicolumn{2}{|l|}{ Mechanisms } \\
\hline $\begin{array}{l}\text { DI } \\
\text { - } \quad \text { advice } \\
\text { - } \quad \text { id_teach }\end{array}$ & $\begin{array}{l}\text { Demand inducement index } \\
\text { - } \quad \text { Student asks teacher for personal advice } \\
\text { - } \quad \text { Student identifies with teacher }\end{array}$ \\
\hline $\begin{array}{ll}\text { CI } & \\
- & \text { satisfy } \\
- & \text { motiv } \\
- & \text { role_mod } \\
- & \text { look_up }\end{array}$ & $\begin{array}{l}\text { Coproduction inducement index } \\
\text { - } \quad \text { Student wants teacher to be satisfied } \\
\text { - } \quad \text { Teacher motivates student to work hard } \\
\text { - } \quad \text { Teacher is a role model for student } \\
\text { - } \quad \text { Student looks up to teacher }\end{array}$ \\
\hline $\begin{array}{l}\text { Adv } \\
\text { - } \quad \text { stand_up } \\
\text { - } \quad \text { decisions }\end{array}$ & $\begin{array}{l}\text { Advocacy } \\
\text { - } \quad \text { Teacher stands up for student } \\
\text { - } \quad \text { Teacher makes decisions that benefit student }\end{array}$ \\
\hline $\begin{array}{l}\text { VE } \\
\text { - } \quad \text { values } \\
\text { - } \quad \text { emp_und }\end{array}$ & $\begin{array}{l}\text { Values \& Empathy } \\
\text { - } \quad \text { Teacher and student share same values } \\
\text { - } \quad \text { Empathic understanding of student by teacher }\end{array}$ \\
\hline
\end{tabular}


Appendix E: List of interview participants

The table of the interviewed teachers contains exclusively information on the migration background and on who immigrated to Germany. Given that all teachers work in Lower Saxony and Bremen, the inclusion of demographic information such as age or sex for each participant or the school form they teach at would have jeopardized the anonymity of the teachers and was thus excluded. The interviewees appear in the order of the date of the interview.

\begin{tabular}{|c|c|c|}
\hline & Migration background & Who immigrated \\
\hline Participant \#1 & Macedonian & parents \\
\hline Participant \#2 & Spanish & self when adult \\
\hline Participant \#3 & none & 1 \\
\hline Participant \#4 & none & I \\
\hline Participant \#5 & Turkish & parents \\
\hline Participant \#6 & Turkish & parents \\
\hline Participant \#7 & none & I \\
\hline Participant \#8 & none & l \\
\hline Participant \#9 & Turkish & self when child \\
\hline Participant \#10 & Ukrainian & self when adult \\
\hline Participant \#11 & none & 1 \\
\hline Participant \#12 & Egyptian & self when adult \\
\hline Participant \#13 & Greek & parents \\
\hline Participant \#14 & none & l \\
\hline Participant \#15 & none & I \\
\hline Participant \#16 & Polish & self when adult \\
\hline Participant \#17 & none & 1 \\
\hline Participant \#18 & Czech & one parent \\
\hline Participant \#19 & Spanish & self when adult \\
\hline Participant \#20 & none & l \\
\hline Participant \#21 & Turkish & parents \\
\hline Participant \#22 & Turkish & one parent \\
\hline Participant \#23 & none & 1 \\
\hline Participant \#24 & none & l \\
\hline Participant \#25 & Turkish & parents \\
\hline Participant \#26 & Polish & self when child \\
\hline
\end{tabular}




\section{GRETHA K. BURCHARD}

\section{Born, Hannover, Germany}

2008

2010

$2010-2011$

$2011-2016$

$2013-2017$
B.A. Language and Communication, PhilippsUniversität Marburg, Germany

Exchange semester at Université Marc Bloch, Strasbourg, France

Exchange semester at Universidade de Santiago de Compostela, Spain

M.A. Euroculture, Georg-August-Universität Göttingen, Germany, and Univerzita Palackého, Olomouc, Czech Republic, Dual Degree Exchange semester at Universidad Nacional Autónoma de México

Public Relations Consultant, Westin Grand Munich, Germany

Teaching \& Research Assistant

Florida International University

Miami, Florida

Doctoral Candidate

Florida International University

Miami, Florida

\section{PUBLICATIONS}

Burchard, G. (2015). Brazil: A Prime Example of Decentralization - and Recentralization. Hemisphere, 24, pp. 37-41.

Burchard, G. (2011). The German Population in Mexico City - Maintenance of German culture and Integration into Mexican Society. LAMBERT Academic Publishing. 


\section{PRESENTATIONS}

Burchard, G. (2016) Representative Bureaucracy: The Importance of a (Perceived) Common Identity. IPSA World Congress, Poznan, Poland.

Burchard, G. (2015). Mechanisms of Representative Bureaucracy: Assessing German High Schools. SECoPA Annual Conference, Charleston, SC.

Burchard, G. (2015). The Mechanisms of Representative Bureaucracy. EGPA Annual Conference, Toulouse, France.

Burchard, G. (2015). The Impact that Representative Bureaucracy Can Have: The Case of a German School. ASPA Annual Conference, Chicago, IL.

Burchard, G. (2015). Representative Bureaucracy in German Schools: Impact of Immigrant Teachers on Student performance, career expectations and social climate. Dissertation Proposal. IMISCOE PhD Winterschool Rotterdam, Netherlands.

Burchard, G. (2014). The Effects of Representation in a Country of Increasing Diversity: Assessing German High Schools. EGPA PhD Symposium, Speyer, Germany.

Burchard, G. (2014). Value-neutral Versus Value-based Treatment: Is Weber's Bureaucracy Compatible with the Concept of Representative Bureaucracy? Public Administration Theory Network Annual Conference, Miami, FL.

Burchard, G. (2014). Increasing Women's Presence in Top Positions on the Federal Level - Representative Bureaucracy in Germany, Canada, and the US. ASPA Annual Conference, Washington, DC.

Burchard, G. (2013). Immigrants in the Public Sector - A Way to Integration?. European Group of Public Administration (EGPA) PhD Symposium, Edinburgh, Scotland.

Burchard, G.; Cram, B. (2013). Multiculturalism in Germany - From Utopia to Reality? Public Administration Theory Network, San Francisco, CA.

Burchard, G.; Ganapati S.; Shariati, A. (2013). The insiders vs outsiders: Conflicting perspectives of residents and migrants. ASPA Annual Conference, New Orleans, LA.

Alkadry, M.; Burchard, G.; Nambiar, G. (2013). Are Women Better Off in Unionized Public Sector Workplaces? ASPA Annual Conference, New Orleans, LA. 